Dedicatória

Aos meus filhos Lívia e Marco Antonio, que mudaram definitivamente minha forma de ver a vida. 


\section{AGRADECIMENTOS}

Agradeço à professora Dr. ${ }^{a}$ Maria Aparecida Faustino Pires pela orientação, pelo incentivo, pela amizade e, principalmente, pela confiança em mim depositada durante todas as etapas do projeto.

Ao Prof. Dr. Aparecido Osdimir Bertolin e ao colega prof. MSc. André Senna, por viabilizarem o convênio entre a FMT e o IPEN e para os quais externo minha profunda admiração e respeito. Em especial, ao prof. Dr. Bertolin agradeço pela oportunidade de trabalhar na FMT e pela amizade; meu reconhecimento e gratidão pela contribuição em minha trajetória acadêmica.

À minha irmã Roberta Villibor, meu exemplo de docente, meu exemplo de amor e dedicação à docência, pela correção gramatical da tese.

À minha irmã de coração Anelise Kappes, para a qual não tenho palavras capazes de expressar minha gratidão ao seu companheirismo e amizade desde a época do mestrado na UFT.

À equipe do Centro de Química e Meio Ambiente do IPEN, em especial às alunas Sabine Guilhen e Laís Cordeiro, e professoras Dra. Elizabeth Dantas e Dra. Marycel Cotrim, por realizarem as análises dos teores de mercúrio deste projeto de pesquisa.

Ao prof. Dr. Joênes Mucci Pelluzio e ao colega Wlisses Kennet pela colaboração nas análises estatísticas.

Às instituições financiadoras deste estudo: IPEN, CNPq, Fundação de Medicina Tropical e Secretaria de Ciência e Tecnologia do Estado do Tocantins.

À Prefeitura Municipal de Araguaína e a Escola Técnica de Saúde do Tocantins Dr. Gismar Gomes - ETSUS - por permitirem a realização da parte experimental deste trabalho.

Aos técnicos e colegas da FMT, em especial à técnica Rosa Rosado pela ajuda durante a execução do spot test.

À colega e amiga Alessandra Krakhecke pela colaboração nas análises bioquímicas e inúmeras conversas de apoio nos laboratórios da FMT.

Aos amigos que sempre estiveram ao meu lado me incentivando e me ajudando com os bebês enquanto eu redigia os textos: Gabriel Kunze, Elaine Canuto, Wêdila Aguiar e Welito "Paulista". 
Aos professores que participaram do convênio entre CNEN e FMT, agradeço pelos conhecimentos compartilhados.

Ao Fernando Moreira e Gislene Madeira da Gerência de Ensino do IPEN, agradeço pelo apoio logístico durante o curso.

Aos amigos da primeira turma de odontologia da Universidade Estadual do Oeste do Paraná e aos professores, agradeço pelo exemplo de vida e de luta por um ideal.

Ao meu marido Marcos Venícios, que me ajudou durante todo o curso, impulsionou-me para que eu nunca desistisse e jamais deixou de acreditar que esse projeto fosse possível. Agradeço por você ser parte da minha vida, ser companheiro, ser amigo e contribuir com a realização deste meu maior sonho profissional.

Aos meus filhos Lívia e Marco Antonio, que chegaram em minha vida após o início deste curso; muitas vezes vivenciaram minha ausência enquanto "mãe" e preencheram definitivamente minha vida com alegria e amor verdadeiros. Agradeço por me mostrarem, principalmente, que vale lutar por um sonho e espero que minha trajetória de vida um dia seja motivo de orgulho para vocês, assim como a de meus pais são para mim. 
Aprender é mudar posturas.

Platão 


\title{
AVALIAÇÃO DOS NÍVEIS DE EXPOSIÇÃO OCUPACIONAL AO MERCÚRIO NOS CONSULTÓRIOS ODONTOLÓGIÇOS PÚBLICOS DE ARAGUAÍNA, TO
}

\author{
Fernanda Villibor Xavier
}

\section{RESUMO}

O objetivo deste trabalho foi realizar a avaliação dos riscos ocupacionais ao mercúrio utilizado em odontologia, aos quais os auxiliares em saúde bucal (ASB) da rede pública de saúde do município de Araguaína, Tocantins, estão expostos. O processo odontológico do sistema de saúde no município em questão foi estudado, de modo minucioso, a partir de um levantamento do número de restaurações de amálgama de prata executadas durante o período de janeiro de 2003 a dezembro de 2007 na base de dados DATASUS. Nesse estudo, foram avaliadas as condições de armazenamento dos resíduos de amálgama nos consultórios odontológicos públicos do município analisado. Foram estudadas diferentes soluções-barreira para armazenamento dos resíduos de amálgama no que diz respeito a sua eficácia no combate à emissão de vapores de mercúrio para o ambiente. A solução contendo amoníaco foi a que apresentou melhor tempo para estocagem dos resíduos (19 dias a $37^{\circ} \mathrm{C}$ ), seguida pela solução contendo fixador fotográfico (12 dias) e solução de bicarbonato de sódio (7 dias). Com base nestas informações, caracterizou-se o perfil do ASB que atua nos consultórios públicos do município de Araguaína quanto à idade, ao sexo, ao grau de exposição ao mercúrio e aos procedimentos de biossegurança executados. $O$ estudo possibilitou elaborar um banco de dados, com relação ao manuseio e ao descarte de resíduos de amálgama, com o intuito de subsidiar políticas públicas de saúde voltadas à modificação de situações de risco as quais os profissionais estão submetidos e/ou submetem seus pacientes. Foi realizado também um programa de monitoramento biológico, utilizando como marcador a presença de mercúrio em amostras de urina $(\mathrm{HgU})$, em membros da equipe odontológica da rede municipal de saúde de Araguaína e em alunos da escola técnica de saúde, polo de Araguaína, atuantes como ASB em outros municípios da região norte $(n=91)$. Como comparação, um grupo de "não expostos" ao mercúrio foi avaliado ( $n=43$ ) e os valores de $\mathrm{HgU}$ determinados. A pesquisa permitiu concluir que, em 
relação aos valores de $\mathrm{HgU}$, a equipe odontológica avaliada estava dentro dos limites propostos pela NR 7 (até $35 \mu \mathrm{gHg} \cdot \mathrm{g}^{-1} \mathrm{CR}$ ). Com relação à contaminação por mercúrio, a média da concentração do $\mathrm{HgU}$ para o grupo "expostos" (5,61 $\mu \mathrm{gHg} \cdot \mathrm{g}^{-1} \mathrm{CR}$ ) foi aproximadamente 8 vezes maior se comparada ao do grupo "não expostos" $\left(0,65 \mu \mathrm{gHg} \cdot \mathrm{g}^{-1} \mathrm{CR}\right)$, evidenciando a necessidade de um programa de treinamento de profissionais e de gerenciamento de resíduos, bem como de uma atuação mais efetiva na realização do monitoramento biológico periódico nos profissionais da equipe odontológica.

Palavras-chave: Exposição ocupacional. Mercúrio. Consultórios odontológicos. 


\title{
EVALUATION OF THE LEVELS OF OCCUPATIONAL EXPOSURE TO MERCURY IN THE PUBLIC DENTAL OFFICES IN ARAGUAINA, TO, BRAZIL
}

\author{
Fernanda Villibor Xavier
}

\begin{abstract}
The aim of this work was to evaluate the occupational risks of exposure to mercury utilized in dentistry, to which dental auxiliaries from the public health system of the city of Araguaína, Tocantins, Brazil are exposed. The dentistry process from the city health system was rigorously studied based on an assessment, in the DATASUS database, of the number of amalgam restorations conducted in the period from January 2003 to December 2009. In this study, we evaluated the storage conditions of mercury residuals in the public dental offices in the studied municipality. Different barrier solutions for the storage of mercury residuals were studied regarding their efficacy in controlling the emission of mercury vapor in the environment. The solution containing ammonia presented the best time of storage of residuals ( 19 days at $37^{\circ} \mathrm{C}$ ), followed by the solution containing photographic fixative (12 days) and the sodium bicarbonate solution (7 days). Based on these information, a profile of the dental auxiliaries actuating in the public dental offices of the city of Araguaína was characterized according to age, sex, level of exposure to mercury and conducted biosecurity procedures. The study allowed the elaboration of a database regarding handling and discard of amalgam residuals, with the purpose to assist public health policies to modify risk situations to which the professionals and/or their patients are exposed. A biological monitoring program was also carried out using as marker the presence of mercury in urine samples $(\mathrm{HgU})$ from members of the dentistry team of the Araguaína public health system and from students from the Araguaína unit of the health care technical school who actuated as dental auxiliaries in other municipalities of the north region of the state $(n=91)$. For comparison, a group of "not exposed" to mercury was evaluated $(n=43)$, determining their $\mathrm{HgU}$ values. The research allowed to conclude that the $\mathrm{HgU}$ values from the dentistry team were within the limits set by Regulatory Norm $\mathrm{n}^{\circ} 7$ by the Brazilian Ministry of Labor (up to $35 \mu \mathrm{gHg} \cdot \mathrm{g}^{-1} \mathrm{CR}$ ). Regarding mercury contamination, the average $\mathrm{HgU}$ concentration for the
\end{abstract}


"exposed" group $\left(5,61 \mu \mathrm{gHg} \cdot \mathrm{g}^{-1} \mathrm{CR}\right)$ was approximately 8 times higher when compared to the values from the "not exposed" group $\left(0,65 \mu \mathrm{gHg} \cdot \mathrm{g}^{-1} \mathrm{CR}\right)$, making evident the need for a professional training and residuals management program, as well as for a more effective actuation in the realization of periodical biological monitoring in the professionals from the dentistry team.

Keywords: Occupational exposure. Mercury. Dental offices. 


\section{SUMÁRIO}

Página

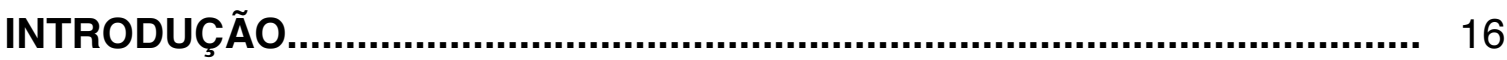

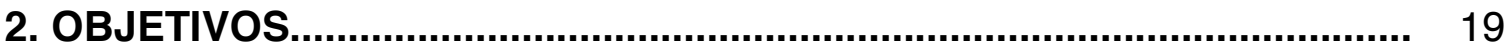

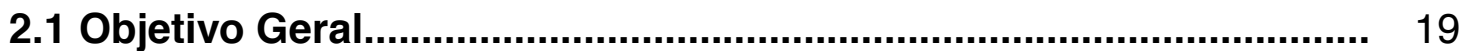

2.2 Objetivos Específicos................................................................ 18

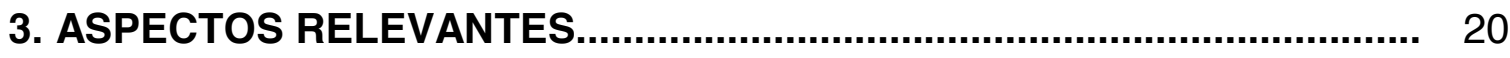

4. REVISÃO DE LITERATURA........................................................... 22

4.10 mercúrio e a odontologia........................................................... 22

4.2 Toxicidade do mercúrio.................................................................. 25

4.3 Avaliação da exposição ocupacional - monitoramento biológico... 30

4.4 Gerenciamento dos resíduos contendo mercúrio............................ 31

4.5 Mercúrio e excreção urinária........................................................... 33

5. MATERIAIS E MÉTODOS................................................................ 39

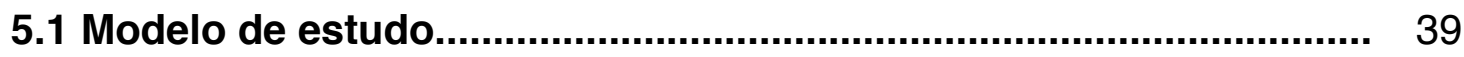

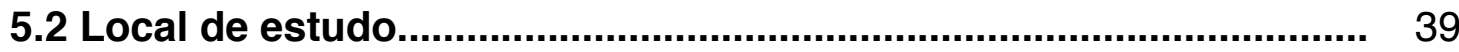

5.3 Seleção de voluntários.................................................................... 40

5.4 Aplicação do questionário............................................................... 41

5.5 Seleção do indicador biológico de exposição: urina........................ 41

5.6 Procedimento de coleta e determinação de mercúrio na urina....... 42

5.7 Liofilização das amostras de urina..................................................... 43

5.8 Determinação do valor da creatinina urinária................................. 45

5.9 Metodologia analítica de determinação de mercúrio inorgânico.... 46

5.10 Simulação de amostras de amálgama odontológico para estudos de estocagem e liberação atmosférica de mercúrio................. 49

5.11 Simulação de amostras de amálgama odontológico para estudos de estocagem e liberação atmosférica de mercúrio................ 50

6. RESULTADOS E DISCUSSÃO............................................................ 53

6.1 Caracterização do sistema odontológico do município de estudo 53

6.2 Inventário sobre a produção ambulatorial de restaurações de amálgama.

6.3. Caracterização do perfil da população estudada............................ 57

6.4 Monitoramento biológico para Hg................................................ 62

6.5 Avaliação da rotina de biossegurança dos profissionais da equipe odontológica........................................................................ 73

6.5.1 Segregação de resíduos......................................................... 73

6.5.2 Processo de esterilização e prevenção da infecção cruzada......... 74

6.5.3 Sistema de preparo dos amálgamas odontológicos....................... 77

6.5.4. Local de descarte dos resíduos de amálgama........................... 82

6.6 Avaliação das soluções para armazenamento de resíduos de

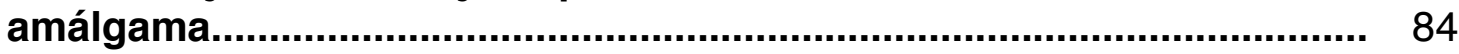

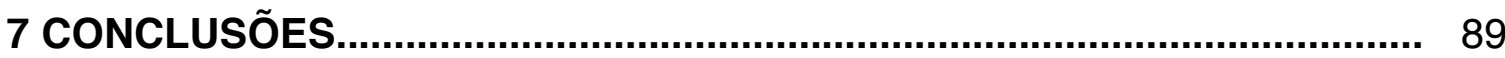

8 RECOMENDAÇÕES AOS PROFISSIONAIS EXPOSTOS AO

MERCÚRIO

APÊNDICE A - APROVAÇÃO DO COMITÊ DE ÉTICA................................ 93 
APÊNDICE B - CERTIFICADOS DOS MATERIAIS DE REFERÊNCIA......... 97 ANEXO A - TERMO DE CONSENTIMENTO LIVRE E ESCLARECIDO DO GRUPO CONTROLE.

ANEXO B - TERMO DE CONSENTIMENTO LIVRE E ESCLARECIDO DO GRUPO "EXPOSTOS"

ANEXO C - QUESTIONÁRIO APLICADO AO GRUPO CONTROLE. 104 ANEXO D - QUESTIONÁRIO APLICADO AO GRUPO DE "EXPOSTOS".. 105 ANEXO E - MÉDIAS DO TEMPO MÁXIMO DE ESTOCAGEM PARA AS SOLUÇÕES ESTUDADAS.. 108 REFERÊNCIAS BIBLIOGRÁFICAS. 


\section{LISTA DE FIGURAS}

FIG.1 Liofilizador Terroni ${ }^{\circledR}$ LS 3000....................................................... 44

FIG.2 (A) urina liofilizada; (B) tubos Sarstedt ${ }^{\circledR}$ vedados............................... 45

FIG.3 Espectrômetro de absorção molecular - Equipamento Labmax Plenno 46

FIG.4 (A) acessório utilizado para a determinação de antimônio e arsênio por geração de hidretos voláteis e de mercúrio por vapor frio; (B) Espectrofotômetro de Absorção Atômica com acessório Forno de Grafita e amostrador automático (PerkinElmer Co., USA).

FIG.5 (A) Cloreto de paládio; (B) papel de filtro antes do contato com o cloreto de paládio; (C) papel de filtro embebido com cloreto de paládio a 1\% (spot-test do branco); (D) papel de filtro após contato com vapor de mercúrio (spot-test positivo)

FIG.6 (A) amalgamador Gnatus ${ }^{\circledR}$ com cápsula de amálgama acoplada; (B) amálgama sendo peneirado.

FIG.7 Montagem individual dos tubos para cada solução barreira estudada... 51

FIG.8 Conjunto de tubos montado para realização do spot-test para as diferentes soluções barreiras estudadas.

FIG.9 Número de restaurações de amálgama de prata realizadas no município de Araguaína - TO - durante o período de janeiro de 2003 a dezembro de 2007

FIG.10 Relação entre as respostas e intervalo de concentração de mercúrio em função da proximidade da moradia (anterior) ser em área de garimpo de ouro.

FIG.11 Médias de HgU em relação a variável grupo de exposição.................... 68

FIG.12 Médias de $\mathrm{HgU}\left(\mu \mathrm{gHg} \cdot \mathrm{g}^{-1} \mathrm{CR}\right)$ em relação a variável "cidade"............... 70

FIG.13 Regressão linear entre número de restaurações de amálgama presentes na boca e $\mathrm{HgU}\left(\mu \mathrm{gHg} \cdot \mathrm{g}^{-1} \mathrm{CR}\right)$ dos participantes da pesquisa 71

FIG.14 Regressão linear entre tempo de trabalho (anos) e $\mathrm{HgU}\left(\mu \mathrm{gHg} \cdot \mathrm{g}^{-1} \mathrm{CR}\right) \quad 72$

FIG.15 Frequência de uso dos EPI de acordo com as respostas dos 91 entrevistados na pesquisa.

FIG.16 (A) Amálgama em cápsula; (B) membrana com mercúrio; (C) cápsula; (D) frasco de mercúrio odontológico.

FIG.17 (A) Processo manual de trituração com grau e pistilo; (B) amalgamador volumétrico usado no processo de trituração mecânica.

FIG.18 Comparação entre as formas de trituração e HgU por meio da análise ANOVA

FIG.19 Tempo máximo de armazenagem dos resíduos de amálgama odontológico para o sistema com volume de $15 \mathrm{~mL}$, diferentes temperaturas e soluções estoque.

FIG.20 Tempo máximo de armazenagem dos resíduos de amálgama odontológico para as soluções em diferentes temperaturas..................... 87

FIG.21 Tempo máximo de armazenagem (em dias) dos resíduos de amálgama para as soluções testadas (ANOVA). 


\section{LISTA DE TABELAS}

TAB.1 Principais fontes de contaminação e absorção do mercúrio

TAB.2 Métodos analíticos frequentemente utilizados para a quantificação de mercúrio e seus limites de detecção.

TAB.3 Produção ambulatorial de restaurações em amálgama segundo o sistema DATASUS e segundo a cópia dos procedimentos arquivada na Secretaria Municipal de Saúde Araguaína - TO....

TAB.4 Características sócio-demográficas dos participantes da pesquisa..... 58

TAB.5 Distribuição de frequência dos participantes da pesquisa para a variável "idade".

TAB.6 Distribuição de frequência dos participantes da pesquisa, para a variável município de residência de acordo com a exposição ocupacional ao mercúrio.

TAB.7 Distribuição dos participantes da pesquisa, considerados "expostos" para as variáveis "função", "horas de trabalho/dia" e "participação no ESF".....

TAB.8 Distribuição de frequência dos participantes da pesquisa considerados "expostos" para a variável "tempo de trabalho" (anos)

TAB.9 Distribuição de frequência da renda familiar dos entrevistados em salários mínimos (SM).

TAB.10 Concentração de $\mathrm{Hg}$ total e de creatinina em 79 amostras únicas analisadas de urina dos participantes da pesquisa considerados expostos durante 0 período de novembro de 2008 a julho de 2010

TAB.11 Concentração de $\mathrm{Hg}$ total em amostras únicas analisadas de urina dos participantes da pesquisa considerados não expostos durante 0 período de novembro de 2008 a julho de 2010 ...

TAB.12 Distribuiccão dos participantes da pesquisa, considerados "expostos" de acordo com as concentrações de mercúrio total na urina ( $\mu \mathrm{gHg} \mathrm{L}^{-}$ de urina)

TAB.13 Distribuição dos participantes da pesquisa, considerados expostos de acordo com as concentrações de mercúrio urinário $\left(\mu \mathrm{gHg} \cdot \mathrm{g}^{-}\right.$ 'CR).

TAB.14 Distribuição dos participantes da pesquisa de acordo com o uso de lixo específico para material com risco biológico (segregação de material contaminado).

TAB.15 Distribuição dos participantes da pesquisa de acordo com o local de descarte de material perfurocortante.

TAB.16 Formas de dosagem de $\mathrm{Hg}$, trituração do amálgama e uso de camurça de acordo com os 91 entrevistados na pesquisa.

TAB.17 Destino dos frascos cheios e vazios de $\mathrm{Hg}$ de acordo com os 91 entrevistados na pesquisa. 


\section{LISTA DE SIGLAS}

$\begin{array}{lll}\text { AAS } & - & \text { Espectrometria de Absorção Atômica } \\ \text { ACD } & - & \text { Auxiliar de Consultório Dentário } \\ \text { ADA } & - & \text { American Dental Association } \\ \text { ANOVA } & - & \text { Análise de Variância } \\ \text { ANVISA } & - & \text { Agência Nacional de Vigilância Sanitária } \\ \text { APHA } & - & \text { American Public Health Association } \\ \text { ASB } & - & \text { Auxiliar de Saúde Bucal } \\ \text { ATSDR } & - & \text { Agency for Toxic Substances and Disease Registry } \\ \text { CD } & - & \text { Cirurgião-Dentista } \\ \text { CDC } & - & \text { Centers for Disease Control and Prevention } \\ \text { CEO } & - & \text { Centro de Especialidades Odontológicas } \\ \text { CEP } & - & \text { Comitê de Ética para Pesquisas em Seres Humanos } \\ \text { CESUPA } & - & \text { Centro de Ensino Superior do Pará } \\ \text { CFM } & - & \text { Cavalo Força por Minuto } \\ \text { CNEN } & - & \text { Comissão Nacional de Energia Nuclear } \\ \text { CNPq } & - & \text { Conselho Nacional de Desenvolvimento Científico e } \\ \text { CNTP } & - & \text { Condições Normais de Temperatura e Pressão } \\ \text { CONAMA } & - & \text { Conselho Nacional de Meio Ambiente } \\ \text { CQMA } & - & \text { Centro de Química e Meio Ambiente } \\ \text { CR } & - & \text { Creatinina } \\ \text { CV-AAS } & - & \text { Espectrofotometria de Absorção Atômica com Geração } \\ \text { DATASUS } & - & \text { Be Vapor Frio } \\ \text { EPA } & - & \text { Environmental Protection Agency } \\ \text { EPI } & - & \text { Equipamento de Proteção Individual } \\ \text { ESF } & - & \text { Estratégia Saúde da Família } \\ \text { ETSUS } & - & \text { Escola Técnica de Saúde } \\ \text { FMT } & - & \text { Fundação de Medicina Tropical } \\ \text { GL } & - & \text { Graus de Liberdade } \\ \text { HgU } & - & \text { Concentração Urinária de Mercúrio } \\ \text { HMDO } & - & \text { Hospital e Maternidade Dom Orione } \\ \text { IBE } & - & \text { Indicador Biológico de Exposição } \\ \text { IBGE } & - & \text { Instituto Brasileiro de Geografia e Estatística } \\ \text { IBMP } & - & \text { Índice Biológico Máximo Permitido } \\ \text { IPEN } & - & \text { Instituto de Pesquisas Energéticas e Nucleares } \\ \text { LD } & - & \text { Limite de Detecção }\end{array}$




$\begin{array}{lll}\text { LQ } & - & \text { Limite de Quantificação } \\ \text { MB } & - & \text { Monitoramento Biológico } \\ \text { MS } & - & \text { Ministério da Saúde } \\ \text { NIST } & - & \text { National Institute of Standards and Technology } \\ \text { NBR } & - & \text { Norma Brasileira Reguladora } \\ \text { NR } & - & \text { Norma de Referência } \\ \text { OMS } & - & \text { Organização Mundial de Saúde } \\ \text { PA } & - & \text { Pará } \\ \text { pH } & - & \text { Potencial Hidrogeniônico } \\ \text { p/p } & - & \text { Grama de soluto em 100 gramas de solvente } \\ \text { PSF } & - & \text { Programa Saúde da Família } \\ \text { SECT } & - & \text { Secretaria de Ciência e Tecnologia } \\ \text { SMS } & - & \text { Secretaria Municipal de Saúde } \\ \text { SUS } & - & \text { Sistema Único de Saúde } \\ \text { TCLE } & - & \text { Termo de Consentimento Livre e Esclarecido } \\ \text { THD } & - & \text { Técnico em Higiene Dental } \\ \text { TO } & - & \text { Tocantins } \\ \text { TSB } & - & \text { Técnico de Saúde Bucal } \\ \text { UBS } & - & \text { Unidade Básica de Saúde } \\ \text { USP } & - & \text { Universidade de São Paulo } \\ \text { V.N. } & - & \text { Valor de Normalidade } \\ \text { VR } & - & \text { Valor de Referência de Normalidade }\end{array}$




\section{LISTA DE SÍMBOLOS}

\begin{tabular}{|c|c|c|}
\hline$\%$ & - & Por cento \\
\hline$\mu g \cdot L^{-1}$ & - & Micrograma por litro \\
\hline$\mu g \mathrm{Hg} \cdot \mathrm{g}^{-1} \mathrm{CR}$ & - & Micrograma de mercúrio por grama de creatinina \\
\hline$\mu g \mathrm{Hg} \cdot \mathrm{L}^{-1}$ & - & Micrograma de mercúrio por litro \\
\hline $\mathrm{Ag}$ & - & Prata \\
\hline $\mathrm{cm}$ & - & Centímetro \\
\hline $\mathrm{CO}_{2}$ & - & Dióxido de carbono \\
\hline $\mathrm{Cu}$ & - & Cobre \\
\hline$g$ & - & Grama \\
\hline $\mathrm{h}$ & - & Horas \\
\hline $\mathrm{H}_{2} \mathrm{O}$ & - & Água \\
\hline $\mathrm{Hg}$ & - & Mercúrio \\
\hline $\mathrm{Hg}^{+1}$ & - & Mercúrio Monovalente \\
\hline $\mathrm{Hg}^{+2}$ & - & Mercúrio Divalente \\
\hline $\mathrm{Hg}^{0}$ & - & Mercúrio Metálico ou Elementar \\
\hline $\mathrm{L}$ & - & Litro \\
\hline $\mathrm{mg} \cdot \mathrm{L}^{-1}$ & - & Miligrama por litro \\
\hline $\mathrm{mL}$ & - & Mililitro \\
\hline $\mathrm{mm}$ & - & Milímetro \\
\hline $\mathrm{ng} \cdot \mathrm{L}^{-1}$ & - & Nanogramas por litro \\
\hline${ }^{\circ} \mathrm{C}$ & - & Graus Celsius \\
\hline $\mathrm{ppb}$ & - & Partes por bilhão \\
\hline Sn & - & Estanho \\
\hline $\mathrm{Zn}$ & - & Zinco \\
\hline
\end{tabular}




\section{INTRODUÇÃO}

O mercúrio é o único metal encontrado na forma líquida em condições normais de temperatura e pressão (CNTP). Mesmo sendo considerado um metal tóxico, sua produção mundial é estimada em 10.000 toneladas por ano para uso nas mais diversas áreas, como indústrias de tintas, de lâmpadas, de cloro-soda, mineração, medicina e odontologia, sendo o Canadá, a Rússia e a Espanha os principais produtores (Hörsted-Bindslev, 2004; Jung, 2004).

Sua ocorrência no ambiente se dá sob as formas metálica ou elementar, inorgânica e orgânica. Em odontologia o mercúrio elementar é comercializado com o nome mercúrio odontológico ou mercúrio vivo, apresentando cor prateada e aparência brilhante. É utilizado para obtenção do amálgama por meio da formação de uma liga composta de mercúrio e outros metais $(\mathrm{Ag}, \mathrm{Cu}, \mathrm{Sn})$ como material restaurador para dentes posteriores há mais de dois séculos (Bates, 2006).

Este tipo de mercúrio representa a principal fonte de intoxicação observada em laboratórios de pesquisa, indústrias, consultórios odontológicos entre outros (Bello et al., 2002; Faria, 2003; Hörsted-Bindslev, 2004).

A exposição a vapores de mercúrio por profissionais ligados ao exercício da odontologia tem atraído a atenção da comunidade acadêmica de diversos países para a tentativa de se reduzir a quantidade de amálgama utilizado nos consultórios e clínicas odontológicas. Ligados ao dentista e às vezes ainda mais expostos que ele estão os membros da equipe auxiliar - o ASB (auxiliar de saúde bucal e o TSB (técnico em saúde bucal) - denominações recentes que substituem as antigas ACD (auxiliar de consultório dentário) e THD (técnico em higiene dental), respectivamente (Rojas et al., 2000; Nadorfy de Lopez \& Mendez, 2000; Lacerda et al., 2002; Moen et al., 2008).

Fica a critério da equipe auxiliar executar os procedimentos reversíveis ligados ao exercício da odontologia que incluem os procedimentos de limpeza, esterilização, manuseio de resíduos, preparo de materiais, entre outros (Finnkbeiner, 2001; Garcia \& Zanetti-Ramos, 2004; Barros, 2006; Lobas et al., 2006). 
Dentre as variadas exposições ocupacionais ao mercúrio em odontologia podemos citar: manipulação do amálgama dental para seu preparo; contato com gotas derramadas acidentalmente; remoção de excessos de mercúrio do amálgama através de torção em camurça; manipulação de amalgamadores com vazamento; inserção, remoção e polimento de restaurações de amálgama de prata; uso de condensadores ultrassônicos; não utilização de suctores de alta potência durante a remoção de restaurações de amálgama e remoção de restaurações de amálgama a seco com turbina de alta rotação (Naleway et al., 1985; Barregård et al., 1995; Glina et al., 1997; Isacsson, 1997; Langworth et al., 1997; Guimarães-Júnior, 2001; Lacerda et al., 2002; Drummond et al., 2003; Novembrino et al., 2006).

Além disso, parte do amálgama preparado para uso em restaurações acaba sendo descartado devido a sua rápida reação de cristalização ou aos excessos provenientes da escultura das mesmas (Glina et al., 1997). Tais excessos são rotineiramente jogados em lixo comum, sendo uma fonte adicional de contaminação para aqueles que permanecem no ambiente clínico.

Aliada à exposição ocupacional, os profissionais ainda podem estar expostos à emissão de vapores de mercúrio gerados durante a mastigação pelas restaurações de amálgama de seus próprios dentes, conforme relatos de Ziff (1987) e Bello et al. (2002).

No Brasil, são poucos os estudos que refletem a realidade vivenciada por profissionais auxiliares da área odontológica ligados ao SUS no que tange aos riscos ocupacionais ligados ao mercúrio. Grande parte dos estudos é voltada para o dentista, no entanto, nos consultórios públicos o auxiliar é o responsável pelo preparo, manuseio e descarte de resíduos de amálgama.

Nos consultórios públicos de Araguaína, TO o profissional auxiliar da equipe de odontologia nem sempre recebe treinamento específico sob o aspecto de que o mercúrio é um metal tóxico e que seu manuseio requer determinadas proteções específicas. Uma avaliação da rotina de biossegurança realizada por estes profissionais em relação ao manuseio e descarte de materiais e instrumentais contendo mercúrio, aliada a avaliação da concentração de mercúrio nestes profissionais, é de extrema importância para que medidas de prevenção de doenças ocupacionais, causadas por contato com metais tóxicos, sejam tomadas nos consultórios públicos de Araguaína - TO. 
Nesse contexto e considerando que: a) o amálgama é o material amplamente utilizado para restaurações de dentes posteriores nos serviços odontológicos prestados pelo Sistema Único de Saúde (SUS) de Araguaína de acordo com dados do sistema DATASUS; b) nem todos os consultórios públicos do município apresentam amalgamadores para dosagem e trituração do amálgama; e, c) os auxiliares de saúde bucal do município (ASB) trabalham em média 40 horas semanais e são responsáveis pelos processos de lavagem, esterilização e manuseio de mercúrio e de resíduos de amálgama, surgiu a necessidade de avaliação dos procedimentos de armazenamento, de manuseio e de descarte do amálgama, bem como a realização da determinação do monitoramento biológico (MB) desses profissionais expostos ao mercúrio. 


\section{OBJETIVOS}

\subsection{Objetivo Geral}

Avaliar os riscos ocupacionais e a exposição ao mercúrio utilizado em odontologia aos quais os auxiliares em saúde bucal (ASB) da rede pública de saúde de Araguaína - TO - estão expostos.

\subsection{Objetivos Específicos}

- Caracterizar o processo odontológico do sistema de saúde no município de Araguaína - TO;

- realizar um levantamento do número de restaurações de amálgama de prata classe I e II executadas no município de Araguaína, durante o período de janeiro de 2003 a dezembro de 2007 na base de dados do Sistema Único de Saúde, o DATASUS;

- avaliar as condições de armazenamento dos resíduos de amálgama nos consultórios odontológicos públicos do município de Araguaína com relação ao cumprimento da resolução da ANVISA RDC n³06;

- caracterizar o perfil do ASB que atua nos consultórios públicos do município de Araguaína quanto à idade, ao sexo, ao grau de exposição ao mercúrio e aos procedimentos de biossegurança executados;

- realizar o monitoramento biológico dos ASB e estender o monitoramento aos cirurgiões-dentistas da rede municipal de saúde de Araguaína e aos alunos da escola técnica de saúde, polo de Araguaína, que atuam como ASB em outros municípios;

- avaliar diferentes soluções para armazenamento dos resíduos de amálgama até o momento do seu descarte no que diz respeito a sua eficácia no combate à emissão de vapores de mercúrio para o ambiente;

- gerar dados sobre o manuseio e o descarte de resíduos de amálgama e as ações de biossegurança executadas pelos ASB;

- subsidiar políticas públicas de saúde voltadas à modificação de situações de risco as quais os profissionais estão submetidos e/ou submetem seus pacientes. 


\section{ASPECTOS RELEVANTES}

Por meio deste projeto de pesquisa, foram geradas informações voltadas para o cenário regional do norte do Tocantins no que diz respeito aos procedimentos odontológicos executados utilizando mercúrio e sobre a rotina de biossegurança realizada pela equipe auxiliar dos consultórios odontológicos de Araguaína quanto à manipulação e ao descarte de amálgama de prata.

O monitoramento biológico dos auxiliares de consultório dentário que trabalham no SUS em Araguaína foi uma contribuição importante e inédita para o sistema de saúde do Estado do Tocantins, uma vez que a região apresenta características climáticas, geográficas, culturais e socioeconômicas distintas de outros locais de estudo no Brasil.

Além disso, foi possível conhecer o perfil do auxiliar de saúde bucal dos consultórios odontológicos públicos de Araguaína, dado importante uma vez que são os profissionais mais estão expostos aos vapores de mercúrio.

A verificação qualitativa de emissão de vapores de mercúrio de restos de amálgama de prata armazenados em diferentes soluções e em diferentes volumes e temperaturas permitirá a criação de protocolos de descarte dos resíduos de amálgama e modificações nas ações dos profissionais que trabalham diretamente com mercúrio.

Desta forma, a pesquisa voltada para a avaliação das ações desenvolvidas pelos profissionais que prestam serviço ao Sistema Único de Saúde (SUS) pode contribuir para modificar atitudes profissionais, intensificar as relações entre a sociedade, instituições de pesquisa e o setor de prestação de serviços no SUS, beneficiando a implantação de políticas públicas estaduais e municipais para monitoramento biológico dos profissionais e gerenciamento dos resíduos contendo mercúrio.

Certamente, este trabalho contribuirá de modo significativo para a melhoria das condições de trabalho no âmbito dos serviços odontológicos prestados pelo SUS no município de Araguaína, com reflexos positivos para os usuários, para profissionais integrantes da equipe de saúde bucal e para gestores, podendo a pesquisa ser estendida aos demais municípios do Estado do Tocantins. 
Ao final do trabalho serão apresentados os protocolos aos profissionais que manuseiam resíduos de mercúrio e de amálgama odontológico. 


\section{REVISÃO DE LITERATURA}

\subsection{0 mercúrio e a odontologia}

O mercúrio tem sido utilizado em odontologia há mais de 150 anos para obtenção do amálgama dental, material restaurador composto de mercúrio adicionado a uma mistura de prata, estanho, cobre e outros metais (índio, zinco, platina, paládio), conhecida por limalha. Por ser a prata o principal metal presente nas limalhas comercializadas (44,5\% a 71\%), o amálgama odontológico é conhecido como amálgama de prata (Mason et al., 2001; Drummond et al., 2003; Giachetti, 1999; Jones, 2004).

O primeiro amálgama de prata odontológico provavelmente foi introduzido na Inglaterra por Joseph Bell, em 1819 (Dunne et al., 1997) e os precursores da utilização da mistura do amálgama em temperatura ambiente foram o dentista francês Onessiphore Taveau, em 1876, que defendia o uso da "pasta prata" para as restaurações permanentes e o químico inglês Charles Bell, que utilizava moedas de prata trituradas com o mercúrio (Claro et al., 2003).

A "pasta prata", proposta por Taveau, era constituída da simples combinação entre a prata e o mercúrio. Por conveniência, moedas de prata eram transformadas em limalha substituindo gradualmente o uso da prata purificada (Simões et al., 2002). As moedas e quantidades suficientes de mercúrio eram adicionadas ao material para torná-lo uma pasta ou uma massa maleável, que foi apresentada ao mundo como amálgama de prata. O mercúrio excedente era removido da pasta e a mistura inserida em cavidades dentinárias nas quais o material endurecia rapidamente (Claro et al., 2003).

Em 1833, os irmãos Crawcour começaram a divulgar maciçamente em Nova Yorque que dispunham de um novo tipo de material muito mais barato e que não exigia o tempo e o trabalho gastos no preparo cavitário que o ouro, material restaurador de escolha da época (Claro et al., 2003).

O uso desse novo material promoveu grande controvérsia, pois a odontologia organizada repudiava e denunciava o uso do amálgama. À frente desta discussão estava a Sociedade Americana de Cirurgiões-Dentistas, fundada em 1840 pelo Dr. Samuel D. Harris, que na mesma época abriu a primeira escola de Odontologia nos Estados Unidos, a Baltimore Dental School. Uma das 
primeiras resoluções aprovadas pela Sociedade Americana de CirurgiõesDentistas foi que "todas as substâncias que contivessem mercúrio eram nocivas aos dentes e a todas as partes da boca e que não haveria obturação na qual o ouro não fosse o material empregado" (Saquy, 1996; Berry et al., 1998).

Em 1870, surgiu o primeiro e marcante movimento organizado a favor do amálgama. Sob a liderança de Flagg, um grupo defendia a tese de que o amálgama era um valioso material para restaurações e que os relatórios indicativos da nocividade à saúde dos pacientes eram mal fundamentados e inverídicos. Como a maioria das experiências para comprovação da nova tese era inconclusiva, os dentistas profissionais permaneciam em dúvida quanto à conveniência do uso do material em restaurações (Berry et al., 1998).

Greene Vardiman Black, considerado um dos grandes fundadores da odontologia moderna, contribuiu muito para o aperfeiçoamento do amálgama de prata, desenvolvendo uma fórmula que continha aproximadamente $68 \%$ de prata, $27 \%$ de estanho e $5 \%$ de cobre (Saquy, 1996).

Apesar do desenvolvimento de novos materiais e técnicas, o amálgama continua sendo indicado para restaurações que requerem durabilidade e resistência conferidas pelas suas propriedades físicas satisfatórias, estabilidade dimensional e insolubilidade aos fluidos bucais (Osborne et al., 1992; Pucci \& Giachetti, 1998; Vilarinho et al., 1999; Fuks, 2002; et al., 2008, Chaari et al., 2009).

É amplamente utilizado como material restaurador de dentes posteriores em situações nas quais a estética não é o fator fundamental. Sua forma de preparo é rápida e fácil, além de ser um material de baixo custo, tendo aceitação satisfatória entre profissionais e pacientes (Dunne et al., 1997; Vilarinho et al., 1999; Felipe et al.,1999; Fuks, 2002; Duran et al., 2004; Zolfaghari et al., 2007).

Dependendo do fabricante, a limalha pode ser constituída por $40 \%$ a $74 \%$ do seu teor de massa de prata, $25-32 \%$ de estanho, 30\% de cobre e $2 \%$ de zinco. A esses metais sólidos é misturado o mercúrio líquido na proporção de 1:1 antes da inserção do amálgama nos preparos cavitários (SCENIHR, 2008; Hylander et al., 2006); o mercúrio é essencial para a preparação do amálgama odontológico e exerce influência em suas propriedades físicas (Campos \& Steagall, 1988). 
Para compor o amálgama, o mercúrio é vendido em duas apresentações comerciais. Pode ser dispensado compartimentado em cápsulas pré-dosadas com a limalha, nas quais a mesma é acondicionada em um compartimento da cápsula e o mercúrio em outro, separados entre si por uma membrana rompida durante o processo de mistura em amalgamador mecânico, ou ser comercializado em frasco com bico dosador contendo normalmente $100 \mathrm{~g}$ do metal (SCENIHR, 2008).

O uso de cápsulas pré-dosadas de amálgama reduz as possibilidades de exposição ao mercúrio metálico durante sua mistura à limalha, diferente do que ocorre durante a trituração manual usando gral e pistilo (Osborne, 1992; SCENIHR, 2008).

A preparação manual do amálgama com gral e pistilo, incluindo pesagem em balança, a não utilização de equipamentos de proteção individual (EPI) durante seu manuseio e descarte e o uso de amalgamadores volumétricos mal conservados e descalibrados podem causar exposição ocupacional à equipe odontológica (Gronka et al., 1970; Osborne, 1992; Zolfaghari et al., 2007).

Desde 1972, o Council on Dental Materials and Devices considera o amalgamador uma máquina essencial na trituração do amálgama, visto que torna desnecessário o uso de mercúrio em excesso para lubrificar a massa de amálgama, problema que ocorre na trituração manual (Council on Dental Materials and Devices, 1972).

Glina et al. (1997) avaliaram a exposição ocupacional ao mercúrio metálico no módulo odontológico de uma unidade básica de saúde localizada na cidade de São Paulo no qual trabalhavam 05 CD e 03 ASB, com mínimo de 02 anos de trabalho. Dentre os riscos ocupacionais relacionados ao ambiente de trabalho, foi relatada a exposição ao mercúrio metálico presente no amalgamador, em ranhuras da bancada de inox e pias, na camurça utilizada para homogeneização do amálgama e retirada do excesso de mercúrio, no lixo e cuspideiras, no vidro com água no qual era descartado o excesso de mercúrio e no recipiente de vidro em que o mercúrio era adquirido. Em relação aos processos que envolviam a manipulação do amálgama, os trabalhadores da unidade utilizavam amalgamador mecânico volumétrico que apresentava problemas de vazamento na lateral e trituração deficiente, além de ser necessária a remoção de excessos de mercúrio utilizando camurça, guardada após uso em 
caixa metálica fechada. Na sua ausência, era feita a trituração manual no gral e pistilo.

Langworth et al. (1997) e Zolfaghari et al. (2007) ressaltam que as concentrações atmosféricas de mercúrio metálico no ambiente dos consultórios odontológicos são influenciadas pela presença de seus resíduos no piso quando derramados acidentalmente durante a preparação, inserção e remoção das restaurações. A ventilação do ambiente (sala clínica), as características dos pisos e das paredes, as práticas de higiene dos profissionais da equipe de odontologia e o tipo de trituração do amálgama influenciam diretamente nos riscos da exposição ocupacional.

\subsection{Toxicidade do mercúrio}

O mercúrio metálico $\left(\mathrm{Hg}^{0}\right)$ também conhecido como elementar em temperatura ambiente, é um líquido volátil, denso e de cor cinza-prateado. Pode ser encontrado estável em outros dois estados de oxidação: mercúrio I $\left(\mathrm{Hg}^{+1}\right)$ e mercúrio II $\left(\mathrm{Hg}^{+2}\right)$, respectivamente (Nuttal, 2004).

Sob a forma líquida, é pouco absorvido pelo trato gastrointestinal, portanto considerado pouco nocivo se ingerido (Nutall, 2004, Kazantzis, 2002). Entretanto, o vapor de mercúrio, quando inalado, entra na corrente sanguínea e se transforma por oxidação em íon $\mathrm{Hg}^{-}$. Como esta reação não é instantânea, o metal permanece em sua forma elementar por alguns minutos no sistema circulatório e se deposita nas células nervosas nos tecidos do córtex cerebral, cerebelo e também no núcleo cerebral, concluindo sua oxidação final podendo ainda transpor a barreira placentária (Lowe, 1980; Kazantzis, 2002; Nutall, 2004).

Quando forma compostos orgânicos, o mercúrio é extremamente tóxico não apenas para o ser humano, mas para toda a biota. Devido ao radical orgânico, o metal pode entrar rapidamente na corrente sanguínea, causando danos irreparáveis ao sistema nervoso central (Canela, 1995).

Alguns autores destacam o perigo que o metal representa para a saúde dos profissionais da equipe odontológica, uma vez que a contaminação pode ocorrer por seu contato direto com a pele ou por meio da inalação de seus vapores (Campos \& Steagall, 1988; Osborne, 1992; Lacerda et al., 2002; Nutall, 2004). 
$\mathrm{Na}$ TAB. 1 é apresentada uma listagem das principais fontes de contaminação e absorção do mercúrio nos consultórios odontológicos, segundo o Ministério da Saúde (Brasil, 2006).

TABELA 1 - Principais fontes de contaminação e absorção do mercúrio

\begin{tabular}{|c|c|}
\hline Fontes de contaminação & Formas de absorção \\
\hline $\begin{array}{l}\text { - Armazenagem (consultórios e lojas } \\
\text { de artigos odontológicos). } \\
\text { - Recipientes não vedados. } \\
\text { - Gotículas espalhadas. } \\
\text { - Resíduos. }\end{array}$ & - Inalação à temperatura acima de $32^{\circ} \mathrm{C}$. \\
\hline $\begin{array}{ll}\text { - } & \text { Transferência e manipulação } \\
& \text { (trituração, homogeneização manual } \\
& \text { e remoção de excessos). } \\
\text { - } & \text { Inserção na cavidade. } \\
\text { - } & \text { Escultura e polimento. } \\
\text { - } & \text { Corte mecânico de restaurações de } \\
& \text { amálgama. }\end{array}$ & $\begin{array}{l}\text { - Inalação. } \\
\text { - Absorção pela pele e mãos } \\
\text { contaminadas. } \\
\text { - Ingestão: mãos contaminadas para a } \\
\text { boca, alimentos e cigarros. } \\
\text { - Inalação: vapores de mercúrio liberados } \\
\text { pelo aquecimento, devido ao desgaste } \\
\text { com brocas; poeira de amálgama } \\
\text { inalada. } \\
\text { Ingestão: partículas de amálgama; } \\
\text { impactos na boca. }\end{array}$ \\
\hline $\begin{array}{l}\text { - Limpeza do equipamento, superfície } \\
\text { de trabalho e assoalho. }\end{array}$ & $\begin{array}{l}\text { - Inalação. } \\
\text { - } \quad \text { Absorção pela pele. } \\
\text { - Ingestão. }\end{array}$ \\
\hline
\end{tabular}

Fonte - Brasil, 2006.

As formas de absorção, distribuição, manifestação toxicológica, excreção e métodos de detecção (determinação) do mercúrio também são influenciadas de acordo com a apresentação dos compostos - forma elementar, sais inorgânicos e compostos orgânicos (Satoh, 2000; Sweeny et al., 2002; Vas \& Monestier et al., 2008).

Em relação ao tempo de exposição, são identificadas formas de contaminação, com sintomas distintos, de acordo com Asano et al. (2000). São elas:

- Aguda: gerada acidentalmente pelo consumo, aspiração ou contato dérmico de grande quantidade, apresentando síndrome gastroentérica, 
renal, problemas respiratórios, em especial nos pulmões, visuais, mentais e sintomas como fadiga, fraqueza, febre, tremores e salivação.

- Crônica: observada, em especial, nos processos industriais e de manufatura, propiciando lesão no sistema nervoso central, com indicativos de tremores de extremidades, síndromes neuropáticas, mudanças de personalidade referidas ao eretismo, distúrbios de fala, delírios e rigidez.

- Sensibilização: pacientes submetidos a tratamentos com diuréticos mercuriais e posteriormente expostos aos vapores de mercúrio ou que receberam restaurações em amálgama.

- Micromercurialismo: decorrente da exposição a baixas concentrações em longo prazo, caracterizando mais precisamente a doença ocupacional que pode afligir o cirurgião-dentista e equipe auxiliar.

- Hidrargirismo ou mercurialismo: intoxicação mais severa e aguda ocasionada pelo mercúrio.

Os efeitos da exposição ao mercúrio são determinados por diferentes fatores, tais como a forma química do metal, a rota de exposição, a dose e a fatores relacionados ao indivíduo (Micaroni et al., 2000). Quanto a este último, identificam-se variações quanto à idade, à genética, a aspectos ambientais, ao status nutricional e à responsividade de diferentes pessoas a uma mesma dose (Davis et al., 2001; Nuttal, 2004).

Cada forma do mercúrio tem o seu próprio perfil toxicológico, embora, em termos gerais, a toxicidade seja mais elevada com os compostos orgânicos, seguidas por mercúrio elementar e sais inorgânicos. Este fato é importante, pois cada forma de mercúrio influencia em seu modo de ser absorvido, distribuído, excretado e mensurado nos organismos vivos, além de ter manifestações toxicológicas distintas (Sweeny et al., 2002; Vas \& Monestier, 2008).

A maior parte do metilmercúrio presente no sangue é encontrada nos glóbulos vermelhos, o que os torna um meio indicador desejável, sendo a utilização do plasma mais apropriada para monitorar o mercúrio inorgânico, distribuído entre o plasma e os eritrócitos (Skerfving, 1991).

Outra parte se acumula no cabelo, de modo que quando incorporado ao interior da fibra capilar permanece em concentração estável, servindo como 
registro histórico de níveis sanguíneos anteriores de exposição, uma vez que a concentração de mercúrio no escalpo é diretamente proporcional à concentração simultânea no sangue (Guimarães, 2001).

Warfvinge (1995) e Hylander \& Meili (2003) relataram a existência de contaminação pelo mercúrio em membros da equipe de odontologia no momento da preparação do amálgama, pois este se vaporiza a $20^{\circ} \mathrm{C}$ aumentando sua volatilidade à medida que há aumento da temperatura, ampliando-se em até oito vezes, caso a temperatura atinja $50^{\circ} \mathrm{C}$.

Sigeyuki (2000) relatou que uma exposição acima de 1-2 mg. $\mathrm{m}^{3}$ de vapor de mercúrio elementar, por algumas horas, causa bronquiolite química aguda e pneumonite. Duas horas após a exposição, são observados danos ao pulmão através da formação de uma membrana hialina e, posteriormente, a ocorrência de fibrose pulmonar.

Esta forma também é liberada por evaporação na boca de pacientes que possuem amálgamas dentários preparados com mercúrio, o que pode resultar em uma intoxicação dependendo da quantidade de amálgamas presentes (Woods et al., 2007).

Danos pulmonares, elevação da pressão arterial, irritação nos olhos, náuseas, vômitos, diarréia, dores no peito, dispnéia, tosse, gengivite, problemas hepáticos e hipersalivação são causados quando há intoxicação pelo metal, que, ao atingir o cérebro, pode causar vários distúrbios neuropsiquiátricos, dentre eles distorções da visão e da audição, irritabilidade, timidez, tremores e perda de memória (Azevedo et al., 2003).

Em relação aos danos causados no feto quando gestantes são expostas ao mercúrio, Wannag \& Skjaerasen (1975) realizaram um estudo em mulheres grávidas dentistas e não dentistas e verificaram que as dentistas apresentavam acúmulo de mercúrio na placenta e nas membranas fetais, em uma tentativa destes órgãos de protegerem o feto contra a exposição ao metal.

Entretanto Vimy et al. (1990) alertaram o uso de amálgama em gestantes deveria ser restringido uma vez que, segundo os autores, a placenta não seria capaz de impedir a passagem do mercúrio ao feto.

Rowland (1994) relatou decréscimo na fertilidade de assistentes odontológicas do sexo feminino, expostas ao vapor de mercúrio, se comparadas ao grupo controle 
Canela (1995) constatou que, em acidentes por intoxicação, a vida intrauterina é mais suscetível aos danos cerebrais causados pelo metilmercúrio, uma vez que este parece interferir nos processos de divisão celular. Em casos de exposição severa do feto, houve relatos de problemas neurológicos graves e inclusive má formação cefálica.

Grandjean et al. (1997) relataram os efeitos neuroteratogênicos (déficit considerável de inteligência, coordenação motora e outros problemas neurológicos) em crianças, causados por baixas doses de exposição ao mercúrio durante a fase intrauterina e logo após o nascimento.

Sukel (2000) demonstrou a presença de intoxicação fetal através da passagem do metal pela placenta.

Davis et al. (2001) realizaram um estudo em fêmeas de ratos demonstrando que a exposição ao vapor de mercúrio alterou o ciclo de estrogênio, mas não teve efeito significativo na ovulação, implantação ou manutenção da primeira gravidez.

Goldman \& Shannon (2001) afirmam que o mercúrio, em todas as suas formas, é tóxico para fetos e crianças, devendo ser reduzida sua exposição em mulheres grávidas e crianças, bem como da população em geral. Para os autores isso refletiria diretamente na opção do uso do material restaurador nesses pacientes e da exposição ocupacional das gestantes que trabalham com odontologia.

Apesar de existirem inúmeros trabalhos de pesquisa apontando para a não utilização do amálgama de prata por ser tóxico e liberar vapores de mercúrio, Richards (2008) e Jones (2008) apresentaram alguns argumentos para que o uso do amálgama em odontologia não fosse abolido. Para os autores existe uma farsa burocrática, pois, pelo menos $50 \%$ da poluição ambiental causada pelo mercúrio é advinda de fontes naturais e $42 \%$ da queima de combustíveis fósseis, além do que, não há estudos científicos comprovados de que o amálgama dental represente perigo à saúde de pacientes, dentistas ou ao ambiente.

Jones (2008) alerta que a proibição do uso do amálgama na Noruega em 2008 é uma grande tragédia para os escandinavos. Segundo o autor, o amálgama tem características de desgaste semelhante ao dente natural, enquanto que, as resinas compostas desgastam rapidamente, sendo necessária 
sua substituição com maior frequência removendo consequentemente, mais estrutura dentária.

\subsection{Avaliação da exposição ocupacional - monitoramento biológico}

Monitoramento biológico $(\mathrm{MB})$ é definido como a quantificação de substâncias químicas, ou de seus metabólitos, em tecidos, fluidos, secreções, excreções, ar expirado ou em quaisquer combinações, conduzidas para avaliar exposições e riscos à saúde, comparadas a uma referência apropriada (Pivetta et al., 2001).

O monitoramento biológico envolve coleta e análise de tecidos ou líquidos corpóreos para fornecer um índice da exposição a uma substância ou a um metabólito tóxico. O mercúrio inorgânico total pode ser medido em matriz de urina matinal. Um nível de mercúrio de 35 microgramas por grama de creatinina ( $\left.\mu \mathrm{gHg} . \mathrm{g}^{-1} \mathrm{CR}\right)$ deve ser usado como o índice biológico à exposição (Glina et al., 1997; Morales Fuentes \& Reyes Gil, 2003).

Para identificar e classificar substâncias de interesse ecotoxicológico, a Enviromental Protection Agency/Agency for Toxic Substances and Disease Registry (EPA/ATSDR) propôs um método original, que compreende o estabelecimento dos critérios e métodos para o MB e determina os valores de referência. Essa classificação considera três fatores: a toxicidade intrínseca a cada substância, a frequência com a qual estas podem ser encontradas no ambiente e a probabilidade de o homem estar exposto (Pivetta et al., 2001; Agency for Toxic Substances and Disease Registry, 1999).

No Brasil, o Ministério do Trabalho editou o Programa de Controle Médico de Saúde Ocupacional, NR 7, e definiu índices biológicos de exposição para agentes químicos em ambientes de trabalho, adotando valores e estudos realizados em outros países. Atualmente a Legislação Brasileira estabelece 26 agentes químicos para os quais é recomendada a monitorização biológica de grupos de trabalhadores expostos a riscos quantitativamente semelhantes, dentre os quais encontramos o mercúrio (Brasil, 1994).

A Norma Reguladora NR 7 utiliza como indicador biológico a análise de mercúrio presente nas amostras coletadas da primeira urina da manhã. Como método analítico, utiliza-se a espectrofotometria de absorção atômica - AAS; como Valor de Referência da Normalidade - VR (valor possível de ser encontrado 
em populações não expostas ocupacionalmente) até $5 \mu \mathrm{gHg} \cdot \mathrm{g}^{-1} \mathrm{CR}$ e como Índice Biológico Máximo Permitido - IBMP (valor máximo do indicador biológico para o qual se supõe que a maioria das pessoas ocupacionalmente expostas não corre risco de dano à saúde) até $35 \mu \mathrm{gHg} \cdot \mathrm{g}^{-1} \mathrm{CR}$. Acima deste valor significa exposição excessiva ao mercúrio (Brasil, 1994).

Em 25 de janeiro de 2011, o Ministério da Saúde publicou a portaria $\mathrm{n}^{\circ}$ 104, que inclui as "intoxicações exógenas por substâncias químicas, incluindo gases tóxicos e metais pesados" ${ }^{1}$ na lista de notificação compulsória (LNC), conforme o anexo I da referida portaria. A notificação compulsória é obrigatória a todos os profissionais de saúde, incluindo odontólogos e outros no exercício da profissão, bem como os responsáveis por organizações e estabelecimentos públicos e particulares de saúde e ensino (Brasil, 2011).

\subsection{Gerenciamento dos resíduos contendo mercúrio}

De acordo com a Resolução do CONAMA n 358/05, os resíduos com "características de periculosidade quando não forem submetidos a processo de reutilização, recuperação ou reciclagem, devem ser submetidos a tratamento e disposição final específicos" (Brasil, 2005a).

A Norma Brasileira NBR 10004/04 classifica os resíduos sólidos em perigosos e não perigosos quanto ao risco à saúde pública e ao meio ambiente. Nesta norma, o mercúrio é considerado como substância que confere periculosidade ao resíduo (ABNT, 2004).

A resolução da ANVISA RDC $n^{\circ} 306$ estabelece que os resíduos contendo mercúrio devem ser obrigatoriamente segregados de maneira separada, acondicionados em recipientes sob selo d'água, encaminhados para recuperação (ANVISA, 2004, Brasil, 2005a; Brasil, 2006).

\footnotetext{
${ }^{1}$ A denominação metal pesado está presente na lista de notificação compulsória da portaria $n^{\circ} 104 / 2011$ que determina a "relação de doenças, agravos e eventos em saúde pública de notificação compulsória em todo o território nacional e estabelece fluxo, critérios, responsabilidades e atribuições aos profissionais e serviços de saúde", entretanto ressalta-se que a denominação apropriada é metal tóxico.
} 
Ferreira \& Appel (1991) relataram que aproximadamente 55\% do amálgama preparado por dentistas são perdidos durante a preparação; frequentemente este material é descartado como lixo comum.

Se não acondicionadas e destinadas a locais específicos, as pequenas partículas de amálgama podem ser introduzidas no sistema de esgoto local contaminando o meio ambiente, pois apesar de misturado a uma liga o mercúrio contido no amálgama pode ser liberado através de reações químicas naturais (calor, agitação, mudança de $\mathrm{pH}$ ) que ocorrem no ambiente podendo levar bioacumulação e bioincorporação na cadeia alimentar (Mota et al., 2004).

Arenholt-Bindslev (1992) relatou que restaurações de amálgama antigas ou insatisfatórias quando removidas com a alta rotação, geram pequenas partículas que são jogadas na rede de esgoto e, consequentemente, no meio ambiente.

Jokstad \& Fan (2006) afirmam que o amálgama introduz resíduos de mercúrio no meio ambiente por meio de descargas diretas na rede de esgoto, incineração, deposição em aterros sanitários e incineração de lamas de depuração.

Com o intuito de evitar qualquer tipo de contaminação até serem processados, a American Dental Association (ADA) recomenda armazenar os resíduos de amálgama em frasco contendo solução fixadora de radiografias (ADA, 2003).

Em relação à solução utilizada no interior dos frascos de armazenamento de resíduos, Saquy (1996) após estudo comparativo sobre a eficácia de diversas substâncias na retenção da emissão de vapores de mercúrio originários de resíduos de amálgama, concluiu que a solução fixadora de radiografias era a mais eficaz, sendo capaz de reter os vapores por dezessete dias e a água foi capaz de retê-lo durante quatorze dias. Mesmo em solução fixadora radiográfica, vapores de mercúrio são desprendidos, podendo intoxicar gradativamente a equipe.

Entre as mais importantes medidas técnicas de prevenção da exposição ocupacional ao mercúrio estão a avaliação permanente da presença de vapores de mercúrio no ambiente do consultório odontológico, o armazenamento do mercúrio em recipientes fechados e inquebráveis, com tampa envolvida com papel por filtro embebido em cloreto de paládio, para detecção de vazamento, uso 
somente de cápsulas que permaneçam seladas durante a amalgamação e o armazenamento dos resíduos de amálgama em recipientes fechados contendo solução fixadora radiográfica, em período não superior a dezessete dias (Saquy, 1996).

Fortes \& Samuel (1999) compararam a glicerina, a água destilada, a solução fixadora de radiografias e o meio seco visando à diminuição da liberação de vapores de mercúrio gerados por resíduos de amálgama e concluíram que a glicerina foi o meio mais adequado para a armazenagem.

Hörsted-Bindslev (2004) e Sutow et al. (2004) sugerem que, até seu descarte, os resíduos de amálgama de prata devem ser estocados em vidros contendo solução fixadora para revelação de radiografias, e os equipamentos odontológicos devem estar munidos de filtros capazes de reterem os restos de amálgama, evitando que os mesmo sejam jogados diretamente na rede coletora de esgoto.

De acordo com Claro et al. (2003) a presença de fontes de calor (como estufas e autoclaves) no mesmo ambiente onde o amálgama é manipulado, aumenta as possibilidades de intoxicação mercurial.

Grigoletto et al. (2008) ressaltam que mesmo a Legislação Brasileira determinando normas e condutas rigorosas para o gerenciamento de resíduos sólidos perigosos, apenas a lei e a tecnologia não são suficientes para solucionar a problemática dos resíduos gerados em serviços de saúde sendo necessários realizar treinamentos teórico-práticos sobre manuseio adequado desses resíduos bem como investir em educação ambiental.

\subsection{Mercúrio e excreção urinária}

Em humanos, assim como nos demais mamíferos, o rim é o primeiro alvo no qual $\mathrm{o} \mathrm{Hg}^{+2}$ se acumula quando há exposição a concentrações elevadas de $\mathrm{Hg}^{0}$ (Woods et al., 2008). Desta forma, a concentração urinária de mercúrio é amplamente utilizada como uma medida da exposição ao mercúrio resultante de restaurações de amálgamas de prata (Barregård, 2005; Woods et al., 2007; Woods et al., 2008).

$\mathrm{Na}$ exposição ao mercúrio metálico, a excreção é principalmente urinária, podendo ocorrer eliminação pulmonar de vapores de $\mathrm{Hg}$; sua meia vida 
no organismo é de 60 dias. O mercúrio inorgânico é excretado totalmente na urina e apresenta meia vida de 30 a 60 dias (Friberg et al., 1979; WHO, 2003).

Os potenciais efeitos adversos decorrentes da exposição a baixos níveis vapores de $\mathrm{Hg}^{0}$ liberados a partir de restaurações em amálgamas dentários continuam a ser um tema de debate, principalmente em relação à toxicidade do mercúrio em crianças (Brownawell et al., 2005).

De acordo com os estudos de Trepka et al. (1997) e Levy et al. (2004), os níveis de mercúrio em amostras de urina apresentaram correlação positiva com a exposição ao amálgama dentário.

Entretanto, alguns autores discutem sobre o uso da dosagem do mercúrio urinário como indicador preciso da presença de mercúrio proveniente das restaurações de amálgama dentário (Nuttal, 2004; Clarkson \& Magos, 2006; Mutter et al., 2007).

Em relação à excreção, Mason et al. (2001) relataram uma variação diurna na excreção do mercúrio indicando que as coletas para realização de exames de creatinina e dosagem de metais devem ter um horário fixo com 0 intuito de minimizar as variações nos valores de mercúrio encontrados na urina.

Naleway et al. (1985), em um estudo realizado no período de 1975 a 1983, analisaram os níveis de mercúrio urinário em 4.272 dentistas e encontraram que, em média, os dentistas não apresentavam concentrações urinárias de mercúrio acima do limite, concluindo, portanto, que não havia problema de exposição ocupacional deles em relação ao amálgama. Entretanto, as concentrações urinárias foram estatisticamente significativas $(p<0,001)$ quando correlacionadas com o número de restaurações de amálgama que cada dentista colocava por semana. A população geral dos dentistas no grupo de estudo apresentava um intervalo de $0-5 \mu \mathrm{gHg} \cdot \mathrm{L}^{-1}$ de urina, enquanto $10,9 \%$ deles apresentavam concentrações maiores que $30 \mu \mathrm{gHg} \cdot \mathrm{L}^{-1}$, incluindo 1,3\% com níveis acima de $100 \mu \mathrm{gHg} \cdot \mathrm{L}^{-1}$ na urina.

De acordo com Nilsson \& Nilsson (1986) e Minoia et al. (2006) as concentrações de mercúrio na urina podem não refletir a quantidade real do metal retido em tecidos mais sensíveis, tais como cérebro e glândulas endócrinas, fato que poderia explicar o aumento de sintomas ocasionados por intoxicação mercurial associado à redução do mercúrio total excretado na urina, em indivíduos expostos. 
Em relação aos prejuízos causados pela exposição ocupacional ao mercúrio em dentistas, Echeverria et al. (1995) avaliaram os níveis de mercúrio urinário de 19 dentistas e relataram médias de $36,4 \pm 20 \mu \mathrm{gHg} \cdot \mathrm{L}^{-1}$. Tais níveis foram associados ao prejuízo em memória de curto prazo, concentração, além de aumento na irritabilidade. No estudo, foi observada média de $9,6 \mu \mathrm{gHg} \cdot \mathrm{L}^{-1}$ de urina.

Bittner et al. (1998) administraram testes de velocidade, precisão motora, controle, tremor e destreza manuais em dentistas com médias de $\mathrm{Hg} \leq 55$ $\mu \mathrm{gHg} \cdot \mathrm{g}^{-1} \mathrm{CR}(\mathrm{HgU})$ e verificaram que havia uma associação entre desempenho prejudicado nos testes e concentração urinária de mercúrio.

Nadorfy de Lopez \& Mendez (2000) realizaram um estudo com 200 auxiliares de saúde bucal do sexo feminino, com idade compreendida entre 26 e 56 anos, expostas ocupacionalmente ao mercúrio de 5 a 26 anos e com carga laboral de 30 horas semanais. Foram determinados os níveis de mercúrio em urina de $24 \mathrm{~h}$. Para as análises de variância, foram consideradas as variáveis de concentração de mercúrio urinário versus diagnóstico clínico e concentração de mercúrio urinário versus tempo de exposição aos vapores de mercúrio. Os resultados mostraram aumento na complexidade das manifestações clínicas em função dos elevados níveis de mercúrio urinário e do tempo de serviço. Os indivíduos que mostraram níveis urinários médios de mercúrio de $41 \pm 18 \mu \mathrm{Hg} \cdot \mathrm{L}^{-1}$ (V.N. $=0-14 \mu \mathrm{gHg} . \mathrm{L}^{-1}$ de urina) e tempo de serviço igual ou superior a 10 anos apresentaram sintomatologia clínica característica de intoxicação mercurial, sendo os mais afetados aqueles com mais de 20 anos de serviço e níveis de $50 \mu \mathrm{Hg} . \mathrm{L}^{-1}$ na urina. Tais participantes da pesquisa apresentaram manifestações de hidrargismo crônico e foram declarados de risco. Os sintomas mais relatados foram queda de cabelo, cefaléia, transtornos psiquiátricos, digestivos, respiratórios, renais, oftálmicos, nervosos e locomotores. Os autores concluíram que o profissional de odontologia está exposto ao risco permanente de intoxicação por vapores de mercúrio elementar e observaram a existência de uma correlação significativa entre o tempo de exposição a vapores de mercúrio, os níveis de mercúrio ambiental, as taxas urinárias e algumas manifestações clínicas.

Aydin et al. (2003) avaliaram os níveis séricos e urinários de $\mathrm{Hg}$ utilizando a técnica de espectrofotometria de absorção atômica em 46 
profissionais de 05 clínicas odontológicas (04 públicas e 01 privada) da Turquia com o objetivo de associar os possíveis efeitos neuropsicológicos (diagnosticados por meio de testes psicológicos) com a exposição ocupacional ao metal tóxico, comparando-os com um grupo controle. Os resultados demonstraram que o grupo composto por profissionais estudados apresentaram níveis séricos (média de 2,18 $\left.\mathrm{nmolHg} \cdot \mathrm{L}^{-1}\right)$ e urinários $\left(1,17 \mathrm{nmol} . \mathrm{mmolCR}^{-1}\right)$ de mercúrio superiores quando comparados ao grupo controle (sem exposição ocupacional), apresentando também uma relação positiva de aumento de ansiedade.

lavicoli et al. (2004) determinaram os níveis séricos e urinários de mercúrio, titânio, paládio, platina e ródio por meio da técnica de espectrometria de massas em 20 profissionais da equipe odontológica expostos ao mercúrio e 20 não expostos (grupo controle). Devido às baixas concentrações de mercúrio nas amostras estudadas não foi possível determinar se os profissionais participantes da pesquisa estavam expostos ocupacionalmente aos metais pesquisados.

Guzzi et al. (2006) realizaram um estudo em cadáveres que apresentavam restaurações de amálgama em seus dentes e observaram dosagens superiores de mercúrio em tecidos retirados das regiões cerebrais e tireóide, bem como em tecidos retirados no córtex renal, uma vez que rins são os principais contribuintes das taxas de mercúrio urinário (Clarkson \& Magos, 2006; Nuttal, 2004).

Woods et al. (2007) relataram que a dosagem da concentração de mercúrio urinário é um método amplamente utilizado como medida da exposição ao mercúrio advinda de restaurações de amálgamas dentários. Os autores avaliaram a influência do sexo sobre taxas de excreção de mercúrio na urina e concluíram que as mulheres apresentavam as taxas mais elevadas, conferindo menores riscos de intoxicação se comparadas aos homens.

Barregård et al. (1995) e Isacsson et al. (1997) sugeriram que o bruxismo desempenha um importante papel para o aumento da concentração de mercúrio na urina, pois os dentes restaurados com amálgama estão sob estresse mastigatório, ocasionado à liberação de vapores de mercúrio oriunda do atrito entre dente e restauração.

Trzcinka-Ochocka et al. (2007) avaliaram as concentrações urinárias de mercúrio $(\mathrm{HgU})$ através da CV-AAS de um grupo composto por 51 profissionais que atuavam na equipe odontológica na Polônia, com idade entre 
25-63 anos (média de 39,2 anos) expostos ocupacionalmente ao mercúrio (tempo médio de 14,3 anos profissão), comparando-as com as concentrações urinárias de um grupo controle de 16 integrantes não expostos ao vapor de mercúrio. Os resultados demonstraram ser pequena a exposição ocupacional aos vapores de mercúrio nos profissionais que trabalhavam com odontologia; não havia diferenças estatísticas significativas entre o grupo avaliado (média de 0,5 50,27 $\mu \mathrm{gHg} \cdot \mathrm{g}^{-1} \mathrm{CR}$ ) e o grupo controle (média de $0,44 \pm 0,44 \mu \mathrm{gHg} \cdot \mathrm{g}^{-1} \mathrm{CR}$ ). Entretanto, os valores de $\mathrm{HgU}$ eram maiores nos profissionais com maior tempo de trabalho.

No Brasil, Glina et al. (1997) analisaram as dosagens de mercúrio urinário em 05 CD e 03 ACD, com mínimo de 02 anos de exposição ao mercúrio e que trabalhavam em uma unidade básica de saúde em São Paulo. Constataram que em $62,5 \%$ dos trabalhadores as dosagens foram de 10 a $49 \mu \mathrm{gHg} . \mathrm{L}^{-1}$ e que $37,5 \%$ estavam abaixo de $10 \mu \mathrm{gHg} \cdot \mathrm{L}^{-1}$, sendo a mais baixa de $2,5 \mu \mathrm{gHg} \cdot \mathrm{L}^{-1}$. Dos trabalhadores com dosagens entre 10 e $49 \mu \mathrm{gHg} \cdot \mathrm{L}^{-1}, 04$ eram dentistas e 01 era ACD. Em relação aos CD, 03 apresentaram quadros compatíveis com intoxicações crônicas por mercúrio de leves a moderadas e 02 quadro inconclusivo para intoxicação por mercúrio. Das 05 ACD participantes da pesquisa, 02 apresentaram quadros compatíveis com intoxicações crônicas por mercúrio de leves a moderadas e 01 quadro inconclusivo para intoxicação por mercúrio.

Posteriormente, Oikawa et al. (2007) avaliaram os teores de mercúrio na urina de 20 graduandos de Odontologia, de ambos os sexos, na faixa etária de 21 a 27 anos, que tiveram contato com o amálgama no laboratório e na clínica odontológica, do $3^{\circ}$ ao $5^{\circ}$ ano da graduação do Centro de Ensino Superior do Estado do Pará (CESUPA) no ano de 2002 utilizando espectrofotometria de absorção atômica. De acordo os autores, não houve indícios de exposição ocupacional no grupo estudado e $80 \%$ dos alunos estavam com teores de mercúrio dentro dos limites de normalidade $\left(10 \mu \mathrm{gHg} \cdot \mathrm{L}^{-1}\right)$ e apenas 4 encontravam-se acima do limite de normalidade, porém, dentro do limite máximo tolerado $\left(50 \mu \mathrm{gHg} \cdot \mathrm{L}^{-1}\right)$.

Woods et al. (2008) avaliaram a integridade renal em crianças e adolescentes de 8-18 anos com biomarcador de mercúrio durante 07 anos de acompanhamento clínico e observaram que as médias nos níveis de mercúrio foram de $1,8 \mu \mathrm{gHg} . \mathrm{g}^{-1} \mathrm{CR}$ no grupo dos pacientes que receberam tratamento 
restaurador com amálgama e $1,9 \mu \mathrm{gHg} \cdot \mathrm{g}^{-1} \mathrm{CR}$ no grupo controle. Não foram observadas diferenças significativas na função renal das crianças que receberam tratamento restaurador utilizando o amálgama de prata ao serem comparadas ao grupo controle.

Para a Guzzi \& Minoia (2008), a dosagem do teor de mercúrio na urina não é um forte indicador biológico da exposição prolongada a vapores de mercúrio provenientes de amálgamas dentários. Entretanto, cabe ressaltar que tais estudos estão voltados para os vapores de mercúrio emitidos durante a mastigação em indivíduos que apresentavam restaurações de amálgama de prata.

Chaari et al. (2009) avaliaram os teores de mercúrio na urina de 52 CD e ASB de consultórios odontológicos da Tunúsia e de 52 médicos e enfermeiros, como um grupo controle, que trabalhavam em um hospital escola. Os resultados dos teores de $\mathrm{Hg}$ foram expressos em $\mu \mathrm{gHg} \cdot \mathrm{g}^{-1} \mathrm{CR}$ e o teste de ANOVA foi usado como forma de comparação das médias de $\mathrm{HgU}$ dos dois grupos. Os autores relataram uma diferença estatística significante entre as médias de HgU nos grupos estudados $\left(20,4 \pm 42,4 \mu \mathrm{gHg} \cdot \mathrm{g}^{-1} \mathrm{CR}\right.$ para expostos e $0,04 \pm 0,3 \mu \mathrm{gHg} \cdot \mathrm{g}^{-1} \mathrm{CR}$ para não expostos).

Neghab et al. (2010) examinaram os efeitos da exposição ocupacional a baixos níveis de mercúrio em 106 cirurgiões-dentistas e 94 médicos de clínica geral (grupo controle), de clínicas privadas e públicas na cidade de Shiraz - Irã. Os indivíduos foram convidados a preencher um questionário sobre variáveis demográficas, sintomas suspeitos de práticas de intoxicação e de trabalho. Além disso, as concentrações urinárias de mercúrio foram determinadas por AAS e corrigidas pelos valores de creatinina urinária. Os valores da média de HgU foram de $3,16 \mu \mathrm{gHg} \cdot \mathrm{g}^{-1} \mathrm{CR}$ e $2,18 \mu \mathrm{gHg} \cdot \mathrm{g}^{-1} \mathrm{CR}$ para o grupo de "expostos" e "não expostos" respectivamente.

Duncan et al. (2011) publicaram um estudo retrospectivo de 35 anos de monitoramento biológico em profissionais da equipe odontológica da Escócia. Os profissionais foram convidados a participarem da pesquisa por carta e posteriormente foram solicitadas amostras de cabelo, pelo pubiano, unhas das mãos e dos pés. Os autores notaram uma queda nas concentrações de mercúrio dosadas nestas amostras ao longo do tempo provavelmente devido à mudança na forma de preparo e manuseio do amálgama. 


\section{MATERIAIS E MÉTODOS}

A metodologia deste projeto foi elaborada atendendo aos preceitos éticos da Resolução 196/96 do Conselho Nacional de Saúde.

\subsection{Modelo de estudo}

Este estudo está inserido dentro de um projeto de caráter regional e utiliza uma abordagem integrada para investigar a exposição de profissionais de odontologia do Serviço Único de Saúde (SUS) e os fatores de risco envolvidos no processo de trabalho. Foi desenvolvido a partir de um acordo de mútua cooperação técnico-científica firmado entre a Comissão Nacional de Energia Nuclear (CNEN) e a Fundação de Medicina Tropical do Tocantins (FMT), processo $n^{\circ}$ 01342001545/2006-29, tendo ainda uma bolsa de estudo financiada pelo Programa de Apoio a Pós-Graduação (PAPG) da Secretaria de Ciência e Tecnologia do Estado do Tocantins (diário Oficial $n^{\circ} 2.711$ de 13 de agosto de 2008) e atualmente contemplado com financiamento do edital Programa Pesquisa para o SUS: gestão compartilhada em saúde - PPSUS SECT nº 02/2009, com parceria entre o CNPq e a Secretaria de Ciência e Tecnologia do Estado do Tocantins (SECT).

\subsection{Local de estudo}

Situado no centro-norte do país, o Tocantins é o mais novo entre os estados brasileiros; dotado de localização geográfica privilegiada e de oferta abundante de recursos naturais (Gaspar, 2002).

Tocantins, na língua tupi, significa bico de tucano, referência à confluência dos rios Araguaia e Tocantins, o que resulta no formato curvo desse encontro geográfico, lembrando o bico da ave. Dois dos maiores mananciais brasileiros marcam a paisagem local: os rios Tocantins e Araguaia fazem dessa região uma espécie de "mesopotâmia" moderna, cuja prosperidade advém do agronegócio (Tocantins, 2006a).

O município de Araguaína, local de estudo do presente projeto, de acordo com dados do IBGE (2010), possui 149.913 habitantes. Representa $10,91 \%$ da população do estado e está localizado na região norte do Estado do 
Tocantins (IBGE, 2010). É considerado um importante pólo-econômico de negócios e referência em saúde, para o estado do Tocantins, Pará e Maranhão (Lopes, 2008).

A macrorregião de Araguaína possui uma população estimada em 2.000 .000 (dois milhões) de habitantes e está diretamente associada à construção da rodovia Belém-Brasília, à agroindústria, à educação superior e à qualidade em saúde (Lopes, 2008; IBGE, 2010).

\subsection{Seleção de voluntários}

A presente pesquisa foi executada em duas fases. Na primeira fase, foram entrevistados profissionais do município de Araguaína - TO - tendo o entrevistador se deslocado até todas as Unidades Básicas de Saúde (UBS) do Município para convidar os voluntários que trabalhavam como cirurgiões-dentistas nas equipes do "Estratégia Saúde da Família" $(n=35)$ e auxiliares de saúde bucal $(n=51)$, no período de novembro de 2008 a abril de 2009. Aceitaram participar da pesquisa $8 \mathrm{CD}$ e $44 \mathrm{ASB}$.

No intuito de ampliar a amostra, o projeto foi estendido em uma segunda fase, no qual foram convidados os alunos do Curso de Auxiliar de Saúde Bucal da Escola Técnica de Saúde Dr. Gismar Gomes em Araguaína $(n=80)$ durante o período de novembro de 2008 a maio de 2009. Esses alunos apresentam duas características distintas: ou trabalhavam em consultórios odontológicos em outros municípios do estado do Tocantins ou que nunca trabalharam nesta atividade, sendo fator preponderante para a criação do grupo "não expostos", outrora denominado grupo controle.

Os dois projetos dessa pesquisa foram aprovados pelo Comitê de Ética para Pesquisas em Seres Humanos (CEP) da Fundação de Medicina Tropical do Tocantins. Tanto a Secretaria Municipal de Saúde de Araguaína quanto a Presidência da Escola Técnica Dr. Gismar Gomes permitiram a realização da primeira e da segunda etapas da pesquisa, respectivamente, conforme assinatura das folhas de rosto dos projetos submetidos ao CEP (APÊNDICE A).

O questionário utilizado foi avaliado por um psicólogo, de modo a não se apresentar tendencioso; além disso, foi testado previamente em estudo piloto, revisado e retestado antes de ser aplicado à população estudada. 


\subsection{Aplicação do questionário}

Após esclarecimento detalhado sobre o projeto e assinatura do voluntário no termo de consentimento livre e esclarecido (ANEXO A e B), foi distribuído um formulário contendo questões sobre variáveis, como idade, sexo, peso, hábitos alimentares para o grupo "não expostos" ao mercúrio odontológico e para o grupo de "expostos" perguntas adicionais sobre rotinas de biossegurança realizadas no consultório odontológico, no qual o sujeito da pesquisa trabalhava (ANEXO C e D).

Concomitante ao processo de aplicação dos questionários, foram coletadas amostras de urina de adultos, com idades entre 18 e 64 anos, sendo considerado "exposto" o indivíduo com tempo de trabalho em consultório odontológico superior a 12 meses, de acordo com a NR 7 (Brasil, 1994).

\subsection{Seleção do indicador biológico de exposição: urina}

A urina é considerada o melhor indicador biológico de exposição (IBE) ou biomarcador da carga corporal de mercúrio para exposição em longo prazo ao mercúrio elementar e inorgânico (Naleway et al., 1985; Mason et al., 2001; Karahalil et al., 2005; Guilhen et al., 2010). A determinação de mercúrio em urina é confiável e simples, permitindo identificar rapidamente os indivíduos com níveis de mercúrio elevados (Naleway et al., 1985; Karahalil et al., 2005).

Yoshida (1985) ressalta que a urina é o IBE mais adequado para mercúrio inorgânico, uma vez que o mercúrio orgânico representa apenas uma pequena fração do mercúrio urinário. Os níveis urinários de mercúrio inorgânico apresentam uma melhor relação com a exposição se comparados com os níveis sanguíneos de mercúrio inorgânico após a exposição ocupacional a baixos níveis de vapor de mercúrio elementar e a longo prazo (Yoshida, 1985; Mason et al., 2001).

O sangue é adequado para mensurar casos de exposição a altas doses de $\mathrm{Hg}$ em um curto período de tempo, mas não é um indicador muito confiável da carga corporal total em exposições de longo prazo (Naleway et al., 1985; Mason et al., 2001; Guilhen, 2009).

O tempo de meia vida do mercúrio no sangue e na urina é de 3 dias e 40-90 dias respectivamente; já os níveis sanguíneos do metal são mais 
acentuados durante e logo após exposições de curto prazo, sendo necessária coleta imediatamente após as mesmas (Mason et al, 2001).

Em relação ao cabelo, as formas inorgânicas de mercúrio não são excretadas em quantidades significativas no mesmo, fazendo deste um indicador inadequado de exposição a este material.

O presente projeto adotou como referência para monitorar o mercúrio inorgânico a Norma Reguladora NR 7, que utiliza como indicador biológico a análise de mercúrio presente nas amostras coletadas da primeira urina da manhã; como método analítico a espectrofotometria de absorção atômica (AAS); como Valor de Referência da Normalidade - VR (valor possível de ser encontrado em populações não expostas ocupacionalmente) concentração de até $5 \mu \mathrm{gHg} \cdot \mathrm{g}^{-1} \mathrm{de}$ creatinina (CR) e como Índice Biológico Máximo Permitido - IBMP (valor máximo do indicador biológico para o qual se supõe que a maioria das pessoas ocupacionalmente expostas não corre risco de dano à saúde) concentração de até $35 \mu \mathrm{gHg} . \mathrm{g}^{-1} \mathrm{CR}$ na urina $(\mathrm{HgU})$. Dosagem acima deste valor significa exposição excessiva ao mercúrio (Brasil, 1994).

\subsection{Procedimento de coleta e determinação de mercúrio na urina}

Em relação às coletas de amostras de urina com a finalidade de dosagem de creatinina e de metais, Mason et al. (2001) relatam ser necessário realizá-las em horário fixo a fim de minimizar as variações nos valores de mercúrio encontrados, pois há uma variação diurna na excreção do mesmo. Por este motivo, optou-se nesta pesquisa por coletar dos participantes expostos e não expostos ao $\mathrm{Hg}$ a primeira urina da manhã para ser analisada.

Frascos coletores estéreis com capacidade de $80 \mathrm{~mL}$ (frasco de polipropileno de boca larga e tampa de rosca) foram distribuídos aos participantes da pesquisa nas UBS e na Escola Técnica de Saúde de Araguaína. Os voluntários foram orientados a coletarem a primeira urina da manhã do dia seguinte à entrega dos frascos, seguindo a metodologia descrita por TrzcinkaOchocka et al. (2007). Os frascos foram numerados de acordo com o cadastro dos participantes da pesquisa efetuado no dia da distribuição e preenchimento do questionário.

No dia seguinte da distribuição dos frascos, as amostras foram recolhidas pela manhã, no horário de abertura dos consultórios odontológicos e 
do início das aulas (aproximadamente às $7 \mathrm{~h}$ ) e armazenadas em geladeira a $4{ }^{\circ} \mathrm{C}$ até seu processamento no Laboratório de Bacteriologia da Fundação de Medicina Tropical do Tocantins.

As amostras de urina coletadas foram inicialmente preparadas para a liofilização e análise de creatinina urinária no Laboratório de Microbiologia da Fundação de Medicina Tropical do Tocantins. Em câmara de fluxo laminar, as amostras foram homogeneizadas e alíquotas de $10 \mathrm{~mL}$ de cada amostra foram transferidas para frascos estéreis cônicos tipo Falcon (Sarstedt ${ }^{\circledR}$ ), próprios para determinação de mercúrio. Os ensaios foram realizados em triplicata, segundo o protocolo de procedimentos operacionais do Laboratório de Análises Químicas e Ambientais do Centro de Química e Meio Ambiente do IPEN (Guilhen 2009; Guilhen et al., 2010).

As alíquotas em triplicata utilizadas para determinação do mercúrio inorgânico foram congeladas em freezer $-20{ }^{\circ} \mathrm{C}$, para posteriormente serem submetidas à liofilização; as demais foram submetidas à análise de creatinina urinária em laboratório com ensaio certificado do Hospital e Maternidade Dom Orione (HMDO) de Araguaína.

\subsection{Liofilização das amostras de urina}

A liofilização é um processo de desidratação a frio bastante empregado para preservar substâncias perecíveis como determinados produtos farmacêuticos, materiais biológicos e alguns alimentos. Durante o processo, a água é retirada por sublimação, sem que a mesma passe pelo estado líquido (Patel \& Pikal, 2011).

A amostra congelada tem sua temperatura gradativamente aumentada sob vácuo permitindo com que a água congelada passe diretamente da fase sólida à fase gasosa, sem causar alteração em sua composição. Ao final do processo obtém-se uma amostra em pó que, após o frasco ser selado devidamente, apresenta quantidades mínimas de água reduzindo as chances de degradação da mesma por microrganismos e enzimas presentes, podendo ser armazenada a temperatura ambiente por vários anos e favorecendo seu transporte para locais distantes do local de coleta (Ayala, et al, 2010; Patel \& Pikal, 2011). 
Neste experimento, as amostras antes de serem distribuídas nos tubos para liofilização foram homogeneizadas para garantir uma padronização, uma vez que a urina pode sedimentar em poucas horas.

Após congelamento das amostras, os tubos foram abertos e colocados sem tampa em um béquer no interior da estante porta-bandeja do liofilizador, localizada sobre o condensador do aparelho Terroni ${ }^{\circledR}$ LS 3000 (Terroni ${ }^{\circledR}$ Equipamentos Científicos), equipado com bomba a vácuo de 6 CFM (FIG.1).

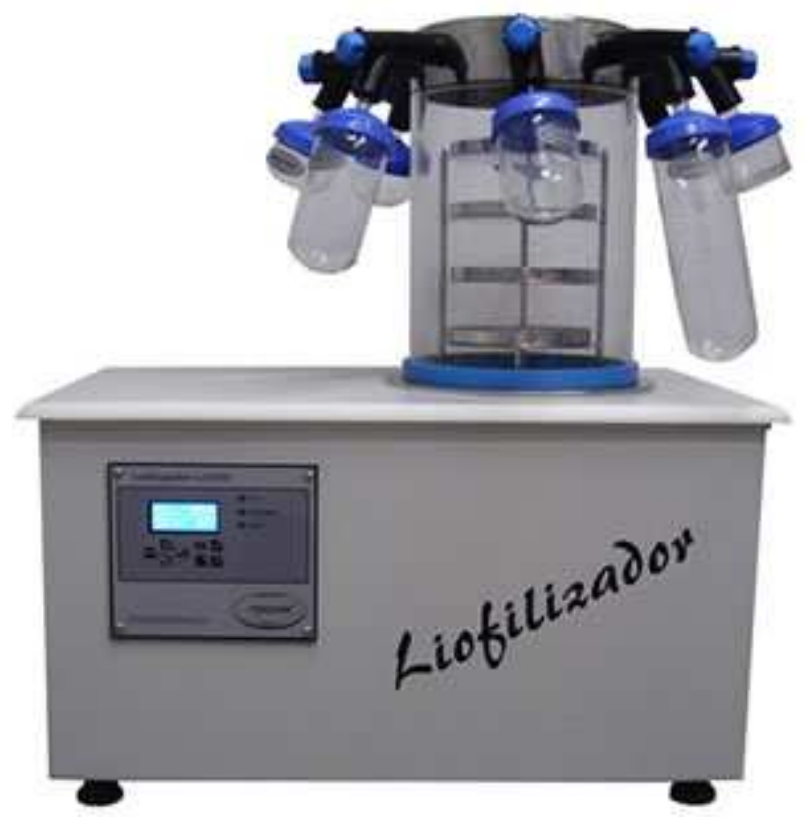

FIGURA 1 - Representação fotográfica do Liofilizador Terroni ${ }^{\circledR}$ LS 3000.

Para processar um volume de $10 \mathrm{~mL}$ de amostra de urina, foi necessária uma permanência no aparelho por $48 \mathrm{~h}$, à temperatura de $-47^{\circ} \mathrm{C}$ e despressurização lenta para não haver perda de amostra. Esse tempo foi mensurado e otimizado a partir de um experimento piloto no qual as amostras de urina foram liofilizadas durante diferentes intervalos de tempo: 24 h, 36 h e 48 h ininterruptamente; após a realização do experimento piloto, observou-se o melhor grau de liofilização, obtido com 48 h, tornando-se esta a permanência padrão.

O liofilizador utilizado tem capacidade de acomodar 12 tubos a cada ciclo de 48 h; decorrido este tempo, a amostra líquida fica em estado sólido - em pó (FIG.2). 


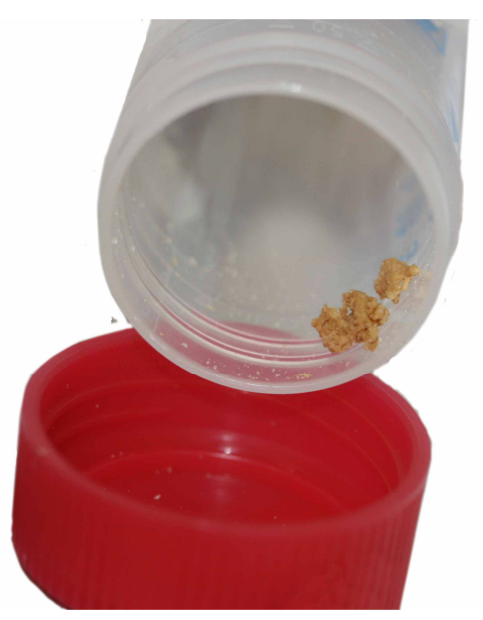

(A)
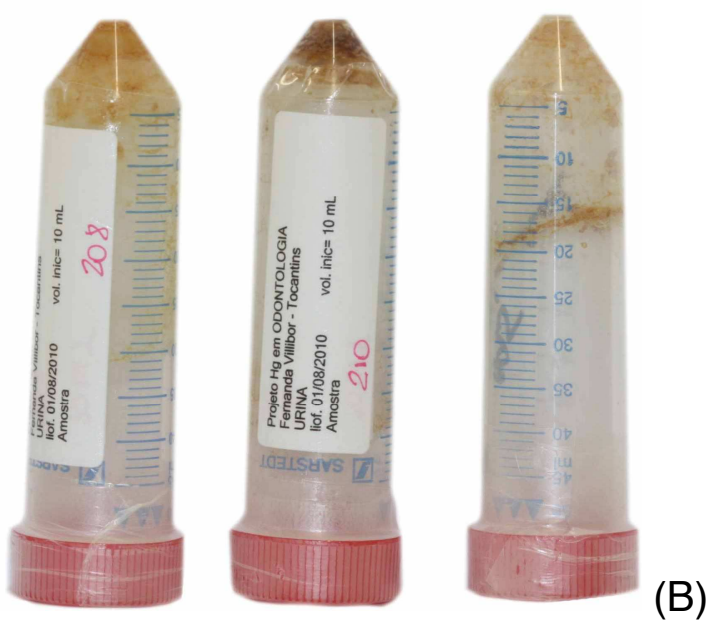

FIGURA 2 - (A) Representação fotográfica da urina liofilizada; (B) representação fotográfica dos tubos Sarstedt ${ }^{\circledR}$ vedados.

Após abertura do liofilizador, os tubos com as amostras de urina em pó foram vedados, lacrados com parafilm ${ }^{\circledR}$ e enviados ao Laboratório de Análises Químicas e Ambientais do Centro de Química e Meio Ambiente do IPEN/CNEN para serem analisados por Espectrometria de Absorção Atômica com Geração de Vapor Frio (CV-AAS); a concentração de mercúrio total foi determinada de acordo com metodologia desenvolvida e validada por Guilhen et al. (2010).

\subsection{Determinação do valor da creatinina urinária}

A determinação da concentração de creatinina foi realizada utilizandose a técnica de espectrometria de absorção molecular, em equipamento automatizado Labmax Plenno (Labtest ${ }^{\circledR}$ ) e Kit de Creatinina K (Labtest ${ }^{\circledR}$ ). Os ensaios foram realizados nos laboratórios de análises clínicas do HMDO de Araguaína, local que apresenta controle de qualidade interno e externo. Para efeito comparativo, o ensaio foi desenvolvido e implementado no laboratório da Fundação de Medicina Tropical do Tocantins (FIG.3). 


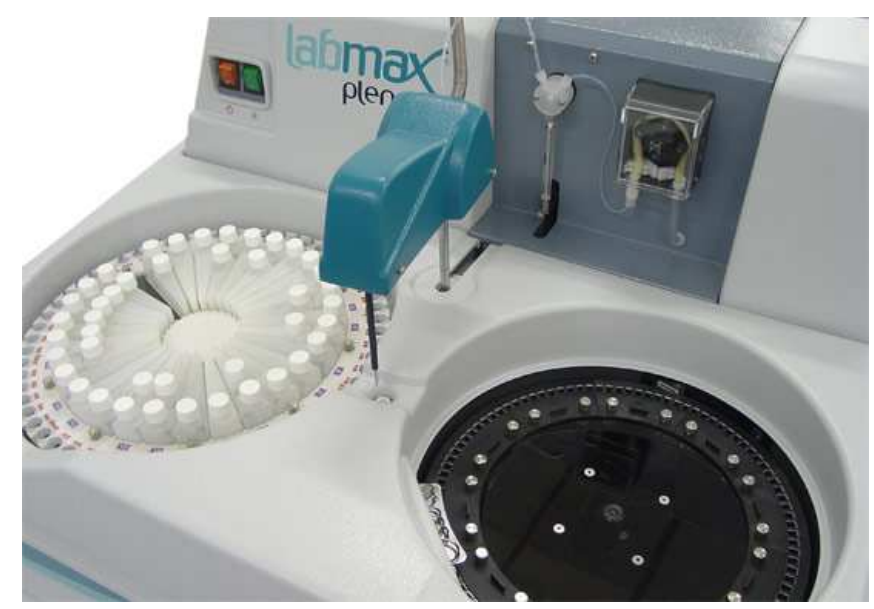

FIGURA 3 - Representação fotográfica do espectrômetro de absorção molecular - Equipamento Labmax Plenno ${ }^{\circledR}$.

O procedimento de medição foi calibrado com o padrão SRM 914 do NIST o que torna os resultados rastreáveis, atendendo às especificações do National Kidney Disease Education Program para a padronização da creatinina.

\subsection{Método analítico de determinação de mercúrio inorgânico}

Para a determinação do mercúrio inorgânico nas amostras de urina, foi utilizada a técnica da Espectrometria de Absorção Atômica com Geração de Vapor Frio (CV-AAS) proposta por Lopez-Colon \& Lozano (2006) e validada por Guilhen et al. (2010) por meio da avaliação dos seguintes parâmetros: limite de detecção e limite de quantificação, seletividade, linearidade, exatidão e precisão.

Nesse projeto, cada amostra de urina foi analisada em triplicata e em cada triplicata foram realizadas três determinações independentes. Além disso, a exatidão e a precisão foram determinadas utilizando materiais de referência certificados: Standard Reference Material R 1641d - Mercury in water (acidificado com $2 \%$ em ácido nítrico), fração em massa $\left(1,59 \mathrm{mg} \cdot \mathrm{Kg}^{-1} \pm 0,018 \mathrm{mg} \cdot \mathrm{Kg}^{-1}\right)$; Standard Reference Material R 2670 - Toxic Elements in Urine (Freeze - Dried), concentração de $\left(0,0663 \mu \mathrm{gHg} . \mathrm{L}^{-1} \pm 0,0058\right)$.

Os limites de detecção (LD) e de quantificação (LQ) estabelecidos para a determinação de mercúrio em matriz de urina desmineralizada utilizando a técnica de espectrometria CV-AAS foram de $0,07 \mu \mathrm{gHg} \cdot \mathrm{L}^{-1}$ (LD) e $0,3 \mu \mathrm{gHg} \cdot \mathrm{L}^{-1}$ (LQ), respectivamente (Guilhen et al., 2010). 
$\mathrm{Na}$ TAB.2, é apresentada uma relação dos métodos analíticos mais frequentemente utilizados para a quantificação de mercúrio e seus respectivos limites de detecção.

TABELA 2 - Métodos analíticos frequentemente utilizados para a quantificação de mercúrio e seus limites de detecção.

\begin{tabular}{|c|c|c|}
\hline \multicolumn{2}{|l|}{ Método } & $\begin{array}{l}\text { Limite de detecção } \\
\text { relatado }\end{array}$ \\
\hline \multicolumn{2}{|l|}{ Método colorimétrico } & $0,01-0,1 \mu \mathrm{g} \cdot \mathrm{g}^{-1}$ \\
\hline \multicolumn{2}{|c|}{ Espectrometria de Absorção Atômica - Forno de grafita (GF AAS) } & $1 \mathrm{ng} \cdot \mathrm{g}^{-1}$ \\
\hline \multicolumn{2}{|c|}{ - Vapor frio (CVAAS) } & $0,01-1 \mathrm{ng} \cdot \mathrm{g}^{-1}$ \\
\hline \multicolumn{2}{|c|}{ Espectrometria de Fluorescência Atômica - Vapor frio (CVAFS) } & $0,001-0,01 \mathrm{ng} \cdot \mathrm{g}^{-1}$ \\
\hline \multicolumn{2}{|c|}{ Análise por Ativação com Nêutrons - Instrumental (INAA) } & $1-10 \mathrm{ng} \cdot \mathrm{g}^{-1}$ \\
\hline \multicolumn{2}{|c|}{ - Radioquímica (RNAA) } & $0,01-1 \mathrm{ng} \cdot \mathrm{g}^{-1}$ \\
\hline \multicolumn{2}{|c|}{ Cromatografia Gasosa - Detector de Captura Eletrônica } & $0,01-0,05 \mathrm{ng} \cdot \mathrm{g}^{-1}$ \\
\hline \multicolumn{2}{|c|}{ - Detector de Emissão Atômica } & $\sim 0,05 \mathrm{ng} \cdot \mathrm{g}^{-1}$ \\
\hline \multicolumn{2}{|c|}{ - Espectrometria de Massas } & $0,1 \mathrm{ng} \cdot \mathrm{g}^{-1}$ \\
\hline \multicolumn{2}{|c|}{ - CVAAS / CVAFS } & $0,01-0,05 \mathrm{ng} \cdot \mathrm{g}^{-1}$ \\
\hline \multicolumn{2}{|c|}{ Cromatografia Líquida de Alta Eficiência - Detector de Ultra-violeta } & $1 \mathrm{ng} \cdot \mathrm{mL}^{-1}$ \\
\hline \multicolumn{2}{|c|}{ - CVAAS } & $0,5 \mathrm{ng} \cdot \mathrm{mL}^{-1}$ \\
\hline \multicolumn{2}{|r|}{ - CVAFS } & $0,08 \mathrm{ng} \cdot \mathrm{mL}^{-1}$ \\
\hline \multirow{3}{*}{ Plasma Acoplado Indutivamente } & - Eletroquímico & $0,1-1 \mathrm{ng} \cdot \mathrm{mL}^{-1}$ \\
\hline & - Espectrometria de Massas (ICP MS) & $0,01 \mathrm{ng} \cdot \mathrm{mL}^{-1}$ \\
\hline & - Espectrometria de Emissão Atômica (ICP OES) & $2 \mathrm{ng} \cdot \mathrm{mL}^{-1}$ \\
\hline \multicolumn{2}{|l|}{ Espectometria Foto-Acústica } & $0,05 \mathrm{ng}$ \\
\hline \multicolumn{2}{|l|}{ Fluorescência de Raios- $X$} & $5 \mathrm{ng} \cdot \mathrm{g}^{-1}-1 \mu \mathrm{g} \cdot \mathrm{g}^{-1}$ \\
\hline \multicolumn{2}{|l|}{ Métodos Eletroquímicos } & $0,1-1 \mu \mathrm{g} \cdot \mathrm{g}^{-1}$ \\
\hline \multicolumn{2}{|l|}{ Analisador de Filme de Ouro } & $0,05 \mu \mathrm{g} \cdot \mathrm{g}^{-1}$ \\
\hline
\end{tabular}

Fonte - Adaptado de Micaroni et al. (2000).

A exatidão de um método é definida como sendo a concordância entre o resultado de um ensaio e o valor de referência aceito como convencionalmente verdadeiro. A precisão é definida como grau de concordância entre resultados de medições independentes (em torno de um valor central) efetuadas várias vezes em uma amostra homogênea sob condições experimentais pré-estabelecidas. Os procedimentos geralmente utilizados para avaliar a exatidão são feitos pela análise de materiais de referência com valores certificados (Sandborgh-Englund et al., 1998; Guilhen et al., 2010). No APÊNDICE B são apresentadas as cópias dos certificados dos materiais de referência utilizados nesta pesquisa.

A metodologia aplicada neste trabalho validada por Guilhen et al. (2010) pode ser considerada exata (com recuperação de mercúrio na faixa de 96,3-99,6\%) e precisa (com desvio padrão relativo de no máximo de 6\%). 
O mercúrio é talvez o mais tradicional dos elementos determinados pelo sistema de geração de hidretos gasosos/vapor frio. Tal sistema utiliza um agente redutor, geralmente $\mathrm{NaBH}_{4}$, que pode ser substituído por $\mathrm{SnCl}_{2}$ com resultados semelhantes.

O tratamento da amostra se inicia com sua digestão ácida com ácido nítrico $\left(\mathrm{HNO}_{3}\right)$ e ácido sulfúrico $\left(\mathrm{H}_{2} \mathrm{SO}_{4}\right)$ 1:1 e aquecimento das amostras de urina em estufa à $60^{\circ} \mathrm{C}$ durante uma noite (overnight). Ap ós mineralização, a amostra é avolumada; segue-se então com a oxidação do $\mathrm{Hg}^{0}$ a $\mathrm{Hg}^{+2}$ com a adição de solução de permanganato de potássio em excesso para garantir que todos os íons de mercúrio em solução estejam sob a sua forma mais oxidada $\left(\mathrm{Hg}^{+2}\right)$ para subsequente redução a mercúrio elementar $\left(\mathrm{Hg}^{0}\right)$ com o borohidreto de sódio $\left(\mathrm{NaBH}_{4}\right)$ ou cloreto estanhoso $\left(\mathrm{SnCl}_{2}\right)$ no compartimento de reação.

A geração de vapor frio de mercúrio é realizada a partir da reação de mercúrio $\left(\mathrm{Hg}^{+2}\right)$, em meio ácido, com o hidrogênio nascente gerado da decomposição do borohidreto de sódio.

A redução com o borohidreto de sódio impede a distinção das formas de mercúrio presentes na amostra pois reduz todo o mercúrio presente na amostra (sob a forma de $\mathrm{Hg}^{+2}$ ) a mercúrio elementar $\left(\mathrm{Hg}^{0}\right)$ e, assim, permite dosar apenas o mercúrio total (Guilhen, 2009).

O gás de arraste (argônio, Ar) transporta o mercúrio elementar $\left(\mathrm{Hg}^{\circ}\right)$. para a célula de reação (absorção), posicionada no caminho óptico do espectrômetro de absorção atômica. O mercúrio na forma metálica absorve radiação de comprimento de onda de 253,7 nm emitida por uma lâmpada EDL de mercúrio. A intensidade da luz transmitida através da célula é detectada por um fototubo sensor de raios ultravioleta, dosando a quantidade de mercúrio da amostra (Guilhen, 2009). Com esse procedimento, é possível determinar mercúrio na ordem de centenas de ng. $\mathrm{L}^{-1}$.

O procedimento exige uma preparação química prévia das amostras que consome praticamente o mesmo tempo. Desta forma, consegue-se analisar cerca de 40-50 amostras. dia ${ }^{-1}$.

$\mathrm{Na}$ determinação das concentrações de mercúrio em soluções utilizando o método de espectrometria de absorção atômica com atomização por geração de vapor frio, foi obtido um limite de detecção de $0,07 \mu \mathrm{g} \cdot \mathrm{L}^{-1}$ de urina (Guilhen, 2009; Guilhen et al., 2010). 
$\mathrm{Na}$ sequência, estão descritos os procedimentos operacionais do método utilizado:

- Pipetar $10 \mathrm{~mL}$ da amostra previamente mineralizada, adicionar $20 \mu \mathrm{L}$ de solução de permanganato de potássio, para oxidar $0 \mathrm{Hg}^{0} \rightarrow \mathrm{Hg}^{2+}$ presente;

- adicionar $1 \mathrm{~mL}$ de uma solução de $\mathrm{H}_{2} \mathrm{SO}_{4}: \mathrm{HNO}_{3}$ 1:1, avolumando a $25 \mathrm{~mL}$;

- determinar a quantidade de mercúrio total por AAS com atomização por geração de vapor frio.

Na FIG.4 é apresentada a representação fotográfica do equipamento utilizado - Espectrofotômetro de Absorção Atômica e acessórios (PerkinElmer Co., USA), instalados no Centro de Química e Meio Ambiente do IPEN.
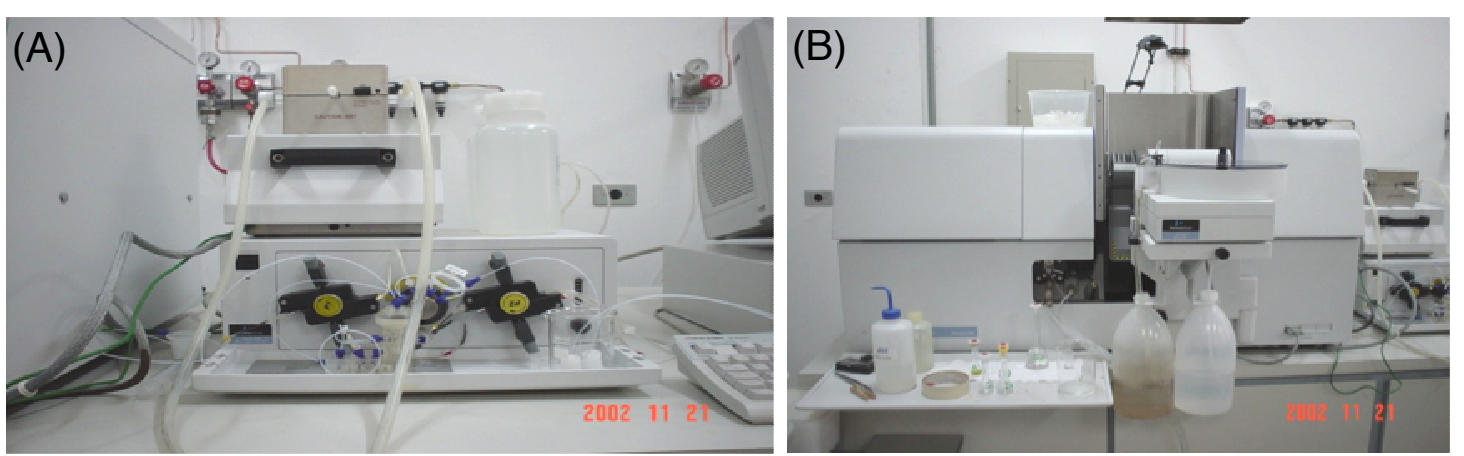

Fonte - Laboratório de Análise Química e Ambiental do CQMA/IPEN

FIGURA 4 - Representação fotográfica: (A) acessório utilizado para a determinação de antimônio e arsênio por geração de hidretos voláteis e de mercúrio por vapor frio; (B) Espectrofotômetro de Absorção Atômica com acessório Forno de Grafita e amostrador automático (PerkinElmer Co., USA).

\subsection{Avaliação de meios de armazenagem de resíduos contendo mercúrio}

Para avaliar a eficácia de meios de armazenagem dos resíduos de amálgama dentro do consultório até que os mesmos tenham o destino correto para descarte, optou-se por realizar um Spot-test para verificação da emissão de vapor de mercúrio proveniente do amálgama de prata armazenado em diferentes soluções. Seguiu-se a metodologia descrita por Saquy (1996), Saquy et al. (1997), Fortes \& Samuel (1999) e Costa et al. (2008) que utilizam um método químico qualitativo por meio da observação da reação química entre cloreto de paládio (1\%) e mercúrio metálico liberado do amálgama de prata. 
Papeis de filtro qualitativo, no formato de fitas redondas com raio de 10 $\mathrm{mm}$, foram embebidos em cloreto de paládio a $1 \%$; essas fitas foram colocadas em dessecador e testadas para verificar a validade do método por meio da exposição à solução de mercúrio verificando mudança de cor (FIG.5).

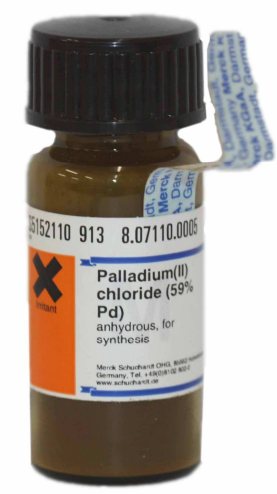

(A)

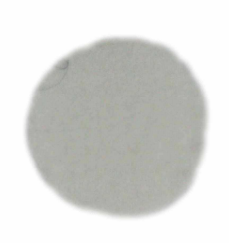

(B)

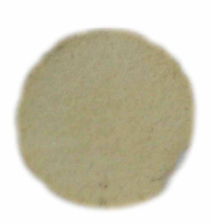

(C)

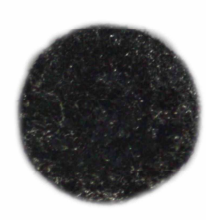

(D)

FIGURA 5 - Representação fotográfica do: (A) Cloreto de paládio; (B) papel de filtro antes do contato com o cloreto de paládio; (C) papel de filtro embebido com cloreto de paládio a $1 \%$ (spot-test do branco); (D) papel de filtro após contato com vapor de mercúrio (spot-testpositivo).

\subsection{Simulação de amostras de amálgama odontológico para estudos de estocagem e liberação atmosférica de mercúrio}

Em amalgamador mecânico (Gnatus ${ }^{\circledR}$ ) foram trituradas cápsulas prédosadas de amálgama GS-80 (porção de $400 \mathrm{mg}$, marca SDI, cristalização regular, partículas esféricas, na proporção $40 \% \mathrm{Ag}, 31,3 \% \mathrm{Sn}, 28,7 \% \mathrm{Cu}$ e $49 \%$ $\mathrm{Hg}$ ) durante 18 segundos para que os ensaios seguissem sempre um procedimento padronizado. Na sequência, o amálgama foi peneirado em malha de $1 \mathrm{~mm}$; para a homogeneização do material, $1 \mathrm{~g}$ foi pesado em balança analítica e colocado em tubos de ensaio de $15 \mathrm{~mm}$ de diâmetro (FIG.6). 


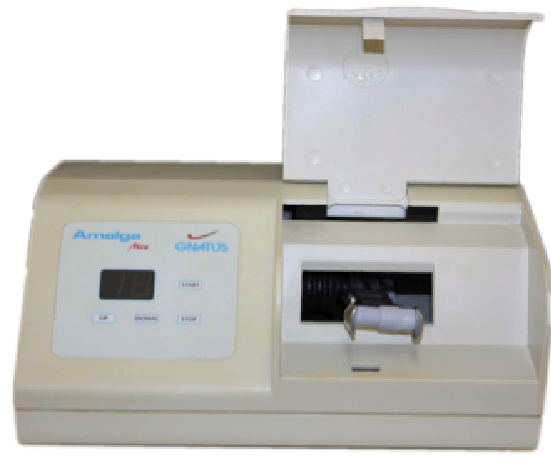

(A)

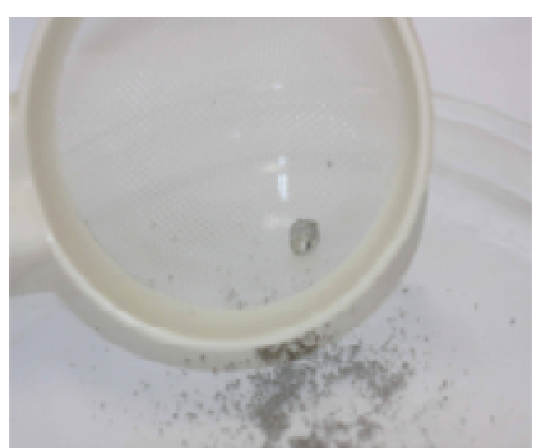

(B)

FIGURA 6 - Representação fotográfica do: (A) amalgamador Gnatus ${ }^{\circledR}$ com cápsula de amálgama acoplada; (B) amálgama sendo peneirado

Em cada tubo de ensaio contendo $1 \mathrm{~g}$ de amálgama odontológico, foram pipetados $15 \mathrm{~mL}( \pm 4 \mathrm{~cm}$ de altura) das soluções a serem testadas para impedir a passagem de vapor de mercúrio (Fig.7).

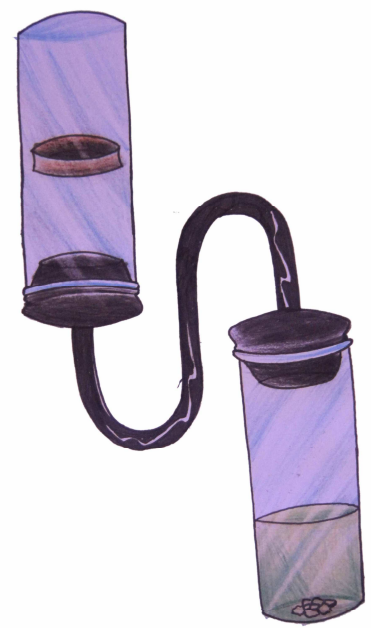

FIGURA 7 - Desenho da montagem individual dos tubos para cada solução barreira estudada.

Foi avaliado o comportamento das seguintes soluções selantes: água; óleo vegetal; solução fixadora de radiografias; vinagre comercial; álcool etílico 96\% comercial; solução comercial de limpeza contendo amoníaco; solução de bicarbonato de sódio (50\%); creme hidratante; hipoclorito de sódio comercial 2,0$2,5 \% \mathrm{p} / \mathrm{p}$; detergente líquido concentrado. 
O critério de escolha das soluções foi testar as soluções que estivessem disponíveis no consultório odontológico não sendo necessária a aquisição de reagentes diferentes dos utilizados na rotina dos consultórios ou unidades básicas de saúde; algumas soluções haviam sido testadas e os resultados estavam disponíveis na literatura publicada.

O conjunto de tubos montado (FIG.8) foi colocado em um suporte plástico e este conjunto foi isolado dentro de uma cuba de vidro, para evitar o contato e a contaminação das amostras com o meio externo. Para manter a temperatura constante, o experimento foi realizado em incubadora tipo BOD, sendo as temperaturas de estudo $4{ }^{\circ} \mathrm{C}, 30^{\circ} \mathrm{C}$ e $37^{\circ} \mathrm{C} \pm 2{ }^{\circ} \mathrm{C}$.

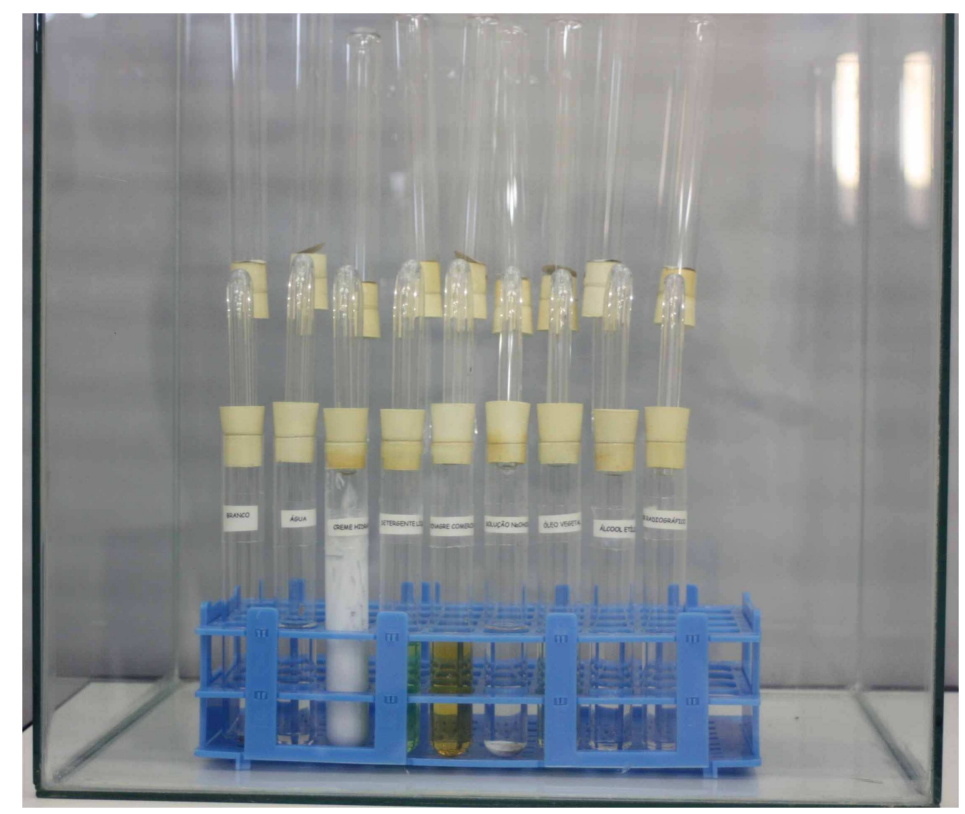

FIGURA 8 - Representação fotográfica do conjunto de tubos montado para realização do spot-test para as diferentes soluções barreiras estudadas.

Para cada substância química estudada como solução barreira, foram realizados 03 ensaios ou repetições; já a leitura para observar mudança de cor na fita de papel foi feita a cada hora durante as primeiras $12 \mathrm{~h}$. Após este período, as leituras foram realizadas em intervalos de $24 \mathrm{~h}$, durante período suficiente para avaliar a eficiência da barreira, no prazo máximo de 30 dias. 


\section{RESULTADOS E DISCUSSÃO}

Os resultados são apresentados a partir dos pré-requisitos que validam os resultados dos ensaios científicos para as duas análises empregadas neste estudo (mercúrio total e creatinina urinária-CR).

A apresentação dos resultados inicia-se com a caracterização do sistema de saúde no município de Araguaína - TO - e a descrição do número de restaurações de amálgama de prata realizada pelos profissionais que trabalhavam nos consultórios públicos do mesmo de 2003 a 2007. A partir da caracterização sócio-demográfica e dos hábitos de manuseio e descarte de resíduos contendo mercúrio e das amostras de urina de profissionais expostos ao mesmo, foi traçado o perfil do ASB que trabalha nos serviços públicos de saúde e, em seguida, são apresentados os resultados dos valores referentes ao monitoramento biológico de ASB de Araguaína e de outros municípios do Estado do Tocantins bem como os resultados referentes aos alunos da ETSUSAraguaína, TO.

Finalmente são apresentados os resultados da avaliação das soluções utilizadas para armazenar os resíduos de amálgama gerados nos consultórios odontológicos até seu descarte com a finalidade de gerar uma barreira aos vapores de mercúrio que se desprendem do amálgama odontológico.

\subsection{Caracterização do sistema odontológico do município de estudo}

O município de Araguaína - TO - é considerado um importante polo econômico de negócios e de referência em saúde para os estados do Tocantins, do Pará e do Maranhão.

Em relação ao seu sistema de saúde, o município apresenta em pleno funcionamento 06 hospitais: o Hospital Regional de Araguaína e o Hospital de Doenças Tropicais do Tocantins, mantidos pelo Estado; o Hospital e Maternidade Dom Orione que presta serviços ao SUS e à rede privada; o Hospital São Lucas, pertencente à rede privada; o Hospital Municipal de Araguaína e a Clínica de Repouso São Francisco, único hospital psiquiátrico do estado do Tocantins, além das unidades básicas de saúde (UBS) e policlínicas voltadas para serviços de Atenção Básica. 
Em relação aos serviços odontológicos, o município dispunha até o ano de 2001 de 24 consultórios odontológicos em funcionamento, sendo 20 nas Unidades Básicas de Saúde distribuídas por bairros e 04 no Centro Odontológico. Os cirurgiões-dentistas (CD) trabalhavam sob o regime de contrato de prestação de serviços para o município com carga horária semanal de 10 h. Em 2001, foram formadas as primeiras equipes do PSF e o CD foi incluído nas mesmas, ficando desta forma a carga horária de $40 \mathrm{~h}$ semanais para atendimento à população, de acordo com as diretrizes do programa (Tocantins, 2003).

Em 2004, foi criado o Centro de Especialidades Odontológicas (CEO) do Município em consonância com a nova Política Nacional de Saúde Bucal, que surgiu como uma necessidade da ampliação da atenção à saúde, preconizando diretrizes para a saúde bucal no âmbito SUS, considerando as diferenças sanitárias, epidemiológicas, culturais e regionais do Brasil. Em 2006, outras duas novas UBS com consultórios odontológicos foram inauguradas na cidade de Araguaína (Brasil, 2005; Tocantins, 2008).

Até dezembro de 2008, de acordo com dados da Secretaria Municipal de Saúde de Araguaína (SMS), foram instalados 31 consultórios odontológicos, sendo 22 consultórios nas Unidades Básicas de Saúde do Município (UBS), 08 no Centro de Especialidades Odontológicas (CEO) e 01 consultório móvel, o odontomóvel (Tocantins, 2008).

De acordo com dados recentes, o município tem instalado 25 consultórios nas UBS com 25 equipes de PSF e até o primeiro semestre de 2011 mais 09 estarão funcionando. Em relação ao número de cirurgiões-dentistas (CD), o município apresenta 78 distribuídos da seguinte forma: 25 com carga horária de $40 \mathrm{~h}$ semanais no ESF nas UBS; 22 no CEO; 23 no suporte das UBS com carga horária de 10h semanais; e 8 na gestão da Secretaria Municipal de Saúde. Os auxiliares de saúde bucal são 60, sendo que 33 estão lotados nas UBS e 27 no CEO ou no suporte da SMS (Tocantins, 2010).

Em fevereiro de 2011, foi realizado um concurso público para o cargo de cirurgião-dentista em Araguaína; até o presente momento, os profissionais estão aguardando a convocação para iniciarem as equipes de ESF com carga horária de 40 h semanais (Tocantins, 2011). 
No município de Araguaína, até a presente data, não foi instituído um programa de monitoramento biológico da exposição ao mercúrio para profissionais que manuseiam diariamente o amálgama de prata.

\subsection{Inventário sobre a produção ambulatorial de restaurações de amálgama}

O amálgama odontológico, uma liga composta de mercúrio e outros metais como a prata, tem sido amplamente usado como material restaurador de dentes posteriores há mais de dois séculos e pelo mesmo tempo tem sido foco de controvérsias (Bates, 2006).

Mesmo com o advento dos materiais ionoméricos e das resinas compostas, que foram desenvolvidos na tentativa de se extinguir o amálgama e obter resultado estético, este permanece sendo utilizado nos serviços de saúde em pelo menos $70 \%$ das restaurações em dentes posteriores (Dalla Costa, 2008; Costa et al., 2008).

O uso do amálgama nos municípios até 2007 pode ser monitorado por meio de acesso ao banco de dados do SUS, o DATASUS. A partir de 2008, a inserção de dados em relação aos procedimentos odontológicos realizado pelos municípios no DATASUS foi modificada. Desta forma, inviabilizou-se estimar a quantidade de restaurações realizadas exclusivamente com amálgama de prata ou outros materiais restauradores, resumindo os procedimentos realizados em procedimentos individuais ou coletivos; dentro dos individuais, apenas restauração em dentes posteriores ou anteriores.

No cenário da odontologia pública brasileira, seu uso pode ser percebido pelo número de restaurações realizadas nos registros de dados que compõem o DATASUS. Em relação à Araguaína, município localizado no norte do Tocantins e vencedor do primeiro Prêmio Brasil Sorridente em 2005, foram realizadas, somente em 2007, 11.916 restaurações utilizando o amálgama de prata (Tocantins, 2007).

Tendo em vista esta mudança na informação prestada do município ao DATASUS, foi possível estimar neste trabalho o número de restaurações de amálgama realizado por classes de acordo com a preconização de Black em 1908, utilizada na dentística atual (Baratieri et al., 2001).

Em relação ao número de restaurações de amálgama de prata tipo Classe I e Classe II de Black executadas por cirugiões-dentistas no município de 
Araguaína, TO, de janeiro de 2003 a dezembro de 2007, foi observada uma redução no número de procedimentos neste período conforme dados do sistema DATASUS (FIG.9). Isto provavelmente se deve à substituição gradativa do uso do amálgama por resina composta, um material restaurador com propriedades estéticas.

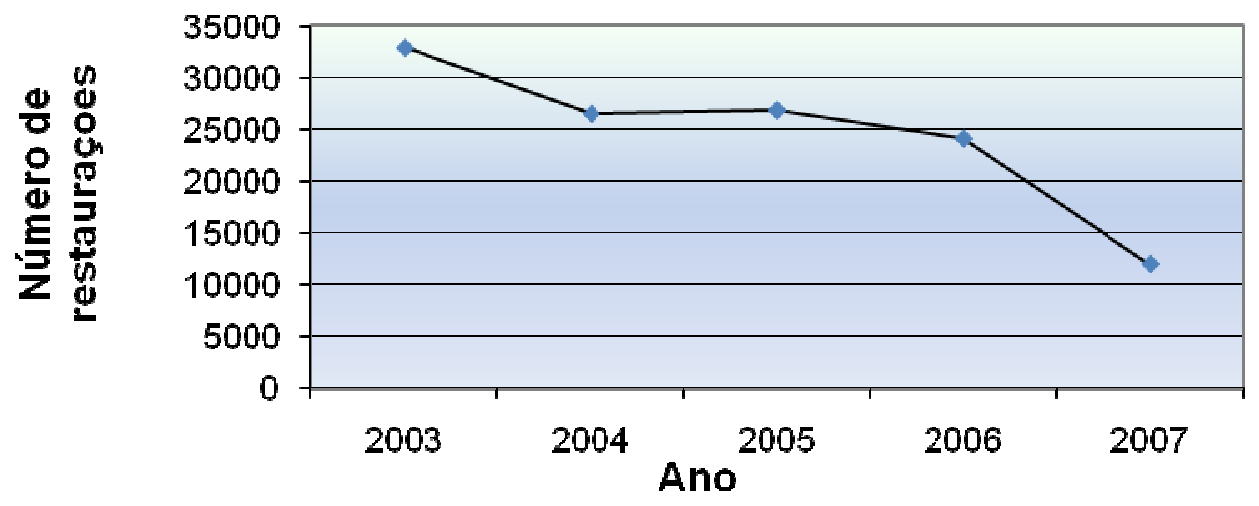

Fonte - DATASUS (2007).

FIGURA 9 - Representação gráfica do número de restaurações de amálgama de prata realizadas no município de Araguaína - TO - durante o período de janeiro de 2003 a dezembro de 2007.

Na TAB.3 são apresentadas informações referentes aos dados da produção ambulatorial de restaurações em amálgama, segundo o cadastro do sistema DATASUS, município de Araguaína, TO. Os dados foram levantados de acordo com a cópia da produção de procedimentos, arquivada na Secretaria Municipal de Saúde, durante o período de janeiro de 2003 a dezembro de 2007.

Analisando-se os dados (TAB.3) quanto ao número de restaurações de amálgama classe I e II, pode-se observar que existe uma diferença entre os dados informados ao DATASUS e os dados no relatório de procedimentos anuais, arquivado na Secretaria Municipal de Saúde. Apesar desta diferença, os dados mostram uma acentuada diminuição de 63\%, entre 2003 e 2007 em relação ao uso de amálgama de prata nos procedimentos que utilizam o amálgama de prata como material restaurador. 
TABELA 3 - Produção ambulatorial de restaurações em amálgama segundo o sistema DATASUS e segundo a cópia dos procedimentos arquivada na Secretaria Municipal de Saúde Araguaína - TO.

\begin{tabular}{l|ccc}
\hline \multirow{2}{*}{ Ano } & \multicolumn{3}{|c}{ Quantidade de restaurações em amálgama (número) } \\
\cline { 2 - 4 } & Dados DATASUS & Dados SEMUS & Média \pm DP \\
\hline 2003 & 31.406 & 32.889 & $32.148 \pm 1.048$ \\
2004 & 23.975 & 26.500 & $25.238 \pm 1.785$ \\
2005 & 26.849 & 26.849 & $26.849 \pm 0$ \\
2006 & 26.815 & 24.098 & $25.457 \pm 1921$ \\
2007 & 11.916 & 11.916 & $11.916 \pm 0$ \\
\hline
\end{tabular}

Fonte - DATASUS (2007); Tocantins (2003); Tocantins (2004); Tocantins (2005); Tocantins (2006); Tocantins (2007).

O amálgama odontológico continua sendo utilizado nos serviços odontológicos públicos por ser de baixo custo e ter sua eficácia comprovada como material restaurador (Chaari et al., 2009).

\subsection{Caracterização do perfil da população estudada}

Os dados obtidos foram convertidos em um banco de dados, o qual foi processado e analisado estatisticamente pelos softwares, Epi info ${ }^{\circledR}$ e Statistica ${ }^{\circledR}$.

A maior parte dos dentistas de Araguaína convidados não respondeu ao questionário e, dos que responderam, apenas uma parcela pequena aceitou fornecer amostras de urina para a pesquisa.

De acordo com Dalla Costa (2008), tal comportamento pode ser atribuído a não confiança sobre o destino das informações prestadas, mesmo após explicação do pesquisador. Aliado a este fator, atribui-se o receio dos sujeitos da pesquisa em relação à participação nela, pois buscou-se avaliar o cumprimento da rotina de biossegurança em consultórios públicos, uma vez que havia perguntas sobre o uso de EPI e destino de resíduos contendo metais tóxicos, como o amálgama de prata.

Como a maioria dos profissionais dentistas que trabalha na prefeitura é contratado temporariamente, existe grande rotatividade de profissionais todos os anos, dificultando a obtenção sistemática de amostras de urina dos mesmos. Considerando que a presente pesquisa obedeceu aos requisitos éticos da resolução CNS 196/96, compuseram esta amostra somente os sujeitos da pesquisa que aceitaram participar da mesma através da assinatura do TCLE. 
As características descritivas dos participantes da pesquisa compõem a TAB.4. Com o intuito de preservar o anonimato dos locais de coleta das amostras, não são apresentados os nomes das Unidades Básicas de Saúde e os números distribuídos para os participantes durante as coletas não correspondem aos que constam nas tabelas apresentadas no trabalho.

TABELA 4 - Características sócio-demográficas dos participantes da pesquisa.

\begin{tabular}{lccc}
\hline & Variável & $\mathbf{n}^{\circ}$ Participantes $(\mathbf{n})$ & Representatividade (\%) \\
\hline Sexo & Masculino & 13 & 9,70 \\
& Feminino & 121 & 90,30 \\
Município de residência & & \\
& Araguaína & 91 & 67,91 \\
& Outros & 43 & 32,09 \\
& & 134 & 100 \\
\hline
\end{tabular}

Em relação à variável sexo, 9,7\% (13) dos indivíduos participantes da pesquisa eram do sexo masculino e $90,3 \%$ (121) do sexo feminino. A profissão de ASB é culturalmente voltada para mulheres, uma vez que a ASB além de auxiliar o CD nas atividades clínicas, acabado exercendo também o trabalho de secretária.

Nazar et al. (2005) avaliaram 54 das 105 USB de Belo Horizonte e observaram que todos os ASB eram mulheres $(n=54)$, fato que comprova a predominância de indivíduos do sexo feminino ocupando o cargo de ASB.

Nas TAB.5 e 6, são apresentados os resultados da distribuição de frequência dos participantes da pesquisa para as variáveis "idade" e "município de residência" de acordo com a exposição ocupacional ao mercúrio, respectivamente.

TABELA 5 - Distribuição de frequência dos participantes da pesquisa para a variável "idade".

\begin{tabular}{|c|c|c|}
\hline Idade (anos) & $\mathrm{n}^{\circ}$ Participantes $(\mathrm{n})$ & Representatividade (\%) \\
\hline $18<x \leq 20$ & 7 & 5,22 \\
\hline $20<x \leq 30$ & 60 & 44,77 \\
\hline $30<x \leq 40$ & 45 & 33,58 \\
\hline $40<x \leq 50$ & 19 & 14,17 \\
\hline $50<x \leq 60$ & 2 & 1,50 \\
\hline $60<x \leq 70$ & 1 & 0,75 \\
\hline Total & 134 & 100 \\
\hline
\end{tabular}


Aproximadamente $44,8 \%(n=60)$ dos 134 participantes tinham idade entre 21 e 30 anos e estavam no início da sua vida produtiva; 33,6\% (45) tinham idade de 31 a 40 anos; e 16,4\% (22) idade superior a 40 anos (TAB.5).

Em relação à distribuição de frequência dos participantes da pesquisa, considerados "expostos" para a variável "município de residência", 57,14\% (52) residiam em Araguaína e 42,86\% (39) em outros municípios do Estado do Tocantins, mas frequentavam o curso de TSB mensalmente, ministrado em Araguaína (TAB.6).

TABELA 6 - Distribuição de frequência dos participantes da pesquisa, para a variável município de residência de acordo com a exposição ocupacional ao mercúrio.

\begin{tabular}{lccc}
\hline & Município & $\mathbf{n}^{\circ}$ Participantes $(\mathbf{n})$ & Representatividade (\%) \\
\hline Exposto & & 52 & \\
& Araguaína & 39 & 42,86 \\
Total & Outros & 91 & 100 \\
& & & \\
\hline Não exposto & & 88,37 \\
\multicolumn{1}{c}{ Araguaína } & 38 & 11,63 \\
Total & Outros & 05 & 100 \\
\hline
\end{tabular}

Para a variável "município de residência" e "tipo de exposição", 88,37\% (38) dos participantes do grupo controle, considerados "não expostos" residiam em Araguaína e 11,63 (05) em outros municípios do Estado do Tocantins. A maioria dos participantes considerados "expostos" residia em Araguaína (57,14\%) e 42,86\% em outros municípios do Tocantins (TAB.6).

$\mathrm{Na}$ TAB.7, são mostrados os resultados da distribuição dos participantes da pesquisa, considerados "expostos" para as variáveis "função", "horas de trabalho/dia" e "participação no ESF".

TABELA 7 - Distribuição dos participantes da pesquisa, considerados "expostos" para as variáveis "função", "horas de trabalho/dia" e "participação no ESF".

\begin{tabular}{llcc}
\hline & Variável & $\begin{array}{c}\mathbf{n}^{\circ} \text { Participantes } \\
(\mathbf{n})\end{array}$ & $\begin{array}{c}\text { Representatividade } \\
(\%)\end{array}$ \\
\hline Função & & & \\
& CD & 8 & 8,79 \\
Total & ASB & 83 & 91,21 \\
& & 91 & 100
\end{tabular}




\section{Conclusão}

\begin{tabular}{|c|c|c|}
\hline \multicolumn{3}{|l|}{ Participação no ESF } \\
\hline Sim & 57 & 62,64 \\
\hline Não & 32 & 35,16 \\
\hline Não respondeu & 02 & 2,20 \\
\hline Total & 91 & 100 \\
\hline \multicolumn{3}{|l|}{ Horas de trabalho/dia } \\
\hline $2 \mathrm{~h}$ & 1 & 1,10 \\
\hline $4 \mathrm{~h}$ & 4 & 4,40 \\
\hline $6 \mathrm{~h}$ & 12 & 13,20 \\
\hline $8 \mathrm{~h}$ & 73 & 80,20 \\
\hline Não respondeu & 1 & 1,10 \\
\hline Total & 91 & 100 \\
\hline
\end{tabular}

Ao se avaliar apenas o grupo considerado "exposto", foi observado que 91,2\% (83) dos entrevistados exerciam a função de ASB, 8,8\% (8) de CD; com predominância de jornada de trabalho de $8 \mathrm{~h} / \mathrm{dia}(80,2 \%)$, sendo que $13,2 \%$ (12) trabalhavam 6h/dia, 4,4\% (4) 4h/dia, 1,1\% (1) 2h/dia e apenas 1 (um) participante não respondeu (TAB.7). Dos 91 profissionais entrevistados, 62,6\% (57) compunham a equipe do "Estratégia Saúde da Família"; 35,2\% (32) não estavam inseridos no referido programa e 2 dos entrevistados não responderam a este quesito (TAB.7).

$\mathrm{Na}$ TAB.8, são apresentados os resultados da pesquisa sobre a distribuição de frequência dos participantes da pesquisa considerados expostos para a variável "tempo de trabalho" (em anos).

TABELA 8 - Distribuição de frequência dos participantes da pesquisa considerados "expostos" para a variável "tempo de trabalho" (anos).

\begin{tabular}{ccc}
\hline $\begin{array}{c}\text { Tempo de trabalho } \\
\text { (anos) }\end{array}$ & $\begin{array}{c}\mathbf{n}^{\circ} \text { Participantes } \\
\text { (n) }\end{array}$ & $\begin{array}{c}\text { Representatividade } \\
(\%)\end{array}$ \\
\hline $1<\mathrm{x} \leq 10$ & 74 & 81,32 \\
$10<\mathrm{x} \leq 20$ & 13 & 14,28 \\
$20<\mathrm{x} \leq 30$ & 1 & 1,10 \\
$30<\mathrm{x} \leq 40$ & 1 & 1,10 \\
Não respondeu & 2 & 2,20 \\
Total & 91 & 100 \\
\hline
\end{tabular}

Nazar et al. (2005) avaliaram o perfil do ASB de 54 consultórios de Belo Horizonte e destes $68,5 \%$ (37) das ASB tinham entre 05 e 10 anos no exercício da função.

No presente estudo, percebe-se que $87 \%(n=67)$ dos profissionais entrevistados do grupo "expostos" exerciam a profissão há pelo menos 10 anos (FIG.8). 
Em relação à renda média familiar em salários mínimos (SM), dos 134 participantes que responderam ao questionário, 32,80\% (44) relataram renda ter familiar de até 1 (um) salário mínimo; 35,01\% (47) de entre 1 a 2 SM; 17,90\% (24) entre 2 e 3 SM; 3,70\% (5) de 3 a 4 SM; 9,70\% (13) mais de 4 SM. Nesta pesquisa, a maioria dos entrevistados $(91,21 \%)$ do grupo considerado "expostos" era ASB vinculado ao SUS, recebendo em média até 02 salários mínimos mensais (TAB.9).

TABELA 9 - Distribuição de frequência da renda familiar dos entrevistados em salários mínimos (SM).

\begin{tabular}{lcc}
\hline $\begin{array}{c}\text { Renda familiar } \\
\left(\mathbf{S M}^{\star}\right)\end{array}$ & $\mathbf{n}^{\circ}$ Participantes & Representatividade \\
& $(\mathbf{n})$ & $\mathbf{( \% )}$ \\
\hline Até 01 salário mínimo & 44 & 32,80 \\
Entre 01 e 02 SM & 47 & 35,01 \\
Entre 02 e 03 SM & 24 & 17,90 \\
Entre 03 e 04 SM & 5 & 3,70 \\
Mais de 04 SM & 13 & 9,70 \\
Não respondeu & 01 & 0,7 \\
Total & 134 & 100 \\
\hline NOTA: *SM referência na data da pesquisa: $\mathrm{R} \$ 415,00(2008) ; \mathrm{R} \$ 465,00(2009) ;$
\end{tabular}

Em relação à exposição prévia ao $\mathrm{Hg}$, dos 91 entrevistados considerados "expostos", 93,41\% (85) dos entrevistados relataram nunca terem morado em local próximo a garimpos de ouro; 3,30\% (3) relataram já terem morado próximo a esses locais e 3 (três) não responderam. Nenhum dos relatos de moradia próximo a garimpos coincidiu com altos valores de $\mathrm{HgU}$ monitorados nas amostras de urina.

Dos considerados "não expostos" ocupacionalmente ao $\mathrm{Hg}, 86,05 \%$ (37) relataram não terem morado em local de garimpo de ouro, 4,65\% (2) responderam já terem morado próximo a áreas desta natureza e 9,30\% (4) ou não responderam a este quesito ou relataram não se recordarem de terem residido próximo a áreas de garimpo.

Utilizando um teste t de Student, com intervalo de confiança de $95 \%$ e valor de $t=0,6731, G L=101, p=0,5$, calcularam-se as médias de $\mathrm{HgU}$ dos participantes da pesquisa não expostos para a variável "moradia anterior em local próximo a garimpo de ouro" e observou-se média de $4,49 \mu \mathrm{gHg} \cdot \mathrm{g}^{-1} \mathrm{CR}$ e de 2,93 $\mu \mathrm{gHg} . \mathrm{g}^{-1} \mathrm{CR}$ para os participantes com resposta positiva de moradia anterior 
próxima a zona de garimpo e resposta negativa, respectivamente. De acordo com os resultados obtidos pelo teste $\mathrm{t}$, os valores de $\mathrm{HgU}$ foram estatisticamente iguais em ambos os casos (FIG.10).

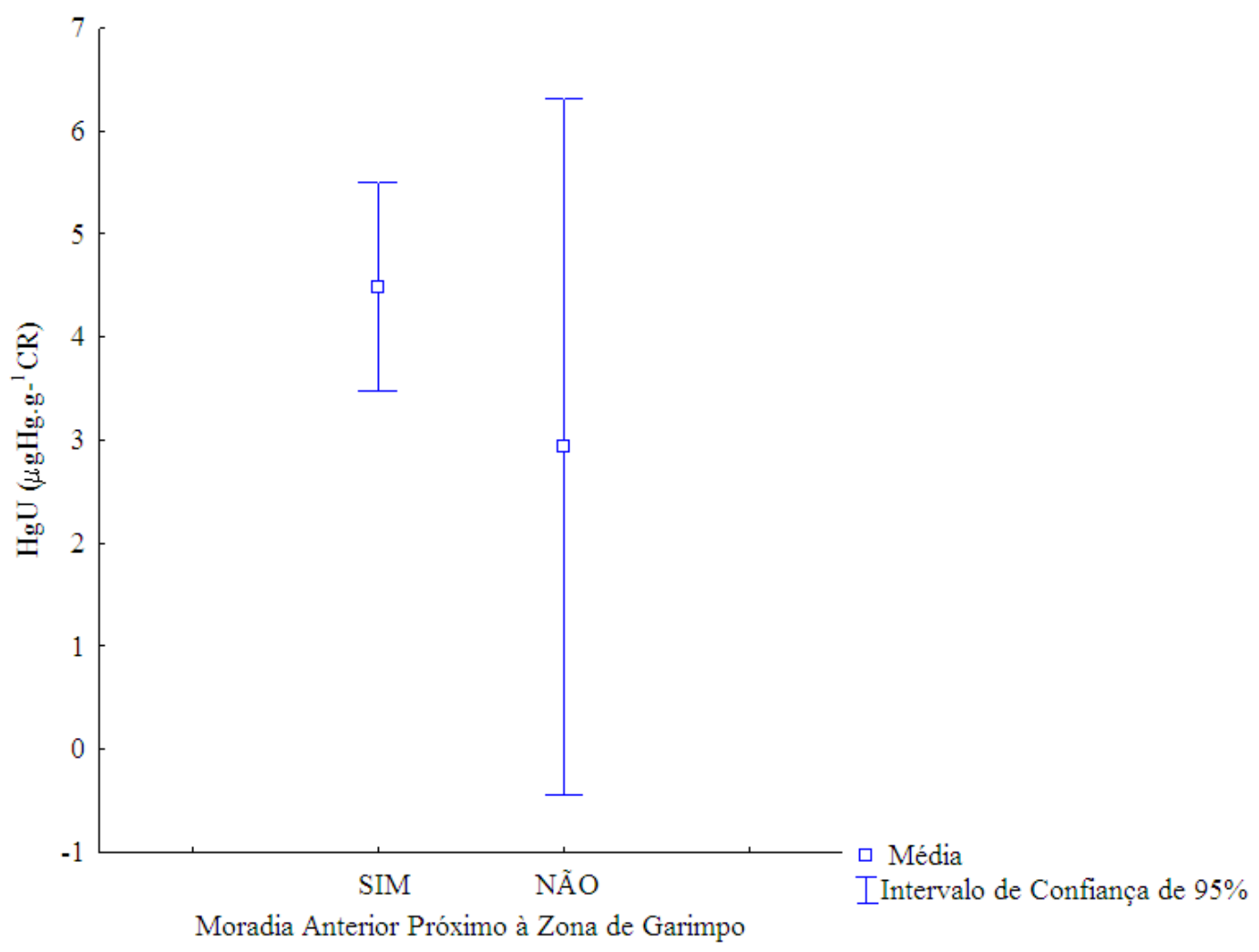

FIGURA 10 - Relação entre as respostas e intervalo de concentração de mercúrio em função da proximidade da moradia (anterior) ser em área de garimpo de ouro.

\subsection{Monitoramento biológico para Hg}

$\mathrm{Na}$ TAB.10, são apresentados os resultados da dosagem do teor de mercúrio total, creatinina (CR) e HgU presente nas amostras de urina coletadas da população estudada.

Em relação aos profissionais da área de odontologia, considerados "expostos" ao $\mathrm{Hg}$, foram coletadas e analisadas 79 amostras durante o período de novembro de 2008 a julho de 2010. Cada número de amostra corresponde a um indivíduo diferente que participou do estudo. Na TAB.10 são descritos os valores da média de três determinações independentes de $\mathrm{Hg}$ em urina com respectivo desvio padrão. 
TABELA 10 - Concentração de $\mathrm{Hg}$ total e de creatinina em 79 amostras únicas analisadas de urina dos participantes da pesquisa considerados expostos durante o período de novembro de 2008 a julho de 2010.

\begin{tabular}{|c|c|c|c|}
\hline \multirow{2}{*}{$\begin{array}{l}\text { Identificação } \\
\text { da amostra } \\
\text { (Número) }\end{array}$} & \multicolumn{3}{|c|}{ Concentração } \\
\hline & $\underset{\left(\mu g^{-L^{-1}}\right)}{\mathbf{H g}^{*}}$ & $\begin{array}{c}\text { CR } \\
\left(\mathbf{g} \cdot \mathrm{L}^{-1}\right)\end{array}$ & $\begin{array}{c}\mathrm{HgU}^{*} \\
\left(\mu \mathrm{gHg} \cdot \mathrm{g}^{-1} \mathrm{CR}\right)\end{array}$ \\
\hline 1 & $23,36 \pm 0,08$ & 1,22 & $19,15 \pm 0,08$ \\
\hline 2 & $2,50 \pm 0,01$ & 1,32 & $1,89 \pm 0,01$ \\
\hline 3 & $1,40 \pm 0,01$ & 1,50 & $0,93 \pm 0,01$ \\
\hline 4 & $11,15 \pm 0,03$ & 0,60 & $18,58 \pm 0,03$ \\
\hline 5 & $3,42 \pm 0,02$ & 1,14 & $3,00 \pm 0,02$ \\
\hline 6 & $1,30 \pm 0,01$ & 0,76 & $1,71 \pm 0,01$ \\
\hline 7 & $8,10 \pm 0,02$ & 1,71 & $4,74 \pm 0,02$ \\
\hline 9 & $29,80 \pm 0,03$ & 2,25 & $13,24 \pm 0,03$ \\
\hline 10 & $4,50 \pm 0,03$ & 1,96 & $2,30 \pm 0,03$ \\
\hline 11 & $15,80 \pm 0,03$ & 1,53 & $10,33 \pm 0,03$ \\
\hline 13 & $7,68 \pm 0,03$ & 1,65 & $4,65 \pm 0,03$ \\
\hline 14 & $5,62 \pm 0,01$ & 1,23 & $4,57 \pm 0,01$ \\
\hline 15 & $4,15 \pm 0,01$ & 0,87 & $4,77 \pm 0,01$ \\
\hline 17 & $5,84 \pm 0,01$ & 0,94 & $6,21 \pm 0,01$ \\
\hline 18 & $3,40 \pm 0,02$ & 1,0 & $3,40 \pm 0,02$ \\
\hline 19 & $1,57 \pm 0,04$ & 0,5 & $3,14 \pm 0,04$ \\
\hline 20 & $6,10 \pm 0,03$ & 0,25 & $24,40 \pm 0,03$ \\
\hline 21 & $6,16 \pm 0,01$ & 0,36 & $17,11 \pm 0,01$ \\
\hline 23 & $6,98 \pm 0,01$ & 1,90 & $3,67 \pm 0,01$ \\
\hline 24 & $2,31 \pm 0,02$ & 0,78 & $2,96 \pm 0,02$ \\
\hline 25 & $3,98 \pm 0,01$ & 0,58 & $6,86 \pm 0,01$ \\
\hline 26 & $11,21 \pm 0,01$ & 1,15 & $9,75 \pm 0,01$ \\
\hline 28 & $10,50 \pm 0,01$ & 0,61 & $17,21 \pm 0,1$ \\
\hline 31 & $7,30 \pm 0,03$ & 1,53 & $4,77 \pm 0,3$ \\
\hline 32 & $10,70 \pm 0,02$ & 0,79 & $13,54 \pm 0,02$ \\
\hline 33 & $5,76 \pm 0,01$ & 0,63 & $9,14 \pm 0,01$ \\
\hline 34 & $4,83 \pm 0,01$ & 1,30 & $3,72 \pm 0,01$ \\
\hline 35 & $4,61 \pm 0,01$ & 1,17 & $3,94 \pm 0,01$ \\
\hline 36 & $0,13 \pm 0,05$ & 0,97 & $0,13 \pm 0,05$ \\
\hline 37 & $9,23 \pm 0,03$ & 1,16 & $7,92 \pm 0,03$ \\
\hline 38 & $2,20 \pm 0,02$ & 1,58 & $1,39 \pm 0,2$ \\
\hline 40 & $0,30 \pm 0,1$ & 0,93 & $1,74 \pm 0,11$ \\
\hline 42 & $7,39 \pm 0,01$ & 0,76 & $9,74 \pm 0,01$ \\
\hline 45 & $1,43 \pm 0$ & 1,33 & $1,08 \pm 0$ \\
\hline 46 & $6,15 \pm 0,03$ & 0,81 & $7,57 \pm 0,03$ \\
\hline 61 & $12,24 \pm 0,03$ & 1,47 & $8,33 \pm 0,03$ \\
\hline 67 & $10,01 \pm 0,03$ & 0,85 & $11,78 \pm 0,03$ \\
\hline 71 & $8,39 \pm 0,01$ & 0,75 & $11,19 \pm 0,12$ \\
\hline 73 & $11,36 \pm 0,07$ & 0,95 & $11,96 \pm 0,07$ \\
\hline 74 & $1,97 \pm 0,02$ & 0,32 & $6,16 \pm 0,02$ \\
\hline 75 & $3,840,01$ & 0,90 & $4,27 \pm 0,01$ \\
\hline 76 & $7,11 \pm 0,2$ & 0,95 & $7,48 \pm 0,25$ \\
\hline 77 & $2,70 \pm 0,03$ & 0,75 & $3,60 \pm 0,03$ \\
\hline
\end{tabular}


conclusão

\begin{tabular}{|c|c|c|c|}
\hline \multirow{2}{*}{$\begin{array}{c}\text { Identificação } \\
\text { da amostra } \\
\text { (Número) }\end{array}$} & \multicolumn{3}{|c|}{ Concentração } \\
\hline & $\begin{array}{c}\mathbf{H g}^{*} \\
\left(\mu \mathbf{g}^{-1} \mathbf{L}^{-1}\right)\end{array}$ & $\underset{\left(g \cdot L^{-1}\right)}{C R}$ & $\begin{array}{c}\mathrm{HgU}^{*} \\
\left(\mu \mathrm{gHg} \cdot \mathrm{g}^{-1} \mathrm{CR}\right)\end{array}$ \\
\hline 78 & $2,09 \pm 0,2$ & 1,25 & $1,67 \pm 0,23$ \\
\hline 79 & $1,77 \pm 0,08$ & 1,20 & $1,48 \pm 0,08$ \\
\hline 80 & $2,59 \pm 0,04$ & 1,22 & $2,12 \pm 0,04$ \\
\hline 81 & $4,17 \pm 0,04$ & 0,49 & $8,51 \pm 0,04$ \\
\hline 82 & $5,57 \pm 0,28$ & 0,50 & $11,14 \pm 0,28$ \\
\hline 83 & $3,04 \pm 0,08$ & 0,39 & $7,79 \pm 0,08$ \\
\hline 84 & $4,75 \pm 0,06$ & 1,30 & $3,65 \pm 0,06$ \\
\hline 85 & $4,44 \pm 0,1$ & 1,05 & $4,23 \pm 0,1$ \\
\hline 86 & $4,96 \pm 0,24$ & 1,18 & $4,20 \pm 0,24$ \\
\hline 87 & $1,53 \pm 0,03$ & 0,90 & $1,70 \pm 0,03$ \\
\hline 88 & $7,05 \pm 2,1$ & 0,45 & $15,67 \pm 2,1$ \\
\hline 89 & $14,43 \pm 4,81$ & 2,40 & $6,01 \pm 4,81$ \\
\hline 92 & $1,0 \pm 0,2$ & 0,70 & $1,42 \pm 0,2$ \\
\hline 94 & $9,5 \pm 0,3$ & 2,17 & $4,37 \pm 0,3$ \\
\hline 97 & $0,90 \pm 0,1$ & 0,38 & $2,37 \pm 0,1$ \\
\hline 99 & $1,70 \pm 0,1$ & 0,76 & $2,24 \pm 0,1$ \\
\hline 100 & $3,40 \pm 0,2$ & 1,36 & $2,50 \pm 0,2$ \\
\hline 101 & $0,90 \pm 0,2$ & 0,39 & $2,28 \pm 0,2$ \\
\hline 102 & $3,80 \pm 0,3$ & 1,96 & $1,94 \pm 0,3$ \\
\hline 107 & $1,30 \pm 0,3$ & 0,82 & $1,59 \pm 0,3$ \\
\hline 113 & $0,30 \pm 0,2$ & 0,54 & $0,56 \pm 0,2$ \\
\hline 115 & $0,90 \pm 0,3$ & 0,75 & $1,20 \pm 0,3$ \\
\hline 116 & $4,40 \pm 0,8$ & 0,72 & $6,11 \pm 0,8$ \\
\hline 122 & $1,90 \pm 0,2$ & 1,07 & $1,77 \pm 0,2$ \\
\hline 127 & $0,73 \pm 0,3$ & 1,01 & $0,72 \pm 0,3$ \\
\hline 132 & $3,0 \pm 0,3$ & 1,63 & $1,83 \pm 0,3$ \\
\hline 139 & $2,31 \pm 0,1$ & 0,98 & $2,36 \pm 0,1$ \\
\hline 188 & $0,6 \pm 0,1$ & 1,17 & $0,51 \pm 0,1$ \\
\hline 189 & $1,50 \pm 0,2$ & 2,05 & $0,73 \pm 0,2$ \\
\hline 190 & $6,7 \pm 0,9$ & 2,5 & $2,68 \pm 0,9$ \\
\hline 192 & $0,60 \pm 0,2$ & 0,49 & $1,22 \pm 0,2$ \\
\hline 193 & 1,30 & 1,45 & $0,90^{\star *}$ \\
\hline 207 & $3,1 \pm 0,2$ & 1,46 & $2,12 \pm 0,2$ \\
\hline 208 & $7,1 \pm 0,8$ & 1,29 & $5,52 \pm 0,8$ \\
\hline 209 & $2,3 \pm 0,2$ & 1,16 & $1,98 \pm 0,2$ \\
\hline 210 & $16,9 \pm 0,7$ & 1,35 & $12,52 \pm 0,7$ \\
\hline Média & 5,40 & 1,19 & 5,61 \\
\hline DP & 5,14 & 0,65 & 4,92 \\
\hline Mínimo & 0,13 & 0,19 & $<0,3$ \\
\hline Máximo & 29,80 & 3,57 & 24,4 \\
\hline
\end{tabular}

NOTA: $\left(^{*}\right)$ média de três determinações independentes

$\left({ }^{\star \star}\right)$ valor de uma determinação

Das 79 amostras analisadas, os maiores valores de $\mathrm{Hg}$ total e $\mathrm{HgU}$ para "expostos" foram $29,80 \mu \mathrm{g} \cdot \mathrm{L}^{-1}$ e $24,40 \mu \mathrm{gHg} \cdot \mathrm{g}^{-1}$, respectivamente, enquanto a média de $\mathrm{HgU}$ foi $5,61 \mu \mathrm{gHg} \cdot \mathrm{g}^{-1} \mathrm{CR}$ (TAB.10). 
$\mathrm{Na}$ TAB.11 podem ser observados os resultados das concentrações de mercúrio total nas amostras de urina analisadas do grupo considerado "não exposto".

TABELA 11 - Concentração de Hg total em amostras únicas analisadas de urina dos participantes da pesquisa considerados não expostos durante o período de novembro de 2008 a julho de 2010.

\begin{tabular}{|c|c|c|c|}
\hline \multirow{2}{*}{$\begin{array}{l}\text { Identificação } \\
\text { da amostra } \\
\text { (Número) }\end{array}$} & \multicolumn{3}{|c|}{ Concentração } \\
\hline & $\underset{\left(\mu g^{-L^{-1}}\right)}{\mathbf{H g}^{*}}$ & $\begin{array}{c}\text { CR } \\
\left(\mathbf{g} \cdot \mathrm{L}^{-1}\right)\end{array}$ & $\begin{array}{c}\mathrm{HgU}^{*} \\
\left(\mu \mathrm{gHg} \cdot \mathrm{g}^{-1} \mathrm{CR}\right)\end{array}$ \\
\hline 48 & $<0,3$ & 1,86 & $<0,3$ \\
\hline 51 & $0,5 \pm 0,1$ & 2,05 & $0,24 \pm 0,1$ \\
\hline 52 & $<0,3$ & 1,35 & $<0,3$ \\
\hline 53 & $<0,3$ & 0,85 & $<0,3$ \\
\hline 57 & $<0,3$ & 1,29 & $<0,3$ \\
\hline 62 & $<0,3$ & 1,22 & $<0,3$ \\
\hline 63 & $<0,3$ & 1,26 & $<0,3$ \\
\hline 64 & $<0,3$ & 1,75 & $<0,3$ \\
\hline 109 & $<0,3$ & 0,26 & $<0,3$ \\
\hline 112 & $<0,3$ & 0,49 & $<0,3$ \\
\hline 117 & $1,4 \pm 0,3$ & 0,67 & $2,08 \pm 0,3$ \\
\hline 125 & $0,40 \pm 0,2$ & 0,68 & $0,58 \pm 0,2$ \\
\hline 131 & $2,90 \pm 0,2$ & 1,30 & $2,23 \pm 0,2$ \\
\hline 137 & $8,70 \pm 0,7$ & 2,05 & $4,24 \pm 0,7$ \\
\hline 163 & $3,50 \pm 0,5$ & 2,04 & $1,72 \pm 0,5$ \\
\hline 169 & $1,10 \pm 0,3$ & 2,52 & $0,44 \pm 0,3$ \\
\hline 171 & $2,20 \pm 0,1$ & 2,52 & $0,87 \pm 0,1$ \\
\hline 181 & $1,0 \pm 0,2$ & 1,67 & $0,60 \pm 0,2$ \\
\hline 182 & $3,4 \pm 0,5$ & 3,57 & $0,95 \pm 0,5$ \\
\hline 185 & $1,0 \pm 0,1$ & 2,27 & $0,44 \pm 0,1$ \\
\hline 187 & $1,5 \pm 0,2$ & 2,95 & $0,51 \pm 0,2$ \\
\hline 194 & $<0,3$ & 0,25 & $<0,3$ \\
\hline 198 & $0,4 \pm 0,1$ & 0,87 & $0,45 \pm 0,1$ \\
\hline 199 & $0,8 \pm 0,1$ & 0,75 & $1,07 \pm 0,1$ \\
\hline 200 & $2,3 \pm 0,2$ & 2,15 & $0,90 \pm 0,2$ \\
\hline 201 & $0,4 \pm 0,1$ & 0,85 & $0,47 \pm 0,1$ \\
\hline 202 & 0,9 & 3,0 & $0,30 \pm 0,2$ \\
\hline 203 & $<0,3$ & 0,4 & $<0,3$ \\
\hline 204 & $0,8 \pm 0,2$ & 0,75 & $1,06 \pm 0,2$ \\
\hline 205 & $<0,3$ & 0,19 & $<0,3$ \\
\hline 206 & $1,0 \pm 0,2$ & 0,9 & $1,11 \pm 0,2$ \\
\hline Média & 1,10 & 1,44 & 0,65 \\
\hline DP & 1,74 & 0,90 & 0,91 \\
\hline Valor Máximo & 8,7 & 3,57 & 4,24 \\
\hline Valor Mínimo & $<0,3$ & 0,19 & $<0,3$ \\
\hline
\end{tabular}

NOTA: (*) média de três determinações independentes.

Analisando os resultados obtidos nas 31 amostras de urina de participantes considerados "não expostos", observou-se que, em 38,70\% das 
amostras (12), a dosagem do $\mathrm{Hg}$ total foi menor que o $\mathrm{LQ}\left(0,3 \mu \mathrm{g} \cdot \mathrm{L}^{-1}\right)$. A média do $\mathrm{HgU}$ encontrado para o grupo de "não expostos" foi de $0,65 \mu \mathrm{gHg} \cdot \mathrm{g}^{-1} \mathrm{CR}$ (TAB.11).

$\mathrm{Na}$ TAB.12, são apresentados os resultados das concentrações de mercúrio total em função da distribuição do grupo "exposto".

TABELA 12 - Distribuição dos participantes da pesquisa, considerados "expostos" de acordo com as concentrações de mercúrio total na urina $(\mu \mathrm{gHg}$. $\mathrm{L}^{-1}$ de urina).

\begin{tabular}{|c|c|c|}
\hline $\begin{array}{c}\text { Intervalo de } \\
\text { concentração de } \mathrm{Hg} \text { em } \\
\text { amostras de urina } \\
\left(\mu \mathrm{gg} \cdot \mathrm{L}^{-1}\right)\end{array}$ & $\begin{array}{c}\text { Participantes } \\
\text { (n) }\end{array}$ & $\begin{array}{c}\text { Representatividade } \\
(\%)\end{array}$ \\
\hline $0<x \leq 5$ & 48 & 60,77 \\
\hline $5<x \leq 10$ & 19 & 24,05 \\
\hline $10<x \leq 15$ & 8 & 10,13 \\
\hline $15<x \leq 20$ & 2 & 2,53 \\
\hline $20<x \leq 25$ & 1 & 1,26 \\
\hline $25<x \leq 30$ & 1 & 1,26 \\
\hline Total & 79 & 100 \\
\hline
\end{tabular}

Observou-se que 60,77\% (48) dos participantes da pesquisa que estavam expostos à presença de $\mathrm{Hg}$ apresentaram dosagens de mercúrio total de até $5 \mu \mathrm{g} \cdot \mathrm{L}^{-1}$ (TAB.12). Apenas 1 (um) participante apresentou dosagem de $\mathrm{Hg}$ total entre 25 a $30 \mu \mathrm{gHg} \cdot \mathrm{L}^{-1}$. Ao se considerar o limite de normalidade para teores de $\mathrm{Hg}$ urinários preconizado pela OMS igual a $10 \mu \mathrm{gHg} \cdot \mathrm{L}^{-1}$ urina, pode-se observar que $84,81 \%$ (67) dos 91 participantes estavam dentro do limite estabelecido e $15,19 \%$ (12) estavam acima deste limite (TAB.12). Todas as amostras analisadas apresentaram-se dentro do limite biológico máximo estabelecido pela OMS $\left(<50 \mu \mathrm{gHg} \cdot \mathrm{L}^{-1}\right)$.

Oikawa et al. (2007) relataram que $80 \%$ dos graduandos de odontologia da CESUPA que participaram de um estudo para verificar a dosagem de Hg urinário (20) encontravam-se dentro do limite de normalidade de $10 \mu \mathrm{gHg} \mathrm{L}^{-}$ ${ }^{1}$ e dentro do limite biológico máximo tolerado de $50 \mu \mathrm{gHg} \cdot \mathrm{L}^{-1}$ preconizado pela OMS.

$\mathrm{Na}$ TAB.13, os resultados das concentrações de mercúrio urinário $(\mathrm{HgU})$ em função da distribuição do grupo "expostos" podem ser observados. 
TABELA 13 - Distribuição dos participantes da pesquisa, considerados expostos de acordo com as concentrações de mercúrio urinário $\left(\mu \mathrm{gHg} \cdot \mathrm{g}^{-}\right.$ $\left.{ }^{1} \mathrm{CR}\right)$.

\begin{tabular}{|c|c|c|}
\hline $\begin{array}{c}\mathrm{HgU} \\
\left(\mu \mathrm{gHg} \cdot \mathrm{g}^{-1} \mathrm{CR}\right)\end{array}$ & $\begin{array}{c}\mathrm{n}^{\circ} \text { Participantes } \\
\text { (n) }\end{array}$ & $\begin{array}{c}\text { Representatividade } \\
(\%)\end{array}$ \\
\hline $0<x \leq 5$ & 50 & 63,3 \\
\hline $5<x \leq 10$ & 15 & 19,0 \\
\hline $10<x \leq 15$ & 8 & 10,1 \\
\hline $15<x \leq 20$ & 5 & 6,3 \\
\hline $20<x \leq 25$ & 1 & 1,3 \\
\hline Total & 79 & 100 \\
\hline
\end{tabular}

Das 79 amostras de urina analisadas dos profissionais participantes da pesquisa (ACD+CD), considerados "expostos" ao Hg nenhuma superou o IBPM valor máximo do indicador biológico para o qual se supõe que a maioria das pessoas ocupacionalmente expostas não corre risco de dano à saúde, determinado pela NR 7. Inclusive, a maior parte dos expostos $(63,3 \%)$ apresentaram $\mathrm{HgU}$ de até $5 \mu \mathrm{gHg} \cdot \mathrm{g}^{-1} \mathrm{CR}$, valor aceito como normal para população não exposta (TAB.13).

As médias de $\mathrm{HgU}$ dos participantes da pesquisa para a variável "grupo de exposição" foram comparadas utilizando um teste t de Student. O teste t é utilizado para verificar se as diferenças entre as medias dos dois conjuntos de amostra é estatisticamente significante. O t calculado com base nos resultados obtidos será então comparado com o t obtido da tabela de distribuição de Student. Se $\circ t_{\text {calculado }}>t_{\text {tabelado, }}$ a diferença entre as medias é estatisticamente significante. Caso contrario, $\mathrm{H}_{0}$ é verdadeira $\mathrm{e}$ as medias podem ser consideradas estatisticamente iguais.

Utilizando um teste t de Student, com intervalo de confiança de 95\% e valor de $t=5,32, G L=108, p<0,01$, calcularam-se as médias de $\mathrm{HgU}$ dos participantes da pesquisa para a variável "grupo de exposição" e observou-se média de $5,61 \mu \mathrm{gHg} \cdot \mathrm{g}^{-1} \mathrm{CR}$ e de $0,65 \mu \mathrm{gHg} \cdot \mathrm{g}^{-1} \mathrm{CR}$ para os participantes do grupo de "expostos" e "não expostos", respectivamente (FIG.10).

As barras azuis apresentadas na FIG.11 descrevem os intervalos de confiança de 95\%. Apesar de existir diferença amostral entre os grupos "expostos" (n=79) e "não expostos" (n=31), os "expostos" apresentaram aproximadamente 8 vezes o valor da média de $\mathrm{HgU}$ se comparados aos "não expostos", evidenciando a exposição ocupacional ao mercúrio por profissionais que atuam nos consultórios odontológicos. 


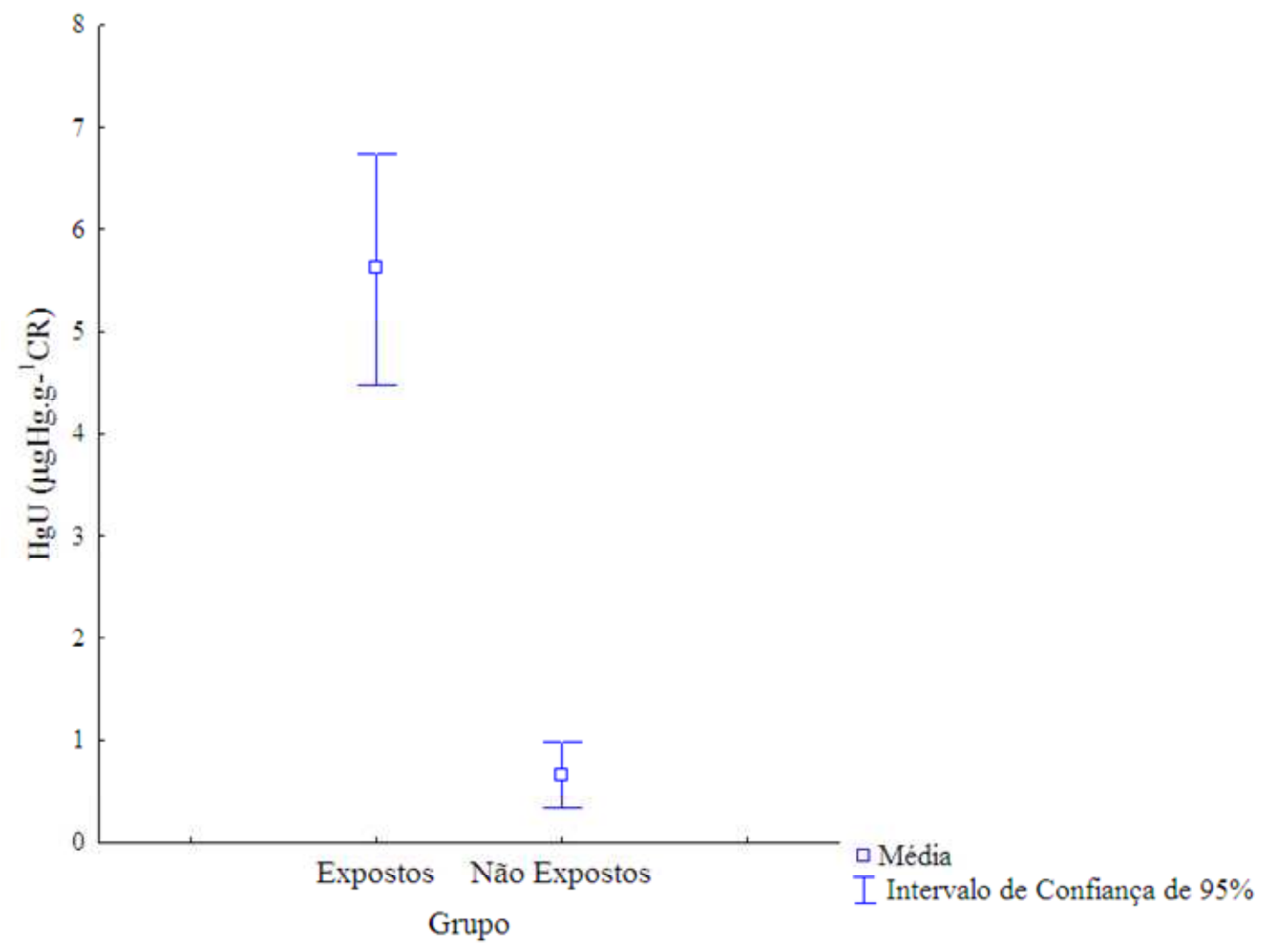

FIGURA 11 - Representação gráfica das médias de HgU em relação a variável grupo de exposição.

A partir dos resultados do teste $\mathrm{t}$ pode-se inferir que, apesar dos valores de $\mathrm{HgU}$ para a população exposta ao mercúrio serem considerados aceitáveis e normais em conformidade com a NR 7, esta população está muito mais exposta a doenças causadas pelo contato com o mercúrio ao ser comparada com o restante da população que não trabalha em consultórios odontológicos. Desta forma, o monitoramento biológico anual nesses profissionais deveria ser instituído como rotina nos exames periódicos ocupacionais.

Ritchie et al. (2004) avaliaram a exposição ocupacional ao mercúrio de 180 CD da Escócia. Os níveis de mercúrio urinário foram 4 vezes maiores no grupo de CD que no grupo controle; a urina foi o melhor marcador biológico para exposição ao mercúrio se comparado aos cabelos ou as unhas.

Karahalil et al. (2005) avaliaram os níveis de $\mathrm{Hg}$ nas amostras de urina de 20 dentistas e 09 não expostos ao Hg utilizando a CV-AAS e observaram que os níveis de $\mathrm{Hg}$ eram 03 vezes maior nos dentistas $\left(6,2 \pm 3,5 \mu \mathrm{g} \cdot \mathrm{L}^{-1}\right)$ que no grupo controle $\left(1,97 \pm 0,9 \mu \mathrm{g} \cdot \mathrm{L}^{-1}\right)$. 
Estudo realizado por Salgado et al. (1986) revelou que 50\% dos cirurgiões dentistas que utilizavam o mercúrio elementar para obtenção do amálgama dentário apresentaram níveis urinários de mercúrio superiores a 5 $\mu \mathrm{gHg} . \mathrm{g}^{-1} \mathrm{CR}$ e $1,6 \%$ acima de $30 \mu \mathrm{gHg} \cdot \mathrm{g}^{-1} \mathrm{CR}$.

De acordo com a American Dental Association (ADA, 2003), o manuseio do amálgama odontológico tem sido relatado como a principal fonte de exposição ocupacional de dentistas ao mercúrio. Langworth et al. (1997) relataram que os níveis de $\mathrm{Hg}$ urinário estão fortemente correlacionados com a exposição ocupacional.

Echeverria et al. (1995) avaliaram os níveis de $\mathrm{Hg}$ urinário e sua relação com a exposição ocupacional, pois os mesmos apresentaram níveis 07 vezes superior ao grupo controle.

Lacerda et al. (2002) estudaram 204 membros da equipe de odontologia sendo 57 CD e 147 ACD e relataram que as médias da concentração de mercúrio total na urina eram maiores nos ASB se comparados aos CD e estatisticamente significante; houve aumento na média de concentração de urina durante os 02 anos de acompanhamento desses profissionais, sendo a diferença mais acentuada entre os ACD.

Chaari et al. (2009) relataram que $61 \%$ dos indivíduos que apresentavam riscos de exposição ao mercúrio trabalhavam em consultórios odontológicos. Os valores de HgU urinários eram estatisticamente significativos e maiores nos indivíduos que trabalhavam em consultórios odontológicos se comparados com os do grupo controle. Além disso, a maioria dos dentistas expostos ao $\mathrm{Hg}$ não cumpria as medidas preventivas para evitar a contaminação pelo metal utilizado no amálgama.

Neghab et al. (2010) examinaram os efeitos da exposição ocupacional a baixos níveis de mercúrio em 106 cirurgiões-dentistas e 94 médicos de clínica geral (grupo controle), de clínicas privadas e públicas na cidade de Shiraz, Irã. Os valores da média de $\mathrm{HgU}$ foram de $3,16 \mu \mathrm{gHg} \cdot \mathrm{g}^{-1} \mathrm{CR}$ e $2,18 \mu \mathrm{gHg} \cdot \mathrm{g}^{-1} \mathrm{CR}$ para o grupo de "expostos" e "não expostos" respectivamente.

Em relação ao município de residência dos participantes da presente pesquisa, as médias de $\mathrm{HgU}$ foram comparadas utilizando um teste t de Student, com intervalo de confiança de $95 \%$ e valor de $t=0,99, G L=107, p=0,325$. Verificouse que a média $\mathrm{HgU}$ dos participantes que residiam em Araguaína foi de 4,57 
$\mu \mathrm{gHg} \cdot \mathrm{g}^{-1} \mathrm{CR}$ enquanto que para os residentes em outros municípios do estado foi de $3,60 \mu \mathrm{gHg} \cdot \mathrm{g}^{-1} \mathrm{CR}$. A partir do teste, pela evidência estatística, pode-se inferir que o fato de residir em Araguaína não interfere nos valores de $\mathrm{HgU}$, resultado que pode ser verificado na FIG.12.

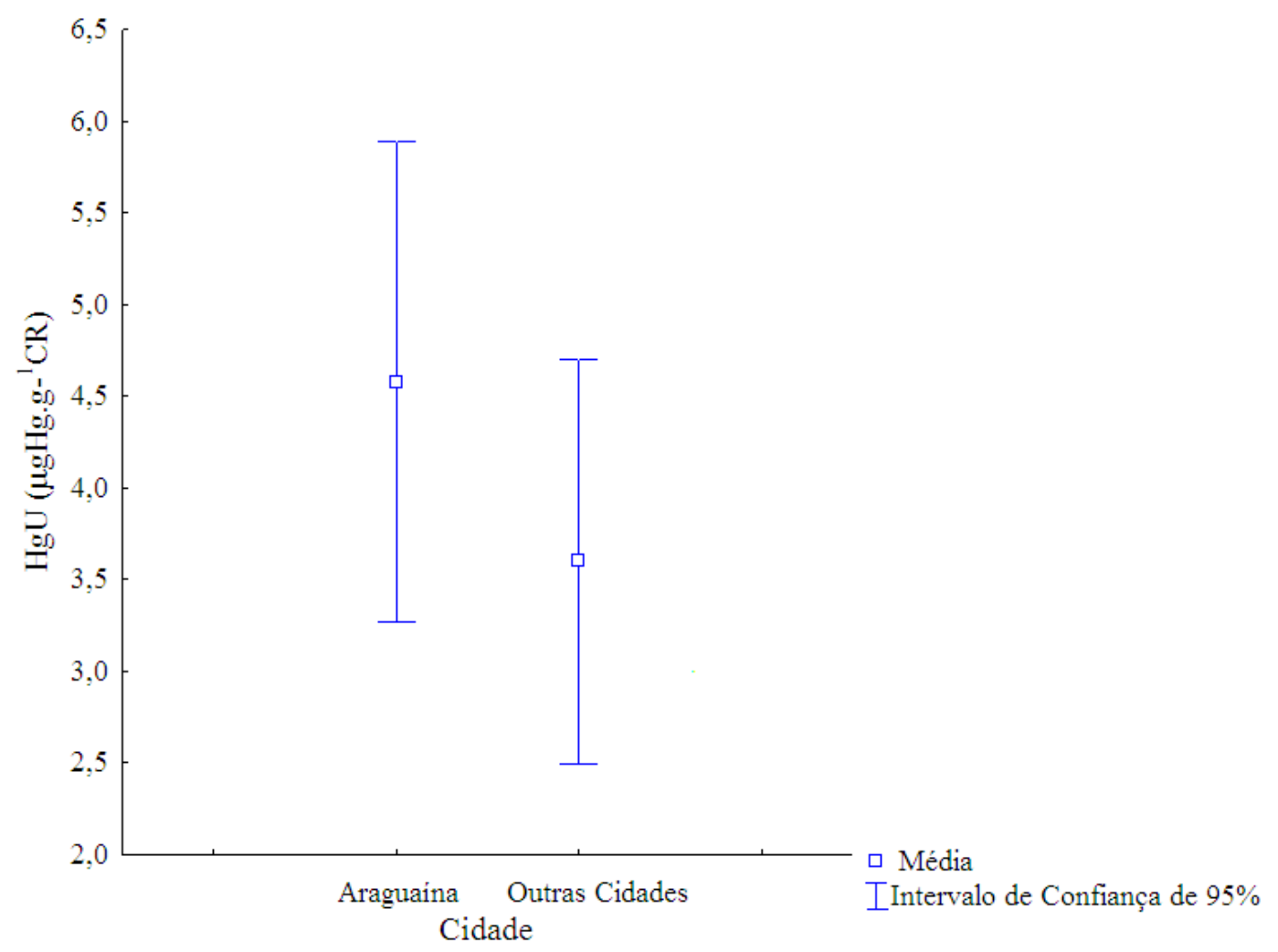

FIGURA 12- Representação gráfica das médias de $\mathrm{HgU}\left(\mu \mathrm{gHg} \cdot \mathrm{g}^{-1} \mathrm{CR}\right)$ em relação a variável "cidade".

Considerando que a presença de restaurações de amálgama de prata poderia interferir nos valores de $\mathrm{HgU}$, realizou-se uma regressão linear simples para testar a hipótese de que a quantidade de restaurações de amálgama presentes na boca implicaria maiores valores de $\mathrm{HgU}$. Nesta pesquisa, o coeficiente de correlação $r=-0,0081$; o coeficiente de determinação $r^{2}=0,0001 ; p$ $=0,9432$ e a equação de regressão foi $y=4,0285+0,0111^{*} x$, no qual $y=\mathrm{HgU} e$ $x=$ número de restaurações. Verificou-se que não houve correlação, o que pode ser observado na FIG.13. 


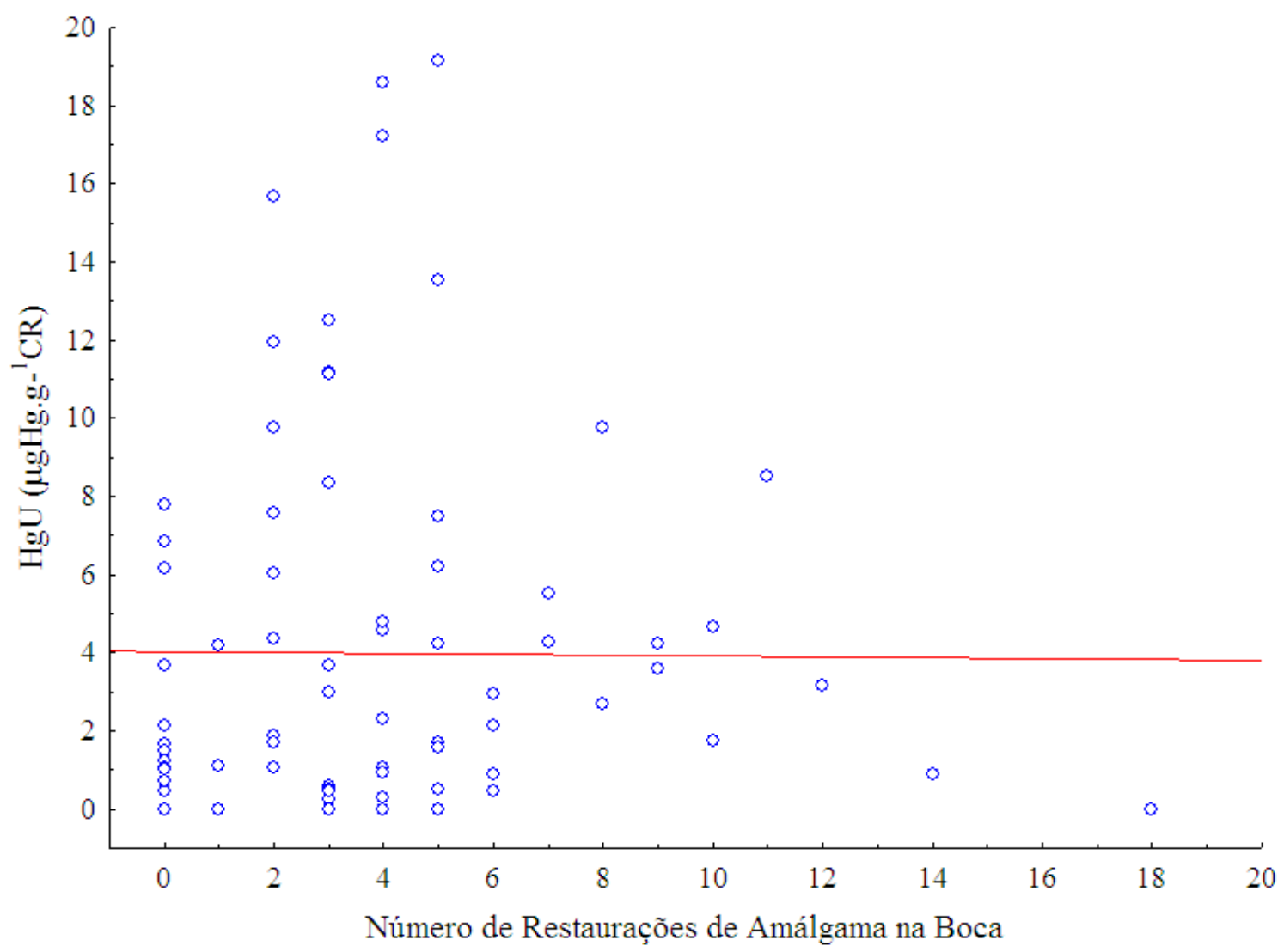

NOTA: $r^{2}=0,0001 ; r=-0,0081 ; p=0,9432 ; y=4,0285+0,0111^{*} x$

FIGURA 13 - Representação gráfica da regressão linear entre número de restaurações de amálgama presentes na boca e $\mathrm{HgU}$ $\left(\mu \mathrm{gHg} . \mathrm{g}^{1} \mathrm{CR}\right)$ dos participantes da pesquisa.

Martin et al. (1995) tentaram relacionar os valores de Hg urinários com quantidade de restaurações de amálgama que os dentistas apresentavam. Apesar da associação ser baixa e fraca, era estatisticamente significativa. Outros estudos reportaram uma associação direta entre exposição ao mercúrio do amálgama e concentrações de mercúrio urinário (Begerow et al., 1994; Skerfving, 1991) em populações não expostas ocupacionalmente.

Karahali et al. (2005) também procuraram correlacionar os elevados níveis de $\mathrm{Hg}$ inorgânico em dentistas com o número de restaurações de amálgama que os mesmos apresentavam em suas bocas. Apesar das controvérsias relatadas na literatura, os autores não relataram diferenças estatísticas entre níveis de $\mathrm{Hg}$ elevados e números de restaurações de amálgama presentes. 
Halbach et al. (2008) relataram uma correlação forte entre concentração de $\mathrm{Hg}$ na urina e números de faces dentárias restauradas com amálgama, sendo dosada $0,09 \mathrm{ngHg} \cdot \mathrm{mL}^{-1}$ de urina para cada face de amálgama.

Lee \& Paek (2010) encontram médias de HgU na urina de participantes que não apresentavam restaurações de amálgama de $0,48 \mu \mathrm{gHg} \cdot \mathrm{g}^{-1} \mathrm{CR}$ e de 1,07 $\mu \mathrm{gHg} \cdot \mathrm{g}^{-1} \mathrm{CR}$ para aqueles que apresentavam mais de 10 amálgamas.

Em relação ao tempo de trabalho e $\mathrm{HgU}$ e considerando que um maior tempo de trabalho com amálgama implicaria em maior contato com amálgama e consequentemente com mercúrio causando valores mais elevados de $\mathrm{HgU}$, realizou-se uma regressão linear simples para testar a hipótese de que um maior tempo de trabalho implicaria maiores valores de HgU. Nesta pesquisa, utilizaramse o coeficiente de correlação, $r=0,2644$; o coeficiente de determinação $r^{2}=$ 0,0699; $p=0,0210$ e a equação de regressão foi $y=3,9783+0,2402^{*} x$, no qual $y=\mathrm{HgU}$ e $\mathrm{x}=$ tempo de trabalho. Verificou-se que houve correlação positiva $e$ significativa, confirmando a hipótese de que maiores tempos de trabalho implicam em maiores valores de $\mathrm{HgU}$ (FIG.14).

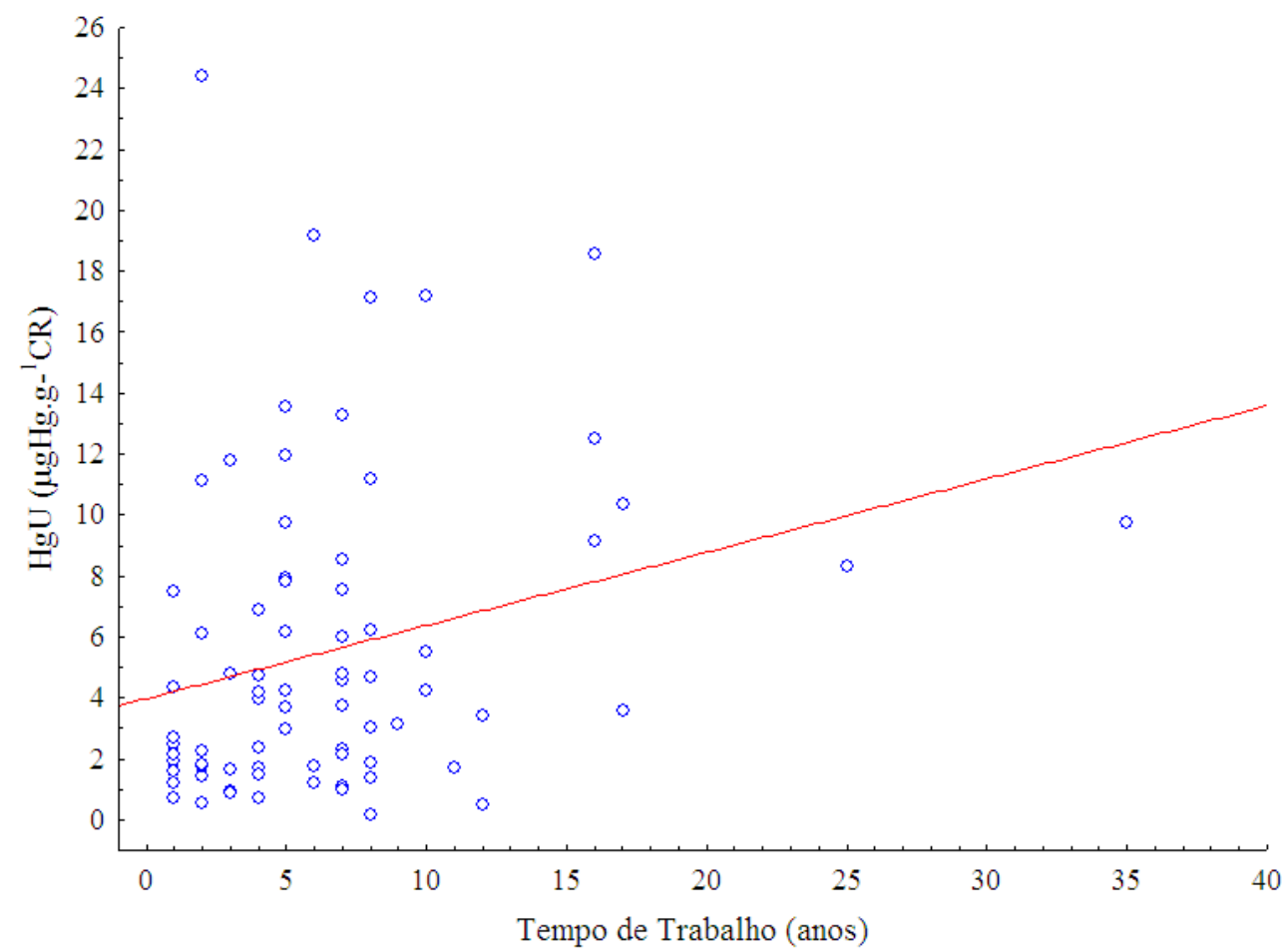

NOTA: $r^{2}=0,0699 ; r=0,2644 ; p=0,0210 ; y=3,9783+0,2402^{*} x$

FIGURA 14 - Representação gráfica da regressão linear entre tempo de trabalho (anos) e HgU $\mu \mathrm{gHg} \cdot \mathrm{g}^{-1} \mathrm{CR}$. 


\subsection{Avaliação da rotina de biossegurança dos profissionais da equipe odontológica}

\subsubsection{Segregação de resíduos}

Os dados referentes à rotina de biossegurança descrita pelos profissionais que participaram desta pesquisa estão apresentados em tabelas ou figuras de representações gráficas a seguir (TAB.14 a 17; FIG.15 a 18).

TABELA 14 - Distribuição dos participantes da pesquisa de acordo com o uso de lixo específico para material com risco biológico (segregação de material contaminado).

\begin{tabular}{ccc}
\hline $\begin{array}{l}\text { Uso de lixo específico para } \\
\text { material com risco biológico }\end{array}$ & $\begin{array}{c}\text { Participantes } \\
(\mathbf{n})\end{array}$ & $\begin{array}{c}\text { Representatividade } \\
(\%)\end{array}$ \\
\hline Sim & 72 & 79,10 \\
Não & 18 & 19,80 \\
Não respondeu & 1 & 1,10 \\
Total & 91 & 100 \\
\hline
\end{tabular}

Em relação à rotina de biossegurança descrita pelos profissionais que participaram desta pesquisa, observou-se que $79,1 \%$ (72) dos entrevistados (91) relataram utilizar lixo específico para material com risco biológico (contaminado com sangue ou saliva); $19,8 \%$ (18) relataram não terem ou não utilizarem lixo específico, e 1,1\% (01) não responderam (TAB.14). A partir destes dados, podese inferir que aqueles que responderam não terem lixo específico para materiais contaminados por amostras biológicas utilizam o mesmo cesto de lixo para descartarem tanto gazes contaminadas com sangue, luvas, máscaras, gorros quanto papéis utilizados para enxugar as mãos ou embalagens utilizadas para esterilizar os materiais.

Em relação ao descarte de perfurocortantes utilizados nos procedimentos odontológicos, como agulhas de anestesia e sutura, lâminas de bisturis, limas, brocas e outros assemelhados, o MS preconiza que os mesmos devem ser descartados imediatamente após o uso, em recipientes estanques, rígidos e com tampa, identificados com o símbolo de infectante e com a transcrição das expressões "Infectante e material perfurocortante". Se possível o frasco coletor de agulhas deve conter desconectador para que as agulhas possam ser desrosqueadas sem a necessidade de reemcape (Santos \& Coimbra, 2004; Brasil, 2006). 
Yüzbasioglu et al. (2009), em estudo sobre local de descarte de perfurocortantes com 135 dentistas, relataram que apenas $37,8 \%$ (51) dos entrevistados utilizavam frasco separado apropriado para descarte.

Diferente dos autores supracitados, nesta pesquisa foi constatado que a maioria dos entrevistados $(72,5 \%)$ fazia uso de um frasco separado para descarte de tais objetos, mas nem sempre havia a transcrição da expressão "Infectante e material perfurocortante", uma vez que nem todos utilizavam caixas específicas para descarte.

Nos resultados apresentados na TAB.15, pode-se verificar que $12,1 \%$ dos entrevistados (11) relataram jogar objetos perfurocortantes no lixo hospitalar, oferecendo riscos aos profissionais que realizam a coleta dos sacos de lixo. Além disso, 9,9\% (9) relataram jogar na pia as agulhas utilizadas, infringindo a legislação de biossegurança vigente para consultórios odontológicos.

TABELA 15 - Distribuição dos participantes da pesquisa de acordo com o local de descarte de material perfurocortante.

\begin{tabular}{ccc}
\hline $\begin{array}{c}\text { Local de descarte de } \\
\text { material perfurocortante }\end{array}$ & $\begin{array}{c}\text { Participantes } \\
(\mathbf{n})\end{array}$ & $\begin{array}{c}\text { Representatividade } \\
(\%)\end{array}$ \\
\hline Lixo hospitalar & 11 & 12,10 \\
Frasco separado & 66 & 72,50 \\
Na pia & 9 & 9,90 \\
Não respondeu & 5 & 5,50 \\
Total & 91 & 100 \\
\hline
\end{tabular}

\subsubsection{Processo de esterilização e prevenção da infecção cruzada}

Em relação ao método de esterilização, $44 \%$ dos entrevistados nesta pesquisa (40) relataram utilizar a autoclavação como método principal de esterilização; 52,7\% (48) a estufa; e 3,3\% (3) não responderam este quesito. Uma vez que todos os consultórios utilizam instrumentais termorresistentes e de acordo com normas do MS (Brasil, 2006), a autoclave deveria ser o método relatado como utilizado em $100 \%$ dos entrevistados.

Graziano \& Graziano (2000) enfatizam que os artigos (insumos e descartáveis) utilizados em consultórios odontológicos podem servir como veículos na transmissão de agentes infecciosos passíveis de causarem doenças em hospedeiros suscetíveis, sendo a esterilização comprovadamente um método eficaz para o controle da infecção cruzada e a autoclavação (com vapor de água 
saturado e sob pressão) o método de eleição para esterilizar instrumentais por oferecer maior segurança.

Yüzbasioglu et al. (2009) avaliaram os conhecimentos e atitudes de 135 dentistas turcos sobre biossegurança e verificaram que 46,70\% (63) dos entrevistados relataram utilizar a autoclave e $65,90 \%$ (89) a estufa. O uso de substâncias químicas para esterilização foi relatado por $34,80 \%$ (47) e água fervente por 2 profissionais (1,50\%). Alguns entrevistados relataram utilizar métodos conjugados de esterilização.

Em relação ao quesito do questionário sobre a responsabilidade da realização da limpeza e reprocessamento dos instrumentais, a maioria dos entrevistados $(73,60 \%)$ relatou ser o responsável pela realização de ambos processos em seu local de trabalho; $20,90 \%$ (19) relataram não serem os responsáveis e 5,50\% (05) não responderam.

Considerando a importância do reprocessamento seguro dos artigos em odontologia na prevenção das infecções e que este deve obedecer aos critérios preconizados pelos órgãos normativos ressaltada por Graziano \& Graziano (2000), inseriu-se no questionário o quesito realização prévia de curso de biossegurança.

Dos entrevistados (91), 78\% (71) relataram terem feito um curso de biossegurança e 20,9\% (19) relataram não terem feito o mesmo; apenas 01 não respondeu (1,1\%). Apesar de apenas $20,9 \%$ dos entrevistados terem relatado não terem formação prévia para o reprocessamento antes de executarem tal procedimento, o relato da realidade nos serviços de saúde mostra-se preocupante, pois o despreparo do trabalhador para o reprocessamento de artigos implica em imperícia, negligência e/ou imprudência de acordo com Tavares et al. (2008), o que novamente confirma a importância da oferta e da realização de cursos técnicos de formação para ASB e TSB no Estado do Tocantins.

$\mathrm{Na}$ FIG.15 podem ser observadas as frequência de uso dos EPIs (equipamentos de proteção individual) pela equipe de odontologia durante o atendimento clínico de pacientes. 


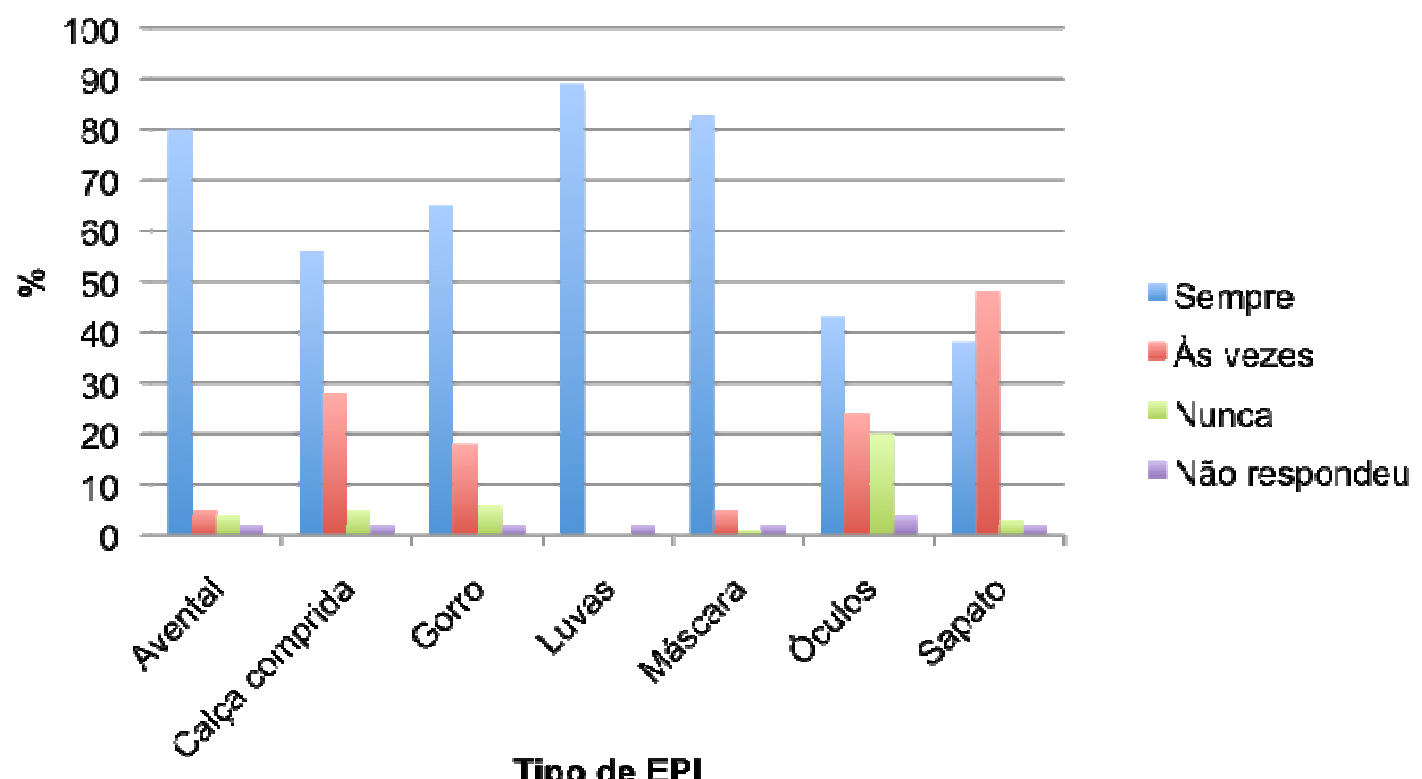

FIGURA 15 - Representação gráfica da frequência de uso dos EPI de acordo com as respostas dos 91 entrevistados na pesquisa.

Observou-se que $87,9 \%$ (80) relataram utilizar o avental (jaleco) sempre; $5,5 \%$ (5) às vezes; $4,4 \%$ (4) nunca; e 2,2\% (2) não responderam. Os EPIs que apresentaram maiores relatos de serem utilizados sempre pelos entrevistados foram: as luvas em $97,8 \%$ (89); máscaras $91,2 \%$ (83), seguido do avental 87,9\% (80); gorro $71,4 \%$ (65); calça comprida $61,5 \%$ (56); óculos de proteção $47,3 \%$ (43) e sapato fechado $41,8 \%$ (38). O EPI com menores adesão no uso foram os óculos de proteção, pois $22 \%$ dos entrevistados (20) relataram nunca os utilizar e $26,4 \%$ (24) utilizam-nos às vezes. O sapato fechado foi o EPI citado com maiores porcentagens de uso para a frequência de uso "às vezes", perfazendo $52,7 \%$ (48) (FIG.15).

Garbin et al. (2005) avaliaram as práticas de biossegurança em Araçatuba - Brasil - de $40 \mathrm{CD}$, sendo 20 da rede pública e 20 da rede privada. Os autores relataram que, em relação ao uso de gorro, 55\% dos entrevistados do serviço público e $90 \%$ do serviço privado relataram utilizá-lo sempre. Todos os entrevistados relataram utilizar luvas e máscaras ao atenderem seus pacientes; $95 \%$ e $85 \%$ do serviço público e privado, respectivamente, utilizavam jaleco durante procedimentos clínicos; por fim, $40 \%$ dos entrevistados que trabalhavam no serviço público relataram não trocarem de luvas no intervalo entre pacientes. 
Duncan et al. (2011) relataram que os membros da equipe odontológica que utilizavam sapatos abertos apresentavam dosagens de mercúrio nas unhas dos pés maiores que os membros que utilizavam sapatos fechados.

\subsubsection{Sistema de preparo dos amálgamas odontológicos}

Para avaliar se os profissionais entrevistados estavam expostos diariamente a possíveis vapores de mercúrio provenientes de resíduos de $\mathrm{Hg}$ puro ou restos de amálgama, foi perguntado se no consultório no qual trabalhavam era feita diariamente alguma restauração de amálgama. Dos 91 entrevistados, 83,5\% (76) responderam manusear diariamente amálgama e $16,5 \%$ (15) responderam não fazê-lo diariamente.

Dependendo do fabricante, a limalha que servirá de base para o amálgama pode ser constituída por $40 \%$ a $74 \%$ do seu teor de massa de prata, $25-32 \%$ de estanho, e $30 \%$ de cobre, e $2 \%$ de zinco. A esses metais sólidos é misturado o mercúrio líquido na proporção de 1:1 antes de sua inserção nos preparos cavitários (SCENIHR, 2008; Hylander et al., 2006); o mercúrio líquido, além de ser um dos elementos essenciais na preparação do amálgama, tem influência sob suas propriedades físicas (Campos \& Steagall, 1988).

Para compor o amálgama, o mercúrio é vendido em duas apresentações comerciais. Pode ser dispensado compartimentado em cápsulas pré-dosadas com a limalha, nas quais fica a limalha em um compartimento da cápsula e mercúrio em outro, separados entre si por uma membrana rompida durante o processo de mistura em um amalgamador mecânico (FIG.16) ou ser comercializado em frascos de plástico ou de vidro (FIG.16), com bico dosador contendo normalmente $100 \mathrm{~g}$ (SCENIHR, 2008).

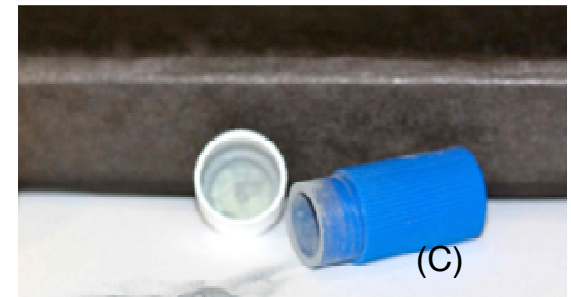

(B)

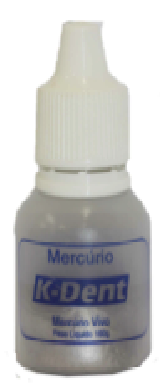

(D)

(A)

FIGURA 16 - Representação fotográfica do amálgama cápsula, sendo (A) limalha; (B) membrana com mercúrio; (C) cápsula; (D) frasco de mercúrio odontológico. 
Desde 1972, o Council on Dental Materials and Devices considera o amalgamador uma máquina essencial na trituração do amálgama, por tornar desnecessário o uso de mercúrio em excesso para lubrificar a massa de amálgama; já na trituração manual, utiliza-se mercúrio em excesso na realização desse processo (Council on Dental Materials and Devices, 1972).

Warfvinge (1995) e Hylander \& Meili (2003) relataram a existência de contaminação por mercúrio em membros da equipe de odontologia no momento do preparo do amálgama, pois o $\mathrm{Hg}$ se vaporiza a $20^{\circ} \mathrm{C}$, tendo sua volatilidade aumentada a medida em que há o aumento da temperatura.

No intuito de verificar se havia risco de exposição ao mercúrio metálico durante preparo e manuseio do amálgama de prata pela equipe auxiliar, os 91 profissionais participantes foram questionados sobre seus hábitos de dosagem do mercúrio utilizado no amálgama, sobre a forma de trituração e sobre o uso de pano de camurça para remoção dos excessos de mercúrio. Os resultados são apresentados na TAB.16.

TABELA 16 - Formas de dosagem de $\mathrm{Hg}$, trituração do amálgama e uso de camurça de acordo com os 91 entrevistados na pesquisa.

\begin{tabular}{|c|c|c|}
\hline Variável & $\begin{array}{l}\text { Participantes } \\
\text { (n) }\end{array}$ & $\begin{array}{c}\text { Representatividade } \\
\%\end{array}$ \\
\hline \multicolumn{3}{|l|}{ Dosagem de $\mathrm{Hg}$} \\
\hline Não pesa & 19 & 20,9 \\
\hline Uso de balança & 0 & 0,0 \\
\hline Uso de cápsula pré-dosada & 15 & 16,5 \\
\hline Uso de outra forma de medida* & 51 & 56,0 \\
\hline Não respondeu & 6 & 6,6 \\
\hline Total & 91 & 100 \\
\hline \multicolumn{3}{|l|}{ Forma de trituração do amálgama } \\
\hline Manual & 14 & 15,4 \\
\hline Amalgamador volumétrico & 57 & 62,6 \\
\hline Amalgamador de cápsula & 14 & 15,4 \\
\hline Não respondeu & 6 & 6,6 \\
\hline Total & 91 & 100 \\
\hline \multicolumn{3}{|l|}{ Uso de camurça } \\
\hline $\mathrm{Sim}^{\circ}$ & 62 & 68,1 \\
\hline Não & 24 & 26,4 \\
\hline Não respondeu & 5 & 5,5 \\
\hline Total & 91 & 100 \\
\hline
\end{tabular}

NOTA: $\left({ }^{*}\right)$ Uso de outra forma de medida: uso de amalgamador volumétrico 
Observou-se que a balança de crandall, indicada para pesar a limalha e o mercúrio quando a trituração é manual em gral e pistilo (FIG. 17), não foi citada como utilizada pelos entrevistados; 16,5\% (15) relataram usar amálgama pré-dosado em cápsula; 20,9\% (19) relataram não pesar o Hg e 56\% (51) utilizar outra opção de medida de Hg. Durante as coletas, observou-se que a rotina de preparo manual do amálgama consistia em colocar uma quantidade aleatória de limalha e adicionar $\mathrm{Hg}$ até que o amálgama ficasse em consistência suficiente para ser condensado no preparo cavitário. A opção marcada como "outra" para medida de mercúrio era relatada ao entrevistador como sendo o uso de amalgamador volumétrico (FIG.17) para proporcionar limalha e $\mathrm{Hg}$, calibrado como cada manipulador do aparelho desejasse a consistência do amálgama, ou seja, com mais ou menos $\mathrm{Hg}$ na liga.
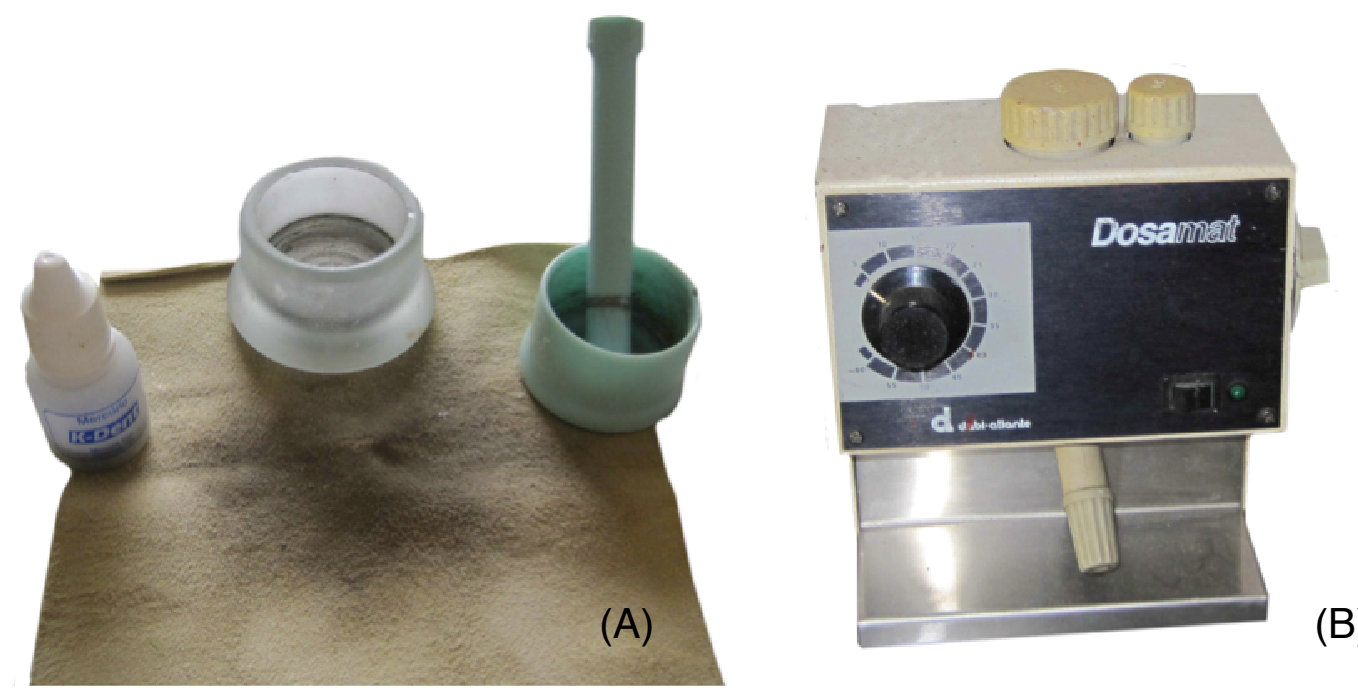

FIGURA 17 - (A) Trituração manual com grau e pistilo; (B) trituração mecânica com amalgamador volumétrico.

Chaari et al. (2009) avaliaram por meio de questionário e dosagem de $\mathrm{HgU}$ os riscos ocupacionais ao mercúrio em profissionais de odontologia da Tunísia e relataram que, em $94 \%$ dos casos, a eliminação dos resíduos de amálgama era inadequada, oferecendo riscos aos profissionais.

Nesta pesquisa foi relatada por $68,1 \%$ (62) dos entrevistados a torção do amálgama em camurça para remoção dos excessos de mercúrio antes do seu uso em pacientes. 
Gronka et al. (1970) mostraram que a operação de maior risco de contaminação em relação ao mercúrio estava na fase de preparação do amálgama.

Em relação ao uso de luvas e máscaras durante o preparo do amálgama 70,3\% (64) dos 91 entrevistados relataram utilizar tais EPI, 17,6\% (16) não utilizar e 12,1\% (11) se abstiveram de respondê-lo.

Kingman et al. (1998) relataram que os dentistas e sua equipe estão ocupacionalmente expostos ao mercúrio, uma vez que realizam manuseio inadequado do amálgama, evidenciado pelo uso de pano de camurça para remoção dos excessos de mercúrio em restaurações realizadas diariamente.

No intuito de observar alguma outra exposição ao Hg metálico sólido, questionou-se sobre a lavagem da camurça utilizada para remoção dos excessos de mercúrio do amálgama. Constatou-se que 58,2\% (53) dos profissionais não efetuavam a lavagem da camurça, que contém excessos de mercúrio, 16,5\% (15) realizavam a lavagem da mesma com frequência e 25,3\% (23) não responderam ao quesito.

Em relação a uma possível exposição aguda ao mercúrio metálico foi solicitado aos entrevistados se alguma vez os mesmos quebraram acidentalmente os frascos de vidro contendo mercúrio metálico. Aproximadamente 65\% (59) dos entrevistados relataram que o fato nunca aconteceu, 25\% (23) que isto já havia acontecido alguma vez e 10\% (9) dos 91 entrevistados não responderam ao quesito.

O uso de cápsulas pré-dosadas de amálgama reduz as possibilidades de exposição ao mercúrio metálico durante sua mistura a limalha, diferente do que ocorre durante a trituração manual usando gral e pistilo (Osborne, 1992; SCENIHR, 2008).

Duncan et al. (2011) e Jokstad (2011) afirmam que a mudança da forma de preparo manual com gral e pistilo para capsular do amálgama odontológico contribuiu para que as dosagens de mercúrio em membros da equipe odontológica apresentassem valores menores se comparados aos valores obtidos em estudos anteriores.

Para verificar a hipótese de que o tipo de trituração poderia interferir nos valores de $\mathrm{HgU}$, realizou-se a análise de variância ANOVA $(F(2,70)=0,89980$; $p=0,41130$ ) e não foram verificadas diferenças estatisticamente significantes nas 
dosagens de $\mathrm{HgU}$ entre as formas de trituração manual com gral e pistilo, mecânica com amalgamador volumétrico e mecânica com amalgamador em cápsula (FIG.18).

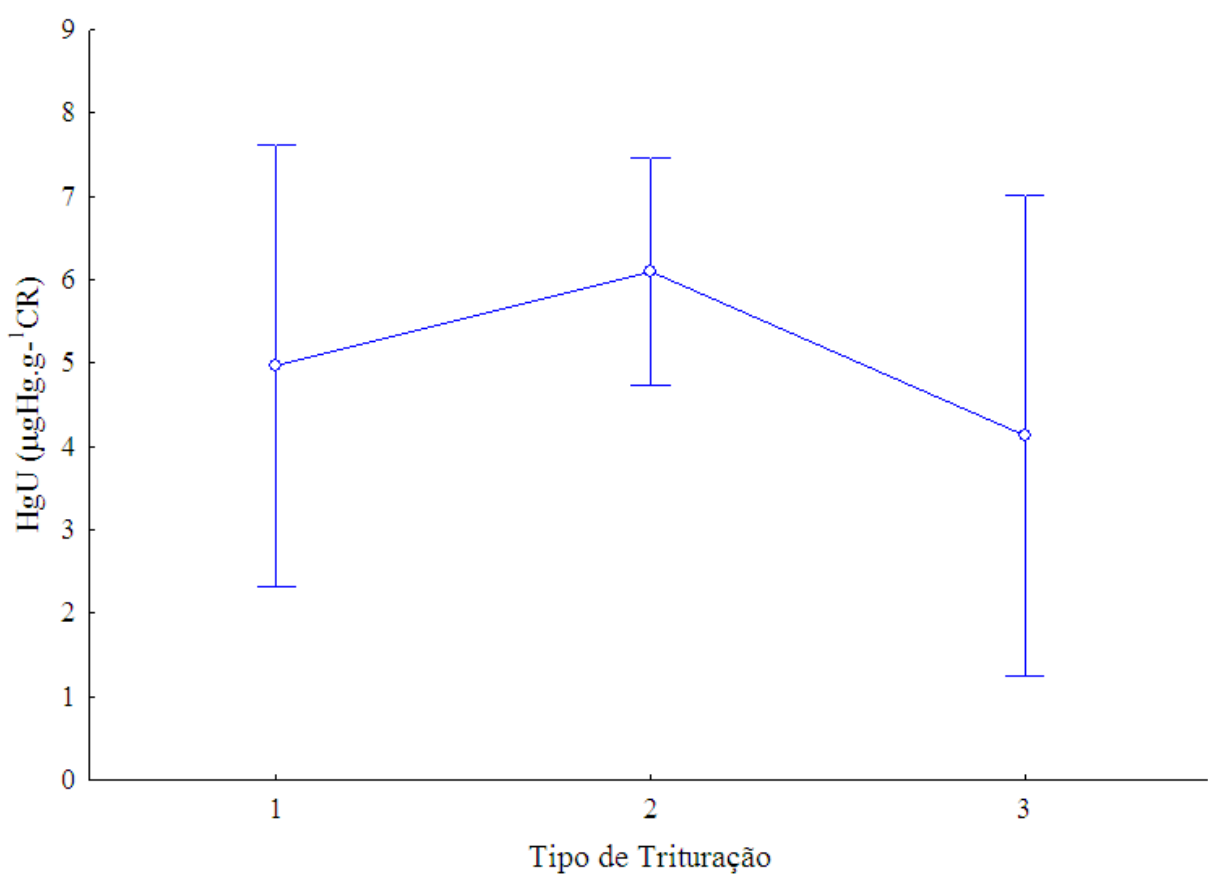

FIGURA 18 - Representação gráfica da comparação entre as formas de trituração e HgU por meio da análise ANOVA.

De acordo com a literatura consultada (Naleway et al., 1985; Barregård et al., 1995; Glina et al., 1997; Isacsson, 1997; Langworth et al., 1997; Novembrino et al., 2006), a trituração manual é um fator de risco para exposição ocupacional.

No manual de biossegurança preconizado pelo Ministério da Saúde é recomendado o uso de amalgamadores capsulares para minimizar tais riscos (Brasil, 2006).

A preparação manual do amálgama com gral e pistilo, incluindo pesagem em balança, a não utilização de EPI durante seu manuseio e descarte e o uso de amalgamadores volumétricos mal conservados e descalibrados podem causar exposição ocupacional dos membros da equipe odontológica (Gronka et al., 1970; Osborne, 1992; Zolfaghari et al., 2007).

Entretanto, Glina et al. (1997) avaliaram a exposição ocupacional ao mercúrio metálico no módulo odontológico de uma unidade básica de saúde 
localizada na cidade de São Paulo no qual trabalhavam 05 CD e 03 ACD, com mínimo de 02 anos de exposição ocupacional. Dentre os riscos ocupacionais relacionados ao ambiente de trabalho, foi relatada a exposição ao mercúrio metálico presente no amalgamador; em ranhuras da bancada de inox e pias; na camurça utilizada para homogeneização do amálgama e retirada do excesso de mercúrio; no lixo e cuspideiras; no vidro com água no qual é descartado o excesso de mercúrio; no recipiente de vidro em que o mercúrio é adquirido. Em relação aos processos que envolviam a manipulação do amálgama, os trabalhadores da unidade utilizavam amalgamador mecânico volumétrico, apresentando problemas de vazamento na lateral e trituração deficiente, além de ser necessária a remoção de excessos de mercúrio utilizando camurça que, após uso, era guardada em caixa metálica fechada. Na sua ausência era feita a trituração manual no gral e pistilo.

Langworth et al. (1997) e Zolfaghari et al. (2007) ressaltam que as concentrações atmosféricas de $\mathrm{Hg}$ metálico em consultórios odontológicos são influenciadas pela presença de seus resíduos no piso ao ser o material acidentalmente derramado durante a preparação, inserção e remoção das restaurações. A ventilação do ambiente (sala clínica), as características dos pisos e das paredes, as práticas de higiene dos profissionais da equipe de odontologia e o tipo de trituração do amálgama influenciam diretamente nos riscos da exposição ocupacional.

Rojas et al. (2000) relatam que o restrito ambiente de trabalho aliado à possibilidade de exposição a vapores de mercúrio provenientes do amálgama odontológico gerados durante o armazenamento inadequado de vidros de mercúrio odontológico mal vedados, as etapas da técnica de restauração em amálgama de prata (tipo de trituração da liga, condensação, brunidura e remoção de excessos), a remoção de restaurações insatisfatórias em amálgama, a esterilização de instrumentos que tiveram contato com mercúrio e o manejo de resíduos de mercúrio são a maior fonte de contaminação dos dentistas ao mercúrio elementar.

\subsubsection{Local de descarte dos resíduos de amálgama}

Quando perguntado aos entrevistados $(n=91)$ sobre o local de armazenamento de frascos de mercúrio odontológico cheios, 60,4\% (55) 
responderam guardá-los dentro do consultório, $13,2 \%$ (12) no almoxarifado da unidade de saúde, 9,9\% (9), disseram não armazenar frasco cheio de mercúrio, $7,7 \%$ (7) usar apenas amálgama em cápsula (TAB.17).

TABELA 17 - Destino dos frascos cheios e vazios de $\mathrm{Hg}$ de acordo com os 91 entrevistados na pesquisa.

\begin{tabular}{|c|c|c|c|}
\hline & Variável & $\begin{array}{c}\text { Participantes } \\
\text { (n) }\end{array}$ & $\begin{array}{c}\text { Representatividade } \\
\%\end{array}$ \\
\hline \multicolumn{4}{|c|}{ Destino dos frascos vazios de $\mathrm{Hg}$} \\
\hline & Lixo comum & 28 & 30,8 \\
\hline & Lixo contaminado & 22 & 24,2 \\
\hline & Armazenamento no consultório & 10 & 11,0 \\
\hline & Não respondeu & 31 & 34,0 \\
\hline Total & & 91 & 100 \\
\hline \multicolumn{4}{|c|}{$\begin{array}{l}\text { Local de armazenamento dos frascos cheios } \\
\text { de } \mathrm{Hg}\end{array}$} \\
\hline & Dentro do consultório & 55 & 60,4 \\
\hline & No almoxarifado & 12 & 13,2 \\
\hline & Usa cápsula & 7 & 7,7 \\
\hline & Não armazena & 9 & 9,9 \\
\hline & Não respondeu & 8 & 8,8 \\
\hline Total & & 91 & 100 \\
\hline
\end{tabular}

O destino dos frascos de mercúrio vazios foi avaliado nesta pesquisa e $30,8 \%$ (28) dos entrevistados relataram jogá-los no lixo comum; $24,2 \%$ (22) no lixo contaminado; $11 \%$ (10) armazenarem no próprio consultório e 34,0\% (31) não responderam.

Ferreira \& Appel (1991) relataram que aproximadamente 55\% do amálgama preparado por dentistas são perdidos durante seu preparo e este material é comumente descartado no lixo comum.

Nesta pesquisa, quanto ao local para armazenamento de resíduos de amálgama, 81,3\% (74) dos entrevistados relataram descartar em frasco separado; $3,3 \%$ (3) no lixo comum; 2,2\% (2) no lixo hospitalar; 6,6\% (6) na pia; e 6,6\% (6) não responderam.

Nazar et al. (2005) visitaram 54 das 105 UBS de Belo Horizonte e verificaram que em $46,5 \%$ (25) das unidades os resíduos de amálgama eram armazenados em frascos de vidro com água e em $53,7 \%$ (29) em frascos de plástico com água.

Em relação ao tipo de frasco separado que utilizavam, 45\% (41) relataram o uso de frasco de vidro para armazenamento, $44 \%$ (40) de plástico e 
$11 \%$ (10) não responderam. Em relação à solução utilizada nos frascos de armazenagem, 73,6\% (67) usavam água, 2,2\% (2) álcool, 2,2\% (2) solução fixadora de radiografias, 1,1\% (1) hipoclorito; 20,9\% (19) não responderam.

De acordo com a RDC $n^{\circ} 306$ os resíduos contendo mercúrio devem ser obrigatoriamente segregados de maneira separada e "acondicionados em recipientes sob selo d'água, encaminhados para recuperação" (ANVISA, 2004).

A recomendação da ADA (2003) - Associação Dental Americana - é colocar os resíduos de amálgama em recipientes inquebráveis, hermeticamente fechados e imersos em solução fixadora de radiografias.

Neste estudo, observaram-se falhas quanto ao cumprimento da norma supracitada em alguns dos consultórios odontológicos das unidades básicas de saúde avaliados denotando uma necessidade do serviço público em ter e seguir protocolos conforme a legislação vigente.

Em relação ao descarte do frasco com os resíduos, $42,8 \%$ (39) dos entrevistados disseram entregar para a vigilância sanitária; 34,1\% (31) que nunca descartaram; 7,7\% (7) que devolvem para funcionário da UBS; 3,3\% (3) que encaminham ao almoxarifado; $2,2 \%$ (2) que jogam na fossa; e 9,9\% (9) não responderam. Não foi avaliado neste trabalho se os recipientes com amálgama eram encaminhados para recuperação do mercúrio e prata.

\subsection{Avaliação das soluções para armazenamento de resíduos de amálgama}

Os ensaios para avaliar a eficácia de soluções barreira para vapores de mercúrio provenientes de amálgama odontológico foram realizados até o tempo máximo de 30 dias. Os resultados, apresentados na FIG.19 foram avaliados em função do tempo necessário para que houvesse a vaporização de mercúrio através da solução barreira em diferentes temperaturas de armazenamento.

Ao comparar os resultados obtidos na amostra denominada de "branco" (isenta de solução barreira) com os ensaios contendo as soluções barreira, é possível observar que de alguma forma as soluções testadas ofereceram resistência à vaporização do mercúrio, uma vez que a mudança de coloração nas fitas contendo o indicador (solução de cloreto de paládio) ocorreu primeiro no branco e na sequência nas demais soluções. O tempo máximo de resistência das soluções à vaporização do mercúrio, neste trabalho, é o intervalo 
de tempo em que a solução não permitiu a passagem de vapores de mercúrio, que ao não serem barrados conseguem chegar à superfície da tira de papel embebida com cloreto de paládio.

De maneira geral, pode-se afirmar que existe interação entre o tipo de solução e a temperatura para a determinação do tempo máximo de estocagem (FIG.19).

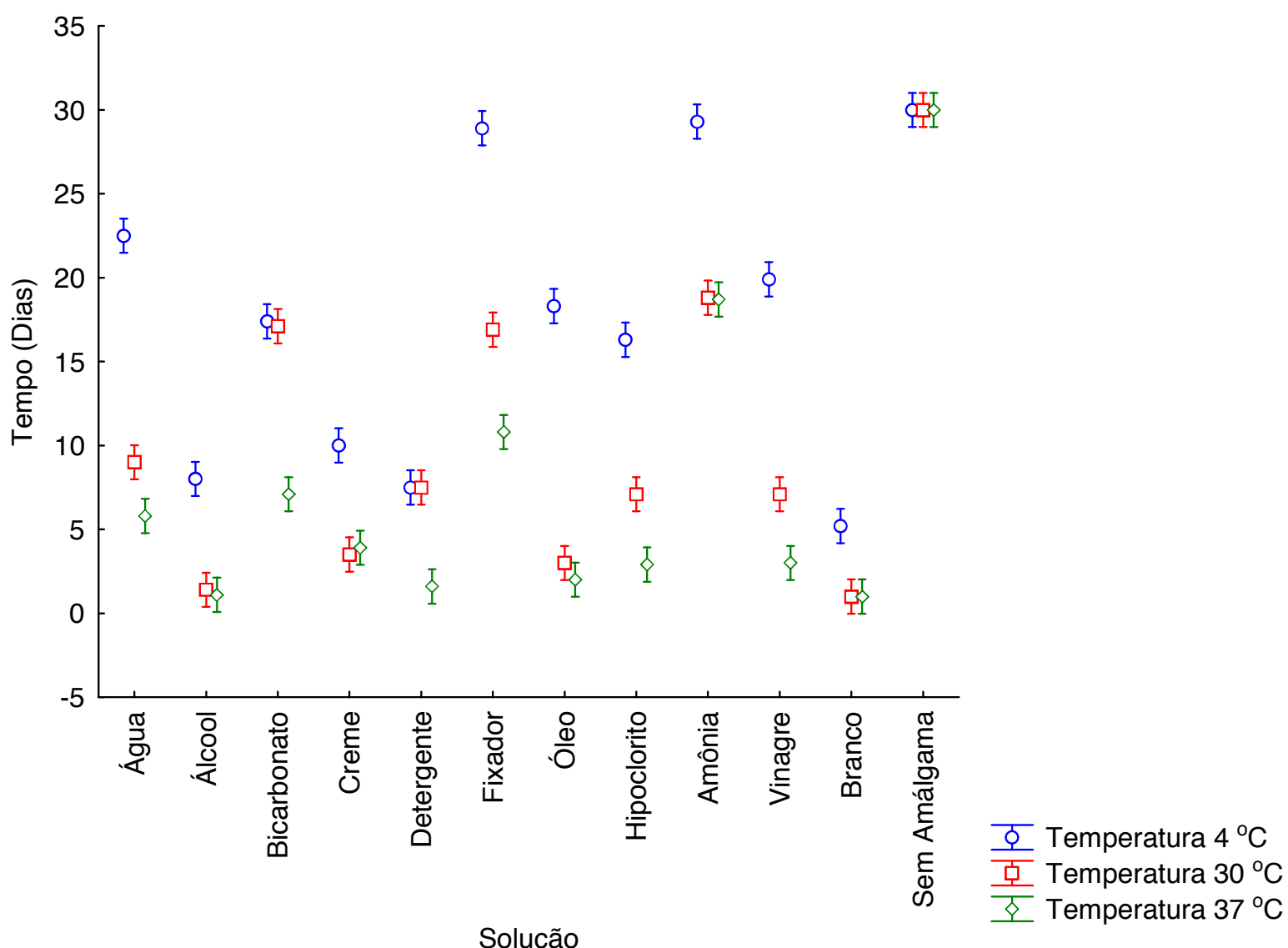

NOTA: Amônia -Solução comercial de limpeza contendo amoníaco.

FIGURA 19 - Representação gráfica do tempo máximo de armazenagem dos resíduos de amálgama odontológico para o sistema com volume de $15 \mathrm{~mL}$, diferentes temperaturas e soluções estoque.

Os experimentos realizados sem a presença de solução barreira (branco) evidenciaram que, para as temperaturas testadas de $30{ }^{\circ} \mathrm{C}$ e $37{ }^{\circ} \mathrm{C}$, houve vaporização de mercúrio em menos de 2 horas, demonstrando uma possível contaminação do ambiente, se não houver cuidados especiais com os 
resíduos de amálgama. Observou-se que a $4{ }^{\circ} \mathrm{C}$ a vaporização do mercúrio ocorreu após 05 dias de estocagem, demonstrando a necessidade de armazenamento dos resíduos em ambiente refrigerado (ANEXO E).

Pela análise de variância ANOVA $(F(22,324)=46.981 ; p<0,01)$ pode-se perceber que o óleo vegetal não apresentou diferenças estatisticamente significantes nas temperaturas de $30{ }^{\circ} \mathrm{C}$ e $37{ }^{\circ} \mathrm{C}$, mas foi mais efetivo como barreira para os vapores de $\mathrm{Hg} \mathrm{a} 4^{\circ} \mathrm{C}$.

A $37^{\circ} \mathrm{C}$, a solução comercial de limpeza contendo amoníaco foi a que apresentou melhor tempo para estocagem dos resíduos (19 dias), seguida da solução fixadora de radiografias (12 dias), da solução de bicarbonato de sódio $50 \%$ (7 dias) e de água (6 dias).

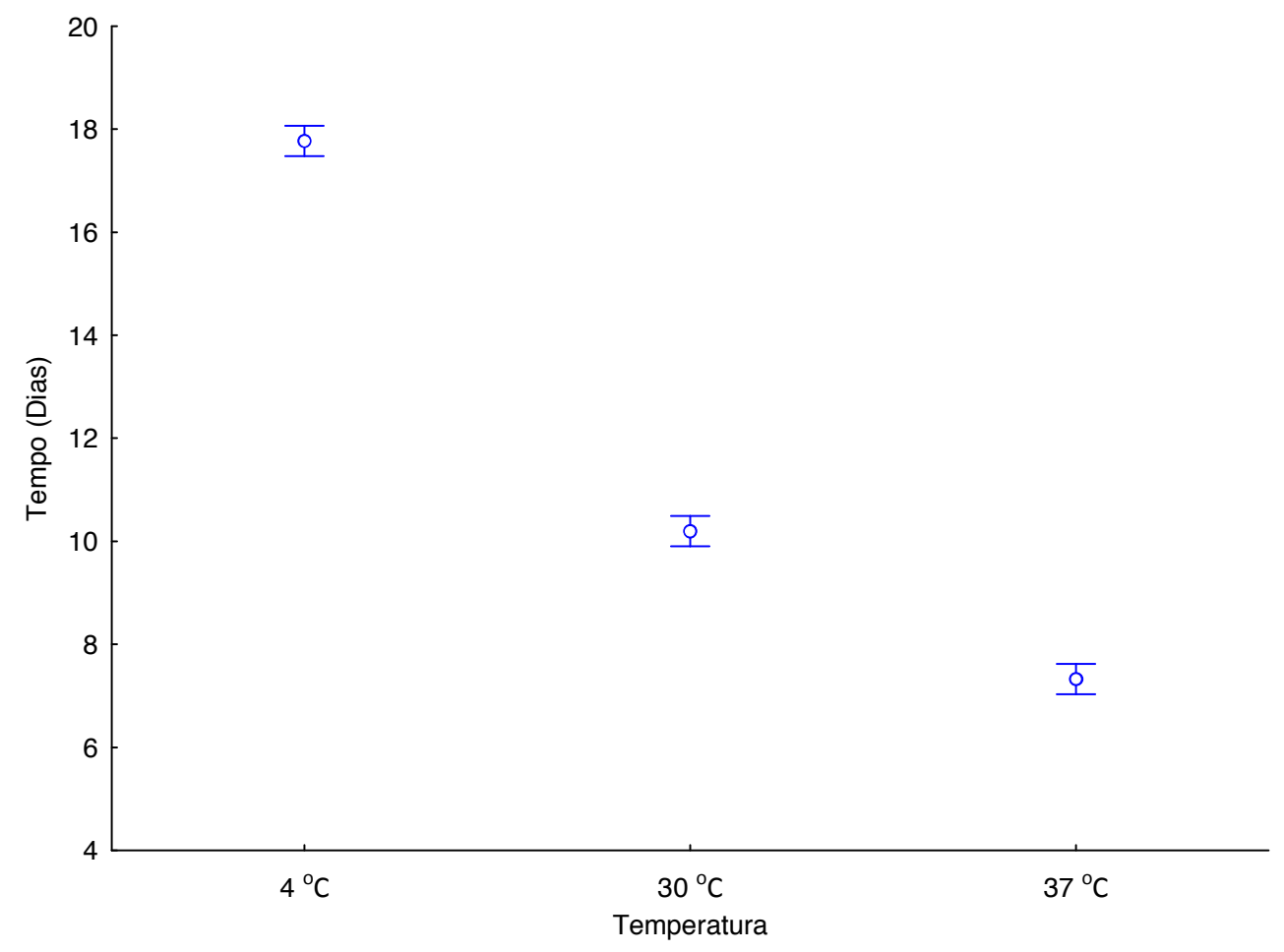

FIGURA 20 - Representação gráfica do tempo máximo de armazenagem dos resíduos de amálgama odontológico para as soluções em diferentes temperaturas.

De um modo geral, considerando todos os tipos de soluções conjuntamente, verificou-se que a temperatura de armazenagem de $4{ }^{\circ} \mathrm{C}$, especificamente, permitiu um maior tempo de armazenamento sem que se observasse a mudança na coloração das tiras contendo cloreto de paládio, indicando uma possível vaporização de $\mathrm{Hg}$, resultado observado na FIG.20. 
Pela análise de variância ANOVA $(F(2,324=1297,8)$ e $p<0,01$, pode-se inferir que o armazenamento dos resíduos incluindo todas as soluções a $4{ }^{\circ} \mathrm{C}$ evita a vaporização do $\mathrm{Hg}$ por mais que o dobro do tempo que a temperatura de $37^{\circ} \mathrm{C}$, provavelmente por impedir a vaporização do $\mathrm{Hg}$, ocorrida próximo a $20^{\circ} \mathrm{C}$.

Considerando que temperatura em Araguaína alcança picos diários de $32{ }^{\circ} \mathrm{C}$ na época de seca (MOTA et al., 2007), sugere- se a partir dos resultados desse estudo que os frascos contendo resíduos de amálgama sejam armazenados sob refrigeração até que os mesmos tenham seu destino final.

Saquy (1996), conseguiu períodos de armazenagem sem a presença de vapor de mercúrio de 17 dias para fixador radiográfico, 14 dias para a água, 9 dias para o óleo vegetal e de 3 dias para álcool etílico, sendo esta última considerada a pior solução para armazenamento, para a temperatura de $25^{\circ} \mathrm{C}$.

Costa et al. (2008) testaram diferentes volumes, soluções barreira e temperaturas e observaram que a temperatura de $25{ }^{\circ} \mathrm{C}$ permitiu, de um modo geral, para todos os sistemas de armazenamento testados, o menor tempo de armazenagem; a solução fixadora foi a que obteve resultados mais satisfatórios em relação ao tempo de armazenamento.

$\mathrm{Na}$ FIG.21 podem ser observadas as soluções estudadas para estocagem dos resíduos de amálgama e o tempo máximo de estocagem das diferentes soluções estudadas. Utilizando ANOVA fatorial $F(11,324)=765,84$; $p<0,01$, observou-se que em relação ao tempo máximo de estocagem o óleo de soja e a solução de hipoclorito não apresentaram diferenças; o mesmo ocorreu para creme hidratante e detergente concentrado. $O$ tubo de ensaio sem "amálgama" foi o que apresentou maior tempo de estocagem e não positivou durante o experimento, confirmando a validade do método utilizado. $\mathrm{O}$ álcool etílico $96 \%$ foi a solução que apresentou a menor eficácia para evitar a vaporização o Hg; já a solução comercial de limpeza contendo amoníaco foi a que apresentou maior tempo de estocagem. 


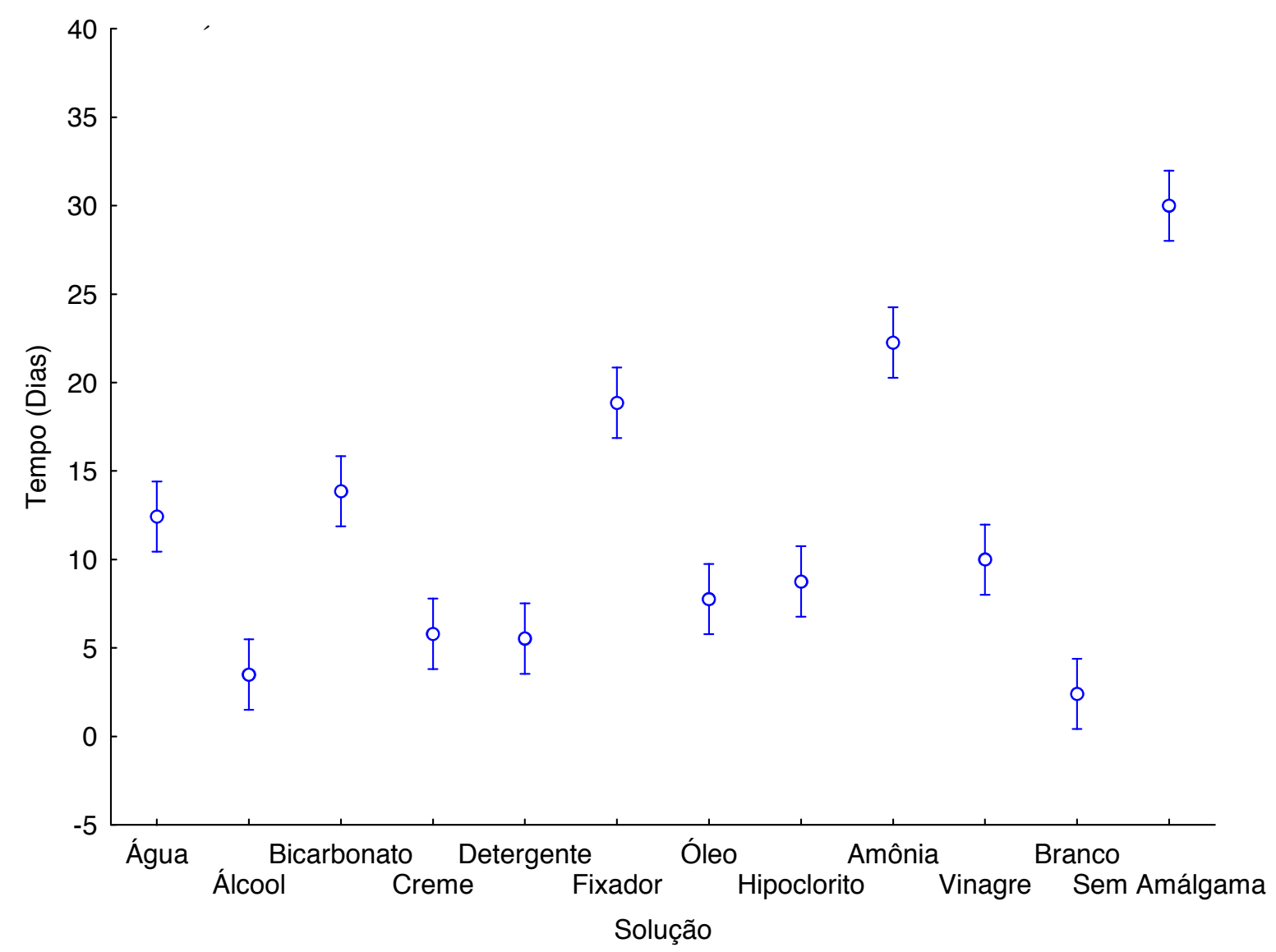

NOTA: Amônia - Solução comercial de limpeza contendo amoníaco.

FIGURA 21 - Representação gráfica do tempo máximo de estocagem (em dias) dos resíduos de amálgama odontológico para as soluções testadas.

Neste trabalho, a temperatura de $37^{\circ} \mathrm{C}$ foi a que apresentou o menor tempo de armazenagem considerando todas as soluções. A solução comercial de limpeza contendo amoníaco foi a que apresentou maior tempo de armazenamento e o álcool etílico $96 \%$ o menor a $30{ }^{\circ} \mathrm{C}$ (FIG.21). 


\section{CONCLUSÕES}

De acordo com os resultados obtidos pode-se concluir que o uso do amálgama de prata como material restaurador para dentes posteriores no município de Araguaína é significativo, de acordo com os dados pesquisados no DATASUS.

Foi observada uma discrepância entre os dados informados ao DATASUS e os dados reais de restaurações de amálgama de prata realizados nos município de Araguaína, provavelmente causado pela transcrição de dados manuais para dados informatizados.

Com relação à contaminação por mercúrio, a concentração média do $\mathrm{HgU}$ observada no período de estudo, de novembro de 2008 a maio de 2009, para o grupo denominado de "expostos" $(\mathrm{n}=91)$ foi aproximadamente 8 vezes maior se comparada com a concentração de mercúrio do grupo controle ou de "não expostos" ( $n=43)$.

Deve ser observado que o grupo denominado de "expostos", avaliado neste estudo, foi formado por três categorias distintas: (a) voluntários que trabalhavam como cirurgiões-dentistas nas equipes do "Estratégia Saúde da Família" de Araguaína, TO ( $\mathrm{n}=8$, do total de 35 CD convidados); (b) auxiliares de saúde bucal de Araguaína, TO ( $\mathrm{n}=44$, do total de 51 ASB convidados); (c) alunos do Curso de Auxiliar de Saúde Bucal da Escola Técnica de Saúde Dr. Gismar Gomes em Araguaína, que trabalhavam em consultórios odontológicos em outros municípios do estado do Tocantins ( $n=39$, do total de 50 alunos convidados).

Esses resultados indicam a necessidade da realização do monitoramento biológico periódico nos profissionais da equipe odontológica.

No que concerne aos cuidados com armazenamento, a temperatura de estocagem dos resíduos de amálgama influencia na vaporização do mercúrio, recomendando a estocagem dos mesmos em geladeira. Como resultados, obteve-se que a $37^{\circ} \mathrm{C}$ a solução comercial de limpeza contendo amoníaco foi a que apresentou melhor tempo para estocagem dos resíduos (19 dias), seguida do fixador de radiografias (12 dias), e da solução de bicarbonato de sódio a 50\% (7 dias), pelo fato de serem barreiras químicas. 
Neste estudo, observaram-se falhas quanto ao cumprimento das normas supracitadas em alguns dos consultórios odontológicos das unidades básicas de saúde avaliados, denotando uma necessidade do serviço público em ter e seguir protocolos conforme a legislação vigente.

O projeto permitiu avaliar os riscos ocupacionais e a exposição ao mercúrio utilizado em odontologia aos quais os auxiliares em saúde bucal (ASB) da rede pública de saúde de Araguaína - TO - estão expostos. Os resultados deste estudo em conjunto indicam que há exposição ocupacional dos profissionais atuantes nos consultórios odontológicos públicos de Araguaína ao mercúrio, mesmo em baixos níveis, mas superior se comparada aos valores médios encontrados em literatura. Cuidados especiais devem ser observados quanto à temperatura do ambiente de trabalho, bem como de armazenamento dos amalgamas contendo mercúrio e seus resíduos, uma vez que a temperatura ambiente da região norte apresenta uma variação anual de $20^{\circ} \mathrm{C}$ a $34^{\circ} \mathrm{C}$ (média de $\left.28^{\circ} \mathrm{C}\right)$.

Sugere-se, a partir dos resultados deste estudo, uma avaliação médica e psicológica dos profissionais da equipe odontológica para verificação de sinais e sintomas de intoxicação mercurial. 


\section{RECOMENDAÇÕES AOS PROFISSIONAIS EXPOSTOS AO MERCÚRIO}

- Não manuseie frascos de vidro de mercúrio vivo; caso seja imprescindível sua aquisição, dê preferência aos frascos de plástico;

- use preferencialmente cápsulas pré-dosadas de amálgama ao amalgamador volumétrico;

- verifique semanalmente se o amalgamador volumétrico não apresenta vazamentos nos compartimentos de mercúrio;

- calibre o amalgamador volumétrico de acordo com as recomendações do fabricante para dispensar o uso de camurça para remoção de excessos antes da inserção do amálgama no preparo cavitário;

- não manuseie amálgama, mercúrio vivo tampouco resíduos dos mesmos sem estar com os EPIs (máscara e luvas);

- acondicione os resíduos de amálgama em frascos plásticos com tampa, pois estes não apresentam riscos de quebra; coloque no frasco o máximo possível de uma solução comercial de limpeza que contenha amoníaco em sua composição; no prazo máximo de 15 dias, entregue o frasco cheio de resíduos à vigilância sanitária;

- para verificar se a solução de limpeza que você tem disponível em seu consultório contém amoníaco ou amônia, leia no verso do frasco a composição química do produto; caso não seja possível adquiri-la, utilize água;

- não utilize frascos de vidro para armazenar os resíduos de amálgama e nem álcool $97 \%$ ou $70 \%$, pois estes não barram os vapores de mercúrio desprendidos dos resíduos de amálgama;

- caso você tenha, inevitavelmente, que remover o excesso de mercúrio da massa de amálgama, utilize uma gaze que pode ser descartada no mesmo frasco usado para acondicionamento dos resíduos de amálgama; 
- se você tem disponível apenas o gral e pistilo para preparar o amálgama, solicite à secretaria municipal de saúde de seu município que os substitua por amalgamador capsular o mais rápido possível;

- solicite seu monitoramento biológico anual para saber a dosagem de mercúrio presente no seu corpo;

- procure um médico do trabalho ou um Centro de Referência em Saúde do Trabalhador caso você suspeite de estar intoxicado por mercúrio;

- o amálgama oferece risco à sua saúde, portanto não o manuseie sem estar paramentado com os EPI. 


\section{APÊNDICE A - Aprovação do Comitê de Ética}

\begin{tabular}{|l|l|c|}
\hline & \multicolumn{2}{|c|}{ COMITE DE ETICA EM PESQUISA - CEP } \\
\hline \multicolumn{2}{|c|}{ PARECER CONSUBSTANCIADO } & \multirow{2}{*}{ PROCESSO NO } \\
\hline PROUETO DE PESQUISA & $\mathrm{X}$ & 103 \\
\hline TRABALHO DE CONCLUSĂO DE CURSO & & \\
\hline
\end{tabular}

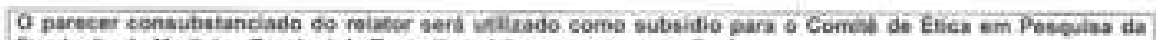
Fundagto de Mesicina Tropical do Tecantins elabover seu parecer fival.

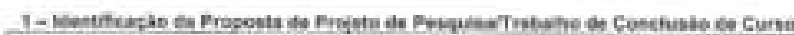

Tum Avaliaço dos nivein de exposiçso ambiental a ocupacional ao mercúrio ne atencimento odonsolbgico nos conaulórios púbilcot de Araguaina-Tocartins.

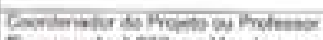

Femanda Viatsor Xavier

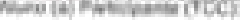

Conerivacise

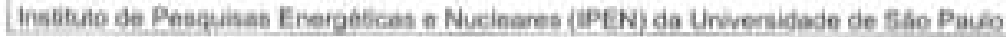

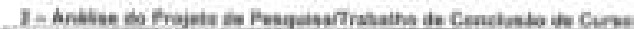

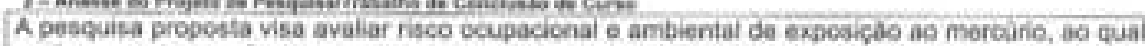
estás exposios piofissionais da equpe atwiliar de odomologia da rode poblica de eaúde de Araguaina, bem ceme evaliar procedimentos de biobsegurança adotados no manuseio do mercuino

O estudo é pertinente e possui valor cientifico, visto que sa propde a ser realizado em uma regiấ onde existe escossez de informaples cientificas na áfea, podendo gerer informacbes que podem consibuir para a meihoria das condiçbes de trabaiho da equipo de odoritologia e reduça dos riscos de exposiçlo ao mercairio.

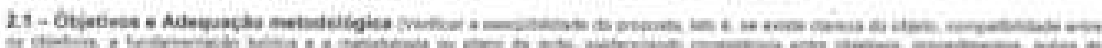

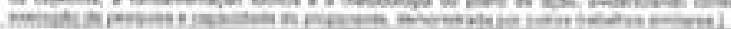

- Os cojativos seo claros, concisos e estlo respaldedos peia Aundansentacas tecrica

- A metodologia 6 exegälvel e atende aos obletivos peopesice

- O cronograma de execusa esta edequado

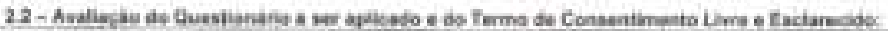

Os questonarios apresentados estato adequados a siendem aos objetwon do projeto.

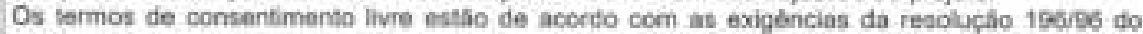
CNS.

13-Revisau nahowaks

Salisfacans

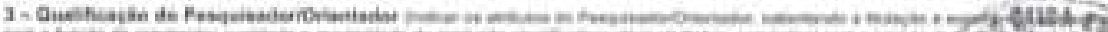

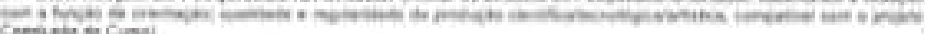
monester cive:

Adequada. 


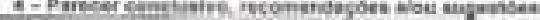

As reccennendecoles de correcie foram alendidas

O- Pahtaneses it

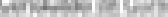

Nilo se apica

\$ - Fuecer Cossubsumiado

\begin{tabular}{|c|c|c|c|}
\hline Apersaso $X$ & 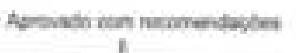 & Pindbecia & Nabe apriveda \\
\hline 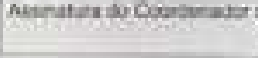 & 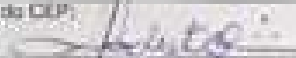 & Gatuer mons: & $12 / 03 / 2008$ \\
\hline
\end{tabular}

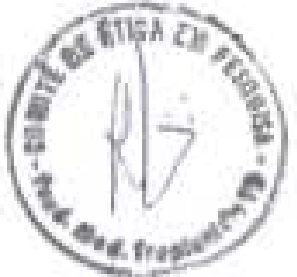

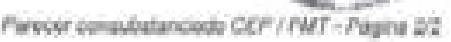




\begin{tabular}{|c|c|c|c|}
\hline 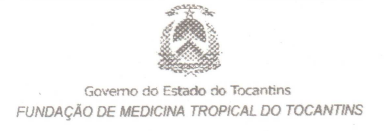 & \multicolumn{3}{|c|}{ COMITÊ DE ÉTICA EM PESQUISA - CEP } \\
\hline \multicolumn{3}{|c|}{ PARECER CONSUBSTANCIADO } & \multirow{3}{*}{$\begin{array}{c}\text { PROCESSO № } \\
\underline{268}\end{array}$} \\
\hline \multicolumn{2}{|l|}{ PROJETO DE PESQUISA } & $\mathbf{X}$ & \\
\hline TRABALHO DE CONCLU & E CURSO & & \\
\hline
\end{tabular}

O parecer consubstanciado do relator será utilizado como subsídio para o Comitê de Ética em Pesquisa da Fundação de Medicina Tropical do Tocantins elaborar seu parecer final.

1 - Identificação da Proposta de Projeto de Pesquisa/Trabalho de Conclusão de Curso

Título:

Avaliação dos níveis de exposição ocupacional ao mercúrio em membros da equipe de odontologia.

Coordenador do Projeto ou Professor Orientador do TCC

Fernanda Villibor Xavier

Aluno(a) Participante (TCC):

Curso/ Faculdade:

Fundação de Medicina Tropical do Tocantins.

2 - Análise do Projeto de Pesquisa/Trabalho de Conclusão de Curso

O projeto visa avaliar os riscos ocupacionais em membros de equipes de odontologia atuantes no

Sistema Único de Saúde (SUS) e que são alunos do curso de auxiliar de consultório dentário de Araguaína. A pesquisa é relevante e poderá fornecer importantes dados sobre a contaminação de profissionais e ambiente de trabalho por resíduos de mercúrio, podendo contribuir para modificação de atitudes profissionais e desenvolvimento de políticas públicas voltadas ao monitoramento e gerenciamento de resíduos contaminantes na área de odontologia.

2.1 - Objetivos e Adequação metodológica (Verificar a exeqüibilidade da proposta, isto é, se existe clareza do objeto, compatibilidade entre os objetivos, a fundamentação teórica e a metodologia ou plano de açăo, evidenciando consistência entre objetivos, procedimentos, açōes de execucão da pesquisa e capacidade do proponente, demonstrada por outros trabalhos similares.)

- Os objetivos são claros, concisos e estão respaldados pela fundamentação teórica.

- A metodologia é exeqüível e contempla os objetivos propostos.

- Na metodologia não foi apresentada qualquer forma de tratamento estatístico, no entanto, julgase que o pesquisador irá, de posse dos dados, selecionar o método mais adequado para análise. - O cronograma de execução está adequado.

2.2 - Avaliação do Questionário a ser aplicado e do Termo de Consentimento Livre e Esclarecido:

O Termo de Consentimento Livre e Esclarecido contempla as exigências da resolução $n^{\circ} 196 / 96$. O questionário está adequado e atende ao previsto nos objetivos, necessitando apenas pequenos ajustes.

2.3 - Revisão Bibliográfica

A revisão de literatura é ampla, atual e fornece embasamento satisfatório.

3 - Qualificação do Pesquisador/Orientador (Indicar os atributos do Pesquisador/Orientador, salientando a titulação e experiência compativel com a funçāo de orientação; qualidade e regularidade da produção científica/tecnológica/artística, compativel com o projeto de pesquisa/trabalio de conolusấdecurso)

A coordenadora da pesquisa possui formação e experiência demonstrada por produção científica na área da pesquisa. 
4- Parecer conclusivo, recomendaçōes elou sugestöes:

- Sugere-se retirar do questionário a ser aplicado no grupo controle a questão 1, visto que os controles sabidamente não deverão ter trabalhado com o contaminante, como explicitado no item 4.1.4.

- Acrescentar no questionário nos itens 16, 17, 24, 25 e 26 a opção "não se aplica" e acrescentar nos itens 18, 19,22, 23 e 27 a opção "Outro destino" "Qual?" pois a resposta a estes questionamentos poderão não estar na lista de opções.

5 - Pendências: (Enumerar sucintamente as pendências a serem sanadas pelo Coordenador do Projeto de Pesquisa/Trabalho de Conclusăon dias. (Enso Não se aplica. Năo se aplica.

6 - Parecer Consubstanciado

Aprovado $\bigotimes$

Pendências $\square$

Não aprovado

Assinatura do Coordenador do CEF P $07 / 10 / 2009$

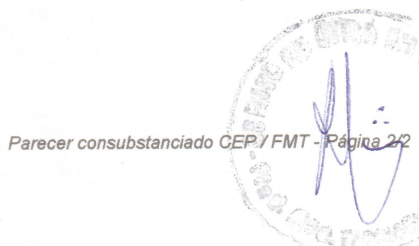




\title{
APÊNDICE B - Certificados dos Materiais de Referência
}

\author{
REFERENCES
}

[1] Christopher, S.J.; Long, S.E.; Rearick, M.S.; Fassett, J.D.; Development of High Accuracy Vapor Generation Inductively Coupled Plasma Mass Spectrometry and its Application to the Certification of Mercury in Standard Reference Materials; Anal. Chem., Vol. 73, pp. 2190-2199 (2001).

[2] ISO; Guide to the Expression of Uncertainty in Measurement; ISBN 92-67-10188-9, 1st ed.; International Organization for Standardization: Geneva, Switzerland (1993); see also Taylor, B.N.; Kuyatt, C.E.; Guidelines for Evaluating and Expressing the Uncertainty of NIST Measurement Results; NIST Technical Note 1297; U.S. Government Printing Office: Washington, DC (1994); available at http//physics nist gov/Puhs/

Certificate Revision History: 19 August 2008 (Certified value for $\mathrm{Hg}$ revised; extension of certification period); 30 December 1999 (Original certificate date

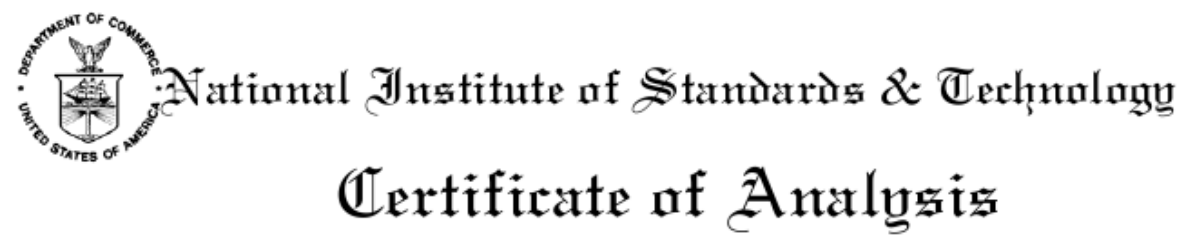

\author{
Standard Reference Material $^{\circledR} 2670 \mathrm{a}$ \\ Toxic Elements in Urine (Freeze-Dried)
}

This Standard Reference Material (SRM) is primarily intended for use in evaluating the accuracy of clinical methods and for the calibration of apparatus used to determine the concentration of toxic metals and other elements in human urine or similar matrices. It can also be used to validate working or secondary reference materials. A unit of SRM 2670a consists of four bottles of freeze-dried urine, two bottles each at the low and high levels. Before use, the urine in each bottle is to be reconstituted with $20.00 \mathrm{~mL}$ of high purity deionized water (see Instructions for Use). The low level urine was prepared from human urine that was lyophilized after pooling and centrifugation. The high level urine was prepared by spiking an aliquot of the pooled and homogenized low-level urine with selected metals, followed by lyophilization. Due to the centrifugation (which improved sample homogeneity), neither level represents a fresh urine pool from a normal human population.

The certified, reference, and information concentration values apply only to properly reconstituted urine at room temperature $\left(20^{\circ} \mathrm{C}\right.$ to $25^{\circ} \mathrm{C}$, see Instructions for Use).

Expiration of Certification: The certification of this SRM is valid within the measurement uncertainties specified until 31 December 2012, provided the SRM is handled and stored in accordance with the instructions given in this certificate (see Instructions for Use). However, the certification will be nullified if the SRM is contaminated or modified.

Maintenance of SRM Certification: NIST will monitor this SRM over the period of its certification. If substantive technical changes occur that affect the certification before expiration of this certificate, NIST will notify the purchaser. Return of the attached registration card will facilitate notification.

Analytical measurements on this SRM were performed by C.M. Beck II, T.A. Butler, W.R. Kelly, S.E. Long, E.A. Mackey, J.L. Mann, M.S. Rearick, R.D. Vocke, Jr., L.J. Wood and L.L. Yu and by Ö. Ertaș, a Research Associate at NIST in the NIST Analytical Chemistry Division. R.L. Jones and G. Shakirova at the Centers for Disease Control and Prevention (CDC), Atlanta, GA and D.E. Nixon at the Mayo Clinic, Rochester, MN performed additional analytical measurements. 
The CDC provided partial financial support for the development of this SRM under the direction of project officers E.W. Gunter, D.C. Paschal, and R.L. Jones of the National Center for Environmental Health, Division of Laboratory Sciences, Atlanta, GA.

The lyophilization and bottling operations were carried out by Bio-Rad Laboratories, Hercules, CA

C. Hagwood of the NIST Statistical Engineering Division provided consultation on the evaluation of the data.

The overall direction and coordination of the analyses were under the chairmanship of R.D. Vocke, Jr. and G.C. Turk of the NIST Analytical Chemistry Division.

The support aspects involved in the issuance of this SRM were coordinated through the NIST Standard Reference Materials Program by B.S. MacDonald of the NIST Measurement Services Division.

Willie E. May, Chief Analytical Chemistry Division

Gaithersburg, MD 20899

Certificate Issue Date: 11 August 2003

John Rumble, Jr., Chief Measurement Services Division

NOTICE AND WARNINGS TO USERS: SRM 2670a IS INTENDED FOR IN-VITRO DIAGNOSTIC USE ONLY. THIS IS A HUMAN SOURCE MATERIAL AND SHOULD BE TREATED AS A BIOHAZARDOUS SUBSTANCE CAPABLE OF TRANSMITTING INFECTIOUS DISEASE. THE RECONSTITUTED URINE SHOULD BE HANDLED WITH PRECAUTIONS SUITABLE FOR FRESH URINE.

INSTRUCTIONS FOR USE: In order for the Certified concentrations to be valid, this SRM must be reconstituted as follows. Remove the bottle from the refrigerator, and allow it to equilibrate at room temperature before reconstitution. Carefully remove the metal seal. Take extra care in removing the rubber stopper, as some of the lyophilized urine may adhere to it. Using a Type I, Class A calibrated volumetric transfer pipette or other dispenser of known accuracy, add $20.00 \mathrm{~mL}$ of CAP/NCCLS Type I water [1] or equivalent to each bottle. After replacing the stopper, the bottle should be allowed to stand at room temperature with occasional swirling for 30 minutes to ensure complete dissolution. DO NOT SHAKE. Vigorous shaking causes foaming, which may lead to an inhomogeneous distribution of the analytes within the bottle. Allow $2 \mathrm{~h}$ for reconstitution. After reconstitution, the contents should be used immediately or stored between $2{ }^{\circ} \mathrm{C}$ and $8{ }^{\circ} \mathrm{C}$ until ready for use, preferably within $12 \mathrm{~h}$. Density measurements made on the reconstituted material with a micro-pycnometer gave values of $1.0024 \pm 0.0003$ $\mathrm{g} / \mathrm{mL}$ for both levels of SRM 2670a.

Stability and Storage: The urine comprising SRM 2670a is lyophilized (freeze-dried) material and should be stored in a refrigerator at a temperature between $2{ }^{\circ} \mathrm{C}$ and $8{ }^{\circ} \mathrm{C}$ until ready for use. It should not be frozen or exposed to sunlight or ultraviolet radiation. After reconstitution, the contents should be used immediately or stored between $2{ }^{\circ} \mathrm{C}$ and $8{ }^{\circ} \mathrm{C}$ until ready for use, preferably within $12 \mathrm{~h}$. Some of the elements, most notably $\mathrm{Hg}$, are volatile and are progressively lost after reconstitution. Freezing of the reconstituted material is not recommended.

Certified Values and Uncertainties: Certified concentration values for 10 elements in the low level and 14 elements in the high level of SRM 2670a are listed in Table 1. A NIST certified value is a value for which NIST has the highest confidence in its accuracy in that all known or suspected sources of bias have been investigated or accounted for by NIST. All values are reported on a mass/volume basis [2] (see Instructions for Use) and are based on mea surements using the entire lyophilized sample mass. 
Table 1. Certified Concentration Values

\begin{tabular}{|c|c|c|c|c|c|c|c|c|}
\hline \multirow[b]{2}{*}{ Element } & \multicolumn{4}{|c|}{ Low Level } & \multicolumn{4}{|c|}{ High Level } \\
\hline & Quantity & Units & Uncertainty & $k$ & Quantity & Units & Uncertainty & $k$ \\
\hline Antimony & 0.971 & $\mu \mathrm{g} / \mathrm{L}$ & \pm 0.033 & 2.45 & 0.824 & $\mu \mathrm{g} / \mathrm{L}$ & \pm 0.070 & 2.57 \\
\hline Cadmium & 0.0591 & $\mu \mathrm{g} / \mathrm{L}$ & \pm 0.0034 & 2.36 & 4.862 & $\mu \mathrm{g} / \mathrm{L}$ & \pm 0.084 & 2.36 \\
\hline Cesium & 1.075 & $\mu \mathrm{g} / \mathrm{L}$ & \pm 0.031 & 2.57 & 1.085 & $\mu \mathrm{g} / \mathrm{L}$ & \pm 0.052 & 2.31 \\
\hline Cobalt & 0.166 & $\mu \mathrm{g} / \mathrm{L}$ & \pm 0.040 & 2.09 & 51.2 & $\mu \mathrm{g} / \mathrm{L}$ & \pm 3.2 & 2.23 \\
\hline Iodine $^{2}$ & 88.2 & $\mu \mathrm{g} / \mathrm{L}$ & \pm 1.1 & 2.00 & 88.2 & $\mu \mathrm{g} / \mathrm{L}$ & \pm 1.1 & 2.00 \\
\hline Lead & 0.49 & $\mu \mathrm{g} / \mathrm{L}$ & \pm 0.16 & 2.57 & 233.2 & $\mu \mathrm{g} / \mathrm{L}$ & \pm 9.4 & 2.57 \\
\hline Mercury & 0.0663 & $\mu \mathrm{g} / \mathrm{L}$ & \pm 0.0058 & 2.57 & 95.1 & $\mu \mathrm{g} / \mathrm{L}$ & \pm 0.98 & 2.00 \\
\hline Manganese & $\cdots$ & ... & -.. & $\cdots$ & 99 & $\mu \mathrm{g} / \mathrm{L}$ & \pm 12 & 2.78 \\
\hline Molybdenum & ... & $\ldots$ & $\ldots$ & ... & 114.1 & $\mu \mathrm{g} / \mathrm{L}$ & \pm 4.8 & 2.01 \\
\hline Platinum & $\ldots$ & ... & ... & ... & 51.5 & $\mu \mathrm{g} / \mathrm{L}$ & \pm 6.6 & 2.00 \\
\hline Selenium & ... & ... & ... & ... & 229.5 & $\mu \mathrm{g} / \mathrm{L}$ & \pm 8.3 & 2.57 \\
\hline Thallium & 0.0162 & $\mu \mathrm{g} / \mathrm{L}$ & \pm 0.0045 & 3.18 & 5.417 & $\mu \mathrm{g} / \mathrm{L}$ & \pm 0.064 & 2.36 \\
\hline Thorium & 0.0053 & $\mu \mathrm{g} / \mathrm{L}$ & \pm 0.0014 & 2.57 & 0.01606 & $\mu \mathrm{g} / \mathrm{L}$ & \pm 0.00077 & 2.45 \\
\hline Uranium & 0.1020 & $\mu \mathrm{g} / \mathrm{L}$ & \pm 0.0023 & 2.57 & 4.997 & $\mu \mathrm{g} / \mathrm{L}$ & \pm 0.071 & 4.30 \\
\hline
\end{tabular}

${ }^{2}$ Iodine concentrations, as measured, are for lodide

The certified values for cadmium, iodine, lead, mercury, thallium, thorium and uranium are the means of results obtained by NIST using isotope dilution-inductively coupled plasma mass spectrometry (ID-ICPMS). The expanded uncertainties are calculated as prediction intervals where $U=k u_{\mathrm{c}}$. The uncertainty component $u_{\mathrm{c}}$ is intended to represent, at the level of one standard deviation, the combined standard uncertainty calculated according to the ISO Guide [3]. The coverage factor, $k$, is determined from the Student's $t$-distribution for the appropriate degrees of freedom to yield $95 \%$ confidence. The certified values and uncertainties for the remaining elements are derived from the results of at least one analysis performed at NIST and independent results from one or more methods provided by the CDC (Atlanta, GA) and/or the Mayo Clinic, (Rochester, Minnesota) using the approach described by Levenson, et al. [4] for combining results from multiple methods. Multiple method results from the laboratories outside NIST were first combined to give a single value and uncertainty before being combined with the NIST results. The certified value is an unweighted mean of the results from NIST and these laboratories. The uncertainty listed with each value is an expanded uncertainty about the mean, $U=k u_{\mathrm{c}}$, with a coverage factor $k$ determined from the Student's $t$-distribution for the appropriate degrees of freedom to yield $95 \%$ confidence. Each $u_{\mathrm{c}}$ is calculated by combining a between-method variance [4] with a pooled, within-method variance [3]. Analytical methods are listed in Appendix A.

Reference Values and Uncertainties: Reference concentration values for 7 elements at the low level and 8 elements at the high level are given in Table 2. Reference values are non-certified values that are the best estimate of the true value; however, the values do not meet the NIST criteria for certification and are provided with associated uncertainties that may not include all sources of uncertainty. 
Table 2. Reference Concentration Values

\begin{tabular}{|c|c|c|c|c|c|c|}
\hline \multirow[b]{2}{*}{ Element } & \multicolumn{3}{|c|}{ Low Level } & \multicolumn{3}{|c|}{ High Level } \\
\hline & Quantity & Units & Uncertainty & Quantity & Units & Uncertainty \\
\hline Calcium & 29 & $\mathrm{mg} / \mathrm{L}$ & \pm 2 & 30 & $\mathrm{mg} / \mathrm{L}$ & \pm 2 \\
\hline Magnesium & 21.0 & $\mathrm{mg} / \mathrm{L}$ & \pm 0.2 & 21.2 & $\mathrm{mg} / \mathrm{L}$ & \pm 0.2 \\
\hline Potassium & 410 & $\mathrm{mg} / \mathrm{L}$ & \pm 10 & 415 & $\mathrm{mg} / \mathrm{L}$ & \pm 10 \\
\hline Sodium & 856 & $\mathrm{mg} / \mathrm{L}$ & \pm 15 & 942 & $\mathrm{mg} / \mathrm{L}$ & \pm 20 \\
\hline Arsenic & -.. & -.. & -.. & 220 & $\mu \mathrm{g} / \mathrm{L}$ & \pm 10 \\
\hline Copper & ... & -.. & $\ldots$ & 110 & $\mu \mathrm{g} / \mathrm{L}$ & \pm 4 \\
\hline Manganese & 2.6 & $\mu \mathrm{g} / \mathrm{L}$ & \pm 0.7 & -.. & -.. & -.. \\
\hline Selenium & 8 & $\mu \mathrm{g} / \mathrm{L}$ & \pm 3 & $\cdots$ & $\cdots$ & $\cdots$ \\
\hline Tin & -.. & -.. & $\cdots$ & 89 & $\mu \mathrm{g} / \mathrm{L}$ & \pm 7 \\
\hline Zinc & 130 & $\mu \mathrm{g} / \mathrm{L}$ & \pm 30 & 410 & $\mu \mathrm{g} / \mathrm{L}$ & \pm 30 \\
\hline
\end{tabular}

The reference concentration values are based either on the results of a single NIST method or on the results of a single NIST method and one or more outside laboratories methods. Reference values and uncertainties were derived from multiple results in the same manner as was done for the certified values and uncertainties. Zinc, an important analyte in urine, was not certified in SRM 2670a due to possible contamination from the stopper used in the packaging. Analytical methods are listed in Appendix A.

Information Values: Information concentration values are provided in Table 3. An information value is considered to be a value that will be of interest and use to the SRM user, but insufficient information is available to assess the uncertainty associated with the value.

Table 3. Information Concentration Values

\begin{tabular}{|c|c|c|c|c|}
\hline \multirow[b]{2}{*}{ Element } & \multicolumn{2}{|c|}{ Low Level } & \multicolumn{2}{|c|}{ High Level } \\
\hline & Quantity & Units & Quantity & Units \\
\hline Aluminum & 4 & $\mu \mathrm{g} / \mathrm{L}$ & 100 & $\mu \mathrm{g} / \mathrm{L}$ \\
\hline Arsenic & 3 & $\mu \mathrm{g} / \mathrm{L}$ & $\ldots$ & $\ldots$ \\
\hline Barium & 2 & $\mu \mathrm{g} / \mathrm{L}$ & 2 & $\mu \mathrm{g} / \mathrm{L}$ \\
\hline Beryllium & ... & $\mu \mathrm{g} / \mathrm{L}$ & 5 & $\mu \mathrm{g} / \mathrm{L}$ \\
\hline Chromium & 2 & $\mu \mathrm{g} / \mathrm{L}$ & 20 & $\mu \mathrm{g} / \mathrm{L}$ \\
\hline Copper & 5 & $\mu \mathrm{g} / \mathrm{L}$ & -.. & $\cdots$ \\
\hline Molybdenum & 17 & $\mu \mathrm{g} / \mathrm{L}$ & -.. & $\ldots$ \\
\hline Nickel & 2 & $\mu \mathrm{g} / \mathrm{L}$ & 100 & $\mu \mathrm{g} / \mathrm{L}$ \\
\hline Tin & $<1$ & $\mu \mathrm{g} / \mathrm{L}$ & $\cdots$ & $\ldots$ \\
\hline Tungsten & $<1$ & $\mu \mathrm{g} / \mathrm{L}$ & $<1$ & $\mu \mathrm{g} / \mathrm{L}$ \\
\hline Vanadium & $<1$ & $\mu \mathrm{g} / \mathrm{L}$ & 30 & $\mu \mathrm{g} / \mathrm{L}$ \\
\hline
\end{tabular}




\section{REFERENCES}

[1] Preparation and Testing of Reagent Water in the Clinical Laboratory; Approved Guideline - Third Edition, NCCLS document C3-A3, NCCLS, Wayne, Pennsylvania (1997).

[2] Taylor, B.N.; Guide for the Use of the International System of Units (SI); NIST Special Publication 811, 1995 Ed.; U.S. Government Printing Office: Washington, DC (1995).

[3] Guide to the Expression of Uncertainty in Measurement, ISBN 92-67-10188-9, 1st Ed. ISO, Geneva, Switzerland (1993); see also Taylor, B.N.; Kuyatt, C.E.; Guidelines for Evaluating and Expressing the Uncertainty of NIST Measurement Results; NIST Technical Note 1297, U.S. Government Printing Office: Washington, DC (1994); available at htp//physics nist gov/Pubs/

[4] Levenson, M.S.; Banks, D.L.; Eberhardt, K.R.; Gill, L.M.; Guthrie, W.F.; Liu, H.K.; Vangel, M.G.; Yen, J.H.; Zhang, N.F.; An Approach to Combining Results from Multiple Methods Motivated by the ISO GUM; J. Res. Natl. Inst. Stand. Technol., Vol. 105, pp. 571-579 (2000).

\section{Appendix A. Methods Used in Analyte Determinations}

\section{Method}

Cold Vapor Isotope Dilution Inductively Coupled Plasma Mass Spectrometry at NIST

Isotope Dilution Inductively Coupled Plasma Mass Spectrometry at $\quad \mathrm{Cd}, \mathrm{I}, \mathrm{Pb}, \mathrm{Th}, \mathrm{Tl}, \mathrm{U}$

NIST

Standard Additions Inductively Coupled Plasma Mass

Spectrometry at NIST

Inductively Coupled Plasma Mass Spectrometry at NIST (High

Level only)

Instrumental Neutron Activation Analysis at NIST

Inductively Coupled Plasma Atomic Emission Spectrometry at

NIST

Flame Emission Spectrometry at NIST

Inductively Coupled Plasma Mass Spectrometry at the CDC,

Atlanta, GA

Inductively Coupled Plasma Mass Spectrometry at the Mayo Clinic,

Rochester, MN

Electrothermal Vaporization Atomic Absorption Spectrometry at the Mayo Clinic, Rochester, MN

\section{Analytes Determined}

$\mathrm{Hg}$

$\mathrm{Mn}, \mathrm{Al}, \mathrm{V}$

$\mathrm{As}, \mathrm{Co}, \mathrm{Cu}, \mathrm{Mn}, \mathrm{Mo}, \mathrm{Pt}, \mathrm{Se}, \mathrm{Sn}$

$\mathrm{Co}, \mathrm{Cs}, \mathrm{Sb}, \mathrm{Se}, \mathrm{Zn}$

$\mathrm{Ca}, \mathrm{K}, \mathrm{Mg}$

$\mathrm{Na}$

$\mathrm{Be}, \mathrm{Ba}, \mathrm{Cd}, \mathrm{Co}, \mathrm{Cs}, \mathrm{Mo}, \mathrm{Pb}, \mathrm{Pt}, \mathrm{Sb}, \mathrm{Tl}, \mathrm{U}, \mathrm{W}$

$\mathrm{Al}, \mathrm{As}, \mathrm{Cd}, \mathrm{Co}, \mathrm{Cr}, \mathrm{Cu}, \mathrm{Hg}, \mathrm{I}, \mathrm{Mn}, \mathrm{Mo}, \mathrm{Ni}$, $\mathrm{Pb}, \mathrm{Pt}, \mathrm{Sb}, \mathrm{Se}, \mathrm{Sn}, \mathrm{Tl}, \mathrm{V}, \mathrm{Zn}$

$\mathrm{Al}, \mathrm{Cr}, \mathrm{Mn}$ 


\section{ANEXO A - CÓPIA DO TERMO DE CONSENTIMENTO LIVRE E ESCLARECIDO DO GRUPO CONTROLE}

\section{TERMO DE CONSENTIMENTO LIVRE E ESCLARECIDO}

Você está sendo convidado (a) a participar, como voluntário (a) de uma pesquisa. Após ser esclarecido (a) sobre as informações a seguir, no caso de aceitar fazer parte do estudo, assine ao final deste documento, que está em duas vias. Uma delas é sua e a outra do pesquisador responsável. Em caso de dúvida você pode procurar o Comitê de Ética em Pesquisa da Fundação de Medicina Tropical do Tocantins, pelo através do telefone (63) 3415-8300.

Titulo do Projeto de Pesquisa: Avaliação dos níveis de exposição ocupacional ao mercúrio em membros da equipe odontológica.

A Fundação de Medicina Tropical do Tocantins e o Instituto de Pesquisas Energéticas e Nucleares, através da Pesquisadora Fernanda Villibor Xavier, estão realizando um estudo para verificar o nível conhecimento sobre biossegurança e de exposição ocupacional ao mercúrio de membros da Equipe de Saúde Bucal que trabalham nos consultórios públicos e que são alunos do curso de Auxiliar de Saúde Bucal e Técnico em Saúde Bucal da Escola Técnica de Saúde do Tocantins, ETSUS. Através desse estudo poderão ser implantadas ações para prevenir e diagnosticar precocemente a contaminação por mercúrio nos trabalhadores desta Equipe e promover cursos de biossegurança. A pesquisa será realizada através de um questionário contendo 10 perguntas e coletas de amostras de urina dos participantes. Os frascos utilizados para coleta de urina são individuais, esterilizados e descartáveis, não causando nenhum prejuízo a sua saúde utilizá-lo. Esta pesquisa pode trazer como inconveniente a perda de tempo em responder o questionário e o tempo gasto para coleta das amostras de urina.

Por intermédio deste Termo lhe são garantidos os seguintes direitos:

Solicitar, a qualquer tempo, maiores esclarecimentos sobre esse estudo; 2. Sigilo absoluto e a privacidade sobre nomes, apelidos, nome do posto de saúde em que trabalha e qualquer informação que possa levar à identificação pessoal; 3. Absoluta possibilidade de negar-se a responder qualquer questão ou informação que julgue prejudicial à sua integridade física, moral e social; 4. Desistir a qualquer tempo de participar da pesquisa; 5. Não ter qualquer custo para participar da pesquisa.

"Declaro estar ciente das informações constantes neste 'Termo de Consentimento Livre e Esclarecido', e entender que serei resguardado (a) pelo sigilo absoluto dos meus dados pessoais, sem qualquer ônus sobre minha participação no estudo (pesquisa). Poderei pedir a qualquer momento, esclarecimentos sobre este estudo, recusar a dar informação que julgue prejucidial a minha pessoa, solicitar a não inclusão em documentos de quaisquer informações que já tenha fornecido e desistir, a qualquer momento de participar da pesquisa. Fico ciente de que uma cópia deste termo ficará arquivada com a pesquisadora da Fundação de Medicina Tropical do Tocantins, responsável por esta pesquisa."

Nome completo do participante da pesquisa:

Assinatura do participante da pesquisa:

Pesquisadora responsável pela pesquisa: Fernanda Villibor Xavier.

Assinatura da responsável pela pesquisa

Pesquisadoras Participantes: Dra Maria Aparecida Faustino Pires;

Endereço profissional da pesquisadora responsável: Av. Dionísio Farias, 838. Bairro de Fátima.

Araguaína, TO.Tel: $0^{* *} 633415-8300$ ou $0^{* *} 6392098097$ ou 0**63 3411-1530

Araguaína, de de 200 


\section{ANEXO B - TERMO DE CONSENTIMENTO LIVRE E ESCLARECIDO DO GRUPO “EXPOSTOS”}

\section{TERMO DE CONSENTIMENTO LIVRE E ESCLARECIDO}

Você está sendo convidado (a) a participar como voluntário (a) de uma pesquisa. Após ser esclarecido (a) sobre as informações a seguir, no caso de aceitar fazer parte do estudo, assine ao final deste documento, que está em duas vias. Uma delas é sua e a outra do pesquisador responsável. Em caso de dúvida você pode procurar o Comitê de Ética em Pesquisa da Fundação de Medicina Tropical do Tocantins através do telefone (63) 3415-8300.

Titulo do Projeto de Pesquisa: Avaliação dos níveis de exposição ocupacional ao mercúrio em membros da equipe odontológica.

A Fundação de Medicina Tropical do Tocantins e o Instituto de Pesquisas Energéticas e Nucleares, através da Pesquisadora Fernanda Villibor Xavier, estão realizando um estudo para verificar o nível conhecimento sobre biossegurança e de exposição ocupacional ao mercúrio de membros da Equipe de Saúde Bucal que trabalham nos consultórios públicos e que são alunos do curso de Auxiliar de Saúde Bucal e Técnico em Saúde Bucal da Escola Técnica de Saúde do Tocantins, ETSUS. Através desse estudo poderão ser implantadas ações para prevenir e diagnosticar precocemente a contaminação por mercúrio nos trabalhadores desta Equipe e promover cursos de biossegurança. A pesquisa será realizada através de um questionário contendo perguntas sobre contato com mercúrio e normas de biossegurança e coletas de amostras de urina dos participantes. Os frascos utilizados para coleta de urina são individuais, esterilizados e descartáveis, não causando nenhum prejuízo a sua saúde utilizá-lo. Esta pesquisa pode trazer como inconveniente a perda de tempo em responder o questionário e o tempo gasto para coleta das amostras de urina.

Por intermédio deste Termo lhe são garantidos os seguintes direitos:

Solicitar, a qualquer tempo, maiores esclarecimentos sobre esse estudo; 2. Sigilo absoluto e a privacidade sobre nomes, apelidos, nome do posto de saúde em que trabalha e qualquer informação que possa levar à identificação pessoal; 3. Absoluta possibilidade de se negar a responder qualquer questão ou informação que julgue prejudicial à sua integridade física, moral e social; 4. Desistir a qualquer tempo de participar da pesquisa; 5. Não ter qualquer custo para participar da pesquisa.

"Declaro estar ciente das informações constantes neste 'Termo de Consentimento Livre e Esclarecido', e entender que serei resguardado (a) pelo sigilo absoluto dos meus dados pessoais, sem qualquer ônus sobre minha participação no estudo (pesquisa). Poderei pedir a qualquer momento, esclarecimentos sobre este estudo, recusar a dar informação que julgue prejucidial a minha pessoa, solicitar a não inclusão em documentos de quaisquer informações que já tenha fornecido e desistir, a qualquer momento de participar da pesquisa. Fico ciente de que uma cópia deste termo ficará arquivada com a pesquisadora da Fundação de Medicina Tropical do Tocantins, responsável por esta pesquisa."

Nome completo do participante da pesquisa:

Assinatura do participante da pesquisa:

Pesquisadora responsável pela pesquisa: Fernanda Villibor Xavier.

Assinatura da responsável pela pesquisa

Pesquisadoras Participantes: Dra Maria Aparecida Faustino Pires;

Endereço profissional da pesquisadora responsável: Av. Dionísio Farias, 838. Bairro de Fátima. Araguaína, TO.Tel: $0^{* *} 63$ 3415-8300 ou 0** 6392098097 ou 0*63 3411-1530

Araguaína, de de 200 


\section{ANEXO C - QUESTIONÁRIO APLICADO AO GRUPO CONTROLE}

\section{Questionário (grupo controle)}

Título da pesquisa: Avaliação dos níveis de exposição ocupacional ao mercúrio em membros da equipe odontológica

Pesquisadora responsável pelo projeto: Fernanda Villibor Xavier

Entrevistadora : Fernanda Villibor Xavier Data da entrevista: / 200_Número: (_)

1. Você já trabalhou em consultório odontológico? ( ) Sim ( ) Não

2. Qual a sua idade completa? anos

3. Assinale seu sexo: ( ) Masculino ( ) Feminino

4. Qual seu peso atual? ___ $\mathrm{kg}$

5. Qual a sua altura?

6. Quantas restaurações de amálgama de prata você tem na boca?

7. Qual a sua renda familiar em salários mínimos?
( ) até 01 salário mínimo
( ) de 01 a 02 salários mínimos
( ) de 02 a 03 salários mínimos
( ) de 03 a 04 salários mínimos
( ) Mais de 04 salários mínimos

8. Você usa tintura nos cabelos? ( ) não ( ) sim

9. Com qual frequência você come peixe
( ) uma vez por ano
( ) uma vez por mês
( ) mais de uma vez por mês
( ) uma vez por semana
( ) mais de duas vezes por semana
( ) não como peixe

10. Você já morou próximo a uma zona de garimpo (local de exploração de ouro)?
( ) não
( ) $\operatorname{sim}$
( ) não me lembro 


\section{ANEXO D - QUESTIONÁRIO APLICADO AO GRUPO "EXPOSTOS” Questionário}

Título da pesquisa: Avaliação dos níveis de exposição ocupacional ao mercúrio em membros da equipe odontológica.

Pesquisadora responsável pelo projeto: Fernanda Villibor Xavier

Entrevistadora: Fernanda Villibor Xavier. Data da entrevista:

1. Você faz parte da equipe de Saúde Bucal do Estratégia Saúde da Família?

$$
\text { ( ) Sim ( ) Não }
$$

2. Qual a sua idade completa? anos

3. Assinale seu sexo: ( ) Masculino ( ) Feminino

4. Há quanto tempo você trabalha em consultório odontológico? anos

5. Qual seu peso atual? $\mathrm{kg}$

6. Qual a sua altura?

7. Quantas restaurações de amálgama de prata você tem na boca?

8. Quantas horas por dia você trabalha no consultório? ( ) 2h ( )4h ( ) 6h ( )8h

9. Qual a sua renda familiar em salários mínimos?
( ) até 01 salário mínimo
( ) de 01 a 02 salários mínimos
( ) de 02 a 03 salários mínimos
( ) de 03 a 04 salários mínimos
( ) Mais de 04 salários mínimos

10. Você já recebeu algum curso ou treinamento sobre normas de biossegurança antes de trabalhar? ( ) Sim ( ) Não

11. No consultório onde você trabalha tem um lixo específico para jogar o material contaminado por sangue e lou saliva? ( ) Sim ( ) Não

12. No consultório onde você trabalha é realizada todos os dias alguma restauração utilizando o amálgama de prata? ( ) Sim ( ) Não

13. Quando você prepara o amálgama para seu dentista, como você faz para medir a quantidade de mercúrio de cada porção?
( ) Coloco mercúrio até o amálgama dar liga
( ) Uso uma balança para pesar (crandall)
( ) Uso amálgama em cápsula
( ) Outra opção - (amalgamador volumétrico)

14. Quando você prepara o amálgama para seu dentista, como você faz para misturar a limalha com o mercúrio?

( ) Misturando no gral e pistilo

( ) Usando amalgamador volumétrico (limalha colocada de um lado do aparelho e o mercúrio no outro)

( ) Usando amalgamador de cápsula individual

15. Após preparar o amálgama, você costuma usar um pano ou camurça para tirar o que sobra de mercúrio antes de entregar o amálgama para o seu dentista? ( ) Sim ( ) Não

16. Você pega nesse pano ou camurça sem estar usando luvas? ( ) Sim ( ) Não

17. Esse pano ou camurça é lavado? ( ) Sim ( ) Não

18. Em qual lugar você guarda os vidros de mercúrio novos (cheios) até que eles sejam usados?

( ) Não guardo vidros cheios. Só peço outro acaba o que eu estou usando

( ) Guardo dentro do consultório

( ) Guardo no almoxarifado da Unidade de Saúde em que trabalho

( ) Uso amálgama em cápsula 
19. O que você faz com os vidros vazios de mercúrio:
( ) Jogo no lixo comum
( ) Jogo no lixo onde descarto material contaminado de sangue e saliva
( ) Guardo consultório

20. Já aconteceu de quebrar acidentalmente um frasco cheio de mercúrio dentro do consultório?
( ) Sim
( ) Não

21. No seu consultório você é o responsável por lavar e esterilizar os materiais? ( ) Sim ( ) Não

22. Em qual local você descarta as lâminas de bisturi e as agulhas que foram usadas para sutura e anestesia (perfurocortantes)?
( ) no lixo comum
( ) no lixo hospitalar
( ) frasco separado
( ) na pia

23. Em qual local você joga os resíduos de amálgama?
( ) lixo comum
( ) lixo hospitalar
( ) caixa descarpack
( ) frasco de plástico rígido

24. Se você usa um frasco separado, ele é de: ( ) vidro ( ) plástico

25. Nesse frasco, você coloca algum líquido? ( ) Sim ( ) Não

26. Se você coloca algum líquido, qual é?
( ) água da torneira
( ) álcool
( ) solução fixadora de radiografias
( ) água sanitária
( ) outros líquidos. Qual?

27. O que você faz com o frasco quando ele está cheio de resíduos?
( ) entrego para um funcionário da administração do posto de saúde
( ) encaminho para a vigilância sanitária do município
( ) nunca descartei o frasco pois ele ainda não ficou cheio
( ) devolvo o frasco para o almoxarifado
( ) jogo na fossa

28. Qual o método de esterilização principal que você usa no consultório em que você trabalha?
( ) estufa
( ) autoclave
( ) solução química (glutaraldeído) 
29. Você utiliza os equipamentos de proteção individual com qual frequência?

$\begin{array}{llll}\text { Avental / jaleco } & \text { ( ) sempre } & \text { ( ) às vezes } & \text { ( ) nunca } \\ \text { Calça comprida } & \text { ( ) sempre } & \text { ( ) às vezes } & \text { ( ) nunca } \\ \text { Gorro } & \text { ( ) sempre } & \text { ( ) às vezes } & \text { ( ) nunca } \\ \text { Luvas } & \text { ( ) sempre } & \text { ( ) às vezes } & \text { ( ) nunca } \\ \text { Máscara } & \text { ( ) sempre } & \text { ( ) às vezes } & \text { ( ) nunca } \\ \text { Óculos de proteção } & \text { ( ) sempre } & \text { ( ) às vezes } & \text { ( ) nunca } \\ \text { Sapato fechado } & \text { ( ) sempre } & \text { ( ) às vezes } & \text { ( ) nunca }\end{array}$

30. Você usa tintura nos cabelos? ( ) não ( ) sim

31. Com qual frequência você come peixe?
( ) uma vez por ano
( ) uma vez por mês
( ) mais de uma vez por mês
( ) uma vez por semana
( ) mais de duas vezes por semana
( ) não como peixe

32. Você já morou próximo a uma zona de garimpo (local de exploração de ouro)?
( ) não
( ) sim
( ) não me lembro 


\section{ANEXO E - MÉDIAS DO TEMPO MÁXIMO DE ESTOCAGEM PARA AS SOLUÇÕES ESTUDADAS}

\begin{tabular}{lcccc}
\hline Temperatura & $\begin{array}{c}\text { Média } \\
\text { (dias) }\end{array}$ & Desvio padrão & $\begin{array}{c}\text { Valor } \\
\text { Máximo } \\
\text { (dias) }\end{array}$ & $\begin{array}{c}\text { Valor } \\
\text { Mínimo } \\
\text { (dias) }\end{array}$ \\
\hline $4{ }^{\circ} \mathrm{C}$ & 17,8 & 8,8 & 30 & 5 \\
$30^{\circ} \mathrm{C}$ & 10,2 & 8,5 & 30 & 1 \\
$37^{\circ} \mathrm{C}$ & 7,3 & 8,4 & 30 & 1 \\
& & & & \\
\hline
\end{tabular}

\begin{tabular}{ccccc}
\hline Tipo de solução & $\begin{array}{c}\text { Média de } \\
\text { duração* } \\
\text { (dias) }\end{array}$ & Desvio padrão & $\begin{array}{c}\text { Valor } \\
\text { Máximo } \\
\text { (dias) }\end{array}$ & $\begin{array}{c}\text { Valor } \\
\text { Mínimo } \\
\text { (dias) }\end{array}$ \\
\hline Água & 12,4 & 7,5 & 25 & 5 \\
Álcool & 3,5 & 3,3 & 9 & 1 \\
Bicarbonato & 13,9 & 6,6 & 25 & 7 \\
Creme & 5,8 & 3,0 & 10 & 3 \\
Detergente & 5,5 & 2,8 & 8 & 1 \\
Fixador & 18,9 & 7,9 & 30 & 10 \\
Óleo & 7,7 & 7,6 & 20 & 2 \\
Hipoclorito & 8,7 & 5,8 & 18 & 2 \\
Amônia & 22,3 & 5,1 & 30 & 17 \\
Vinagre & 10 & 7,3 & 20 & 3 \\
Branco & 2,4 & 2,0 & 6 & 1 \\
(sem solução) & & 0 & 30 & 30 \\
Sem amálgama & 30 & & & \\
\hline
\end{tabular}

Nota:* refere-se a média de cinco medições independentes de cada uma das triplicatas realizadas no experimento 


\section{REFERÊNCIAS BIBLIOGRÁFICAS}

1 ABNT. Associação Brasileira de Normas Técnicas. Resíduos sólidos: classificação. NBR 10004. 71p. Rio de Janeiro, 2004.

2 ADA. American Dental Association Council on Scientific Affairs. Dental mercury hygiene recommendations. J. Am. Dent. Assoc., v. 134, p. 1498-9, 2003.

3 AGENCY FOR TOXIC SUBSTANCES AND DISEASE REGISTRY - ATSDR. Toxicologycal profile for mercury: (update). Atlanta: US Department of health and human services. Public Health Service, 1999.

4 ARENHOLT-BINDSLEV, D. Dental amalgam: environmental aspects. Adv. Dent. Res., v. 6, p.125-130, September, 1992.

5 ASANO, S.; ETO, K.; KURISAKI, E.; GUNJI, H.; HIRAIWA, K.; SATO, M.; SATO, H.; HASUIKE, M.; HAGIWARA, N.; WAKASA, H. Acute inorganic mercury vapor inhalation poisoning. Pathol. Int., v. 50, p. 169-174, 2000.

6 AYALA, A.A.; SERNA, C.L.; MOSQUERA ,V.E. Freeze-drying in yellow pitahaya (selenicereus megalanthus). Vitae, v. 17, n. 2, p.121-122, 2010.

7 AYDIN, N.; KARAOGLANOGLU, S.; YIGIT, A.; KELES, M. S.; KIRPINAR, I.; SEVEN, N. Neuropsychological effects of low mercury exposure in dental staff in Erzurum, Turkey. Int. Dent. J., v. 53, p. 85-91, 2003.

8 AZEVEDO, F.A; NASCIMENTO, E. S, CHASIN, A. M. Mercúrio. In: Azevedo FA, Chasin AAM, organizadores. Metais: gerenciamento da toxicidade. São Paulo: Atheneu, p. 299-352, 2003.

9 BARATIERI, L.N.; MONTEIRO JÚNIOR, S.; ANDRADA, M.A.C.de ;VIEIRA, L.C.C.; CARDOSO, A. C. Odontologia restauradora: fundamentos e possibilidades. São Paulo: Santos, 2001. v.1, 739 p.

10 BARREGÅRD L.; SÄLLSTEN, G.; JÄRVHOLM, B. People with high mercury uptake from their own dental amalgam fillings. J. Occup. Environ. Med., v. 52, p. 124-128, 1995.

11 BARREGÅRD, L. Mercury from dental amalgam: looking beyond the average. J. Occup. Environ. Med., v. 62, n. 6, p. 352-253, 2005.

12 BARROS, O. B. Posto de trabalho odontológico: conforto, produtividade e rentabilidade. Maringá: Dental Press, 2006.

13 BATES, M. N. Mercury amalgam dental fillings: an epidemiologic assessment. Int. J. Hyg. Environ. Health, v. 209, p. 309-316, 2006. 
14 BEGEROW J.; ZANDER D.; FREIER, I.; DUNEMANN L. Long-term mercury excretion in urine after removal of amalgam fillings. Int. Arch. Occup.

Environm. Health., v. 66, p. 209-212, 1994.

15 BELLO, S.C.; RODRÍGUEZ, M.C.; FERNÁNDEZ, D.R.; VÁSQUEZ, A. del C.; OCANDO, A.M.; CONTRERAS, J.R.; GRANADILLO, V.A. Niveles de mercurio en cabello de individuos expuestos ocupacionalmente en el area odontologica. Acta Odontol., v. 40, n. 2, 2002.

16 BERRY, T.G.; SUMMITT, J.B.; CHUNG, A.K.H.; OSBORNE, J.W. Amalgam at the new millennium. JADA, v. 129, p. 1549-1556, Nov. 1998.

17 BITTNER, A.C.; ECHEVERRIA, D.; WOODS, J.S.;APOSHIAN, H.V.; NALEWAY, C.; MARTIN, M.D. Behavioral effects of low-level exposure to $\mathrm{Hg}^{\circ}$ among dental professionals: a cross-study evaluation of psychomotor effects. Neurotox. Teratol., v. 24, n.4, p. 429-439, 1998.

18 BRASIL, Agência Nacional de Vigilância Sanitária. ANVISA .RDC n³06 de 7 de dezembro de 2004. Dispõe sobre o regulamento técnico para 0 gerenciamento de resíduos de serviços de saúde. Distrito Federal, Brasília, Brasil, 2004.

19 BRASIL, Ministério da Saúde. Portaria n 104 de 25 de janeiro de 2011. Define as terminologias adotadas em legislação nacional, conforme o disposto no Regulamento Sanitário Internacional 2005 (RSI 2005), a relação de doenças, agravos e eventos em saúde pública de notificação compulsória em todo o território nacional e estabelece fluxo, critérios, responsabilidades e atribuições aos profissionais e serviços de saúde. Distrito Federal, Brasília, Brasil, 2011.

20 BRASIL, Ministério do Meio Ambiente. Conselho Nacional do Meio AmbienteCONAMA. Conselho Nacional do Meio Ambiente. Resolução n 358 de 29 de abril de 2005. Dispõe sobre o tratamento e destinação final de resíduos dos serviços de saúde e dá outras providências. Distrito Federal, Brasília, Brasil, 2005a.

21 BRASIL, Ministério do Trabalho. Portaria $n^{\circ}$ 3214. Diário Oficial da União, 08/06/1978. NR-7, alterada pela Portaria 12. Secretaria de Segurança e Medicina do Trabalho, Ministério do Trabalho. Norma Regulamentadora - NR7 - Programa de controle médico de saúde ocupacional - Alteração Portaria GM/SSSTb n. 24, de 29 de dezembro de 1994 - (DOU 30.12.94).

22 BRASIL. Ministério da Saúde. Agência Nacional de Vigilância Sanitária.

Serviços odontológicos: prevenção e controle de riscos. Brasília: Ministério da Saúde. 156 p. - (Série A. Normas e Manuais Técnicos), 2006.

23 BRASIL. Ministério da Saúde. Política de Saúde Bucal. 2005. Disponível em: <http://www.saude.gov.br>. Acesso em 05 outubro 2006.

24 BROWNAWELL, A.M.; BERENT, S.; BRENT, R.L.; BRUCKNER, J.V.; DOULL, J.; GERSHWIN, E.M. The potential adverse health effects of dental amalgam. Toxicol. Rev., v. 24, p.1-10, 2005. 
25 CAMPOS, T.N; STEAGALL, L. Observação da emissão de vapor de mercúrio com técnica do sulfeto de selênio: parte II. Correlação entre a proporção do mercúrio e a área do halo. Rev. Assoc. Paul. Cir. Dent., v. 42, n. 5, p. 311315, 1988.

26 CANELA, M.C.; Determinação de mercúrio a nível traço: aplicação de amostras de interesse ambiental. Campinas. 1995. Dissertação (Mestrado em Química) - Instituto de Química da Universidade de Estadual de Campinas, São Paulo.

27 CHAARI, N.; KERKENI, A.; SAADEDDINE, S.; NEFFATI, F.; KHALFALLAH, T.; AKROUT, M.; L'imprégnation mercurielle des dentistes et der leurs assistants dans la ville de Monastir, Tunisie. Rev. Stomatol. Chir. Maxillofac., v.10, n. 3, p. 139-144, 2009.

28 CLARKSON, T.W; MAGOS, L. The toxicology of mercury and its chemical compounds. Crit. Rev. Toxicol., v. 36, p. 609-662, 2006.

29 CLARO, F.A; ITO, F.R.; BASTOS, F.M; RIBEIRO, M.E. Mercúrio no amálgama odontológico: riscos da exposição, toxicidade e métodos de controle: revisão da literatura. Disponível em: <http://www.bvsde.paho.org/ bvsacd/ cd49/mercurio amalg-N1-2003.pdf>. Acesso em: 23 jul 2007.

30 COSTA, R.D.; COSSICH, E.S.; TAVARES, C.R.G. Influence of the temperature, volume and type of solution in the mercury vaporization of dental amalgam residue. Sci. Total. Environ., v. 407, n.1, p.1-6, 2008.

31 COUNCIL ON DENTAL MATERIALS AND DEVICES. Status report on amalgamators and mercury/alloy proportioners and disposable capsules. $\boldsymbol{J}$. Am. Dent. Assoc., v. 85, n. 4, p. 928-932, 1972.

32 DALLA COSTA, R. Diagnóstico da geração e tratamento dos resíduos gerados pela utilização do amálgama odontológico. 2008. Tese (Doutorado em Engenharia Química) - Universidade Estadual de Maringá, Maringá, Paraná.

33 DATASUS. Banco de dados do Sistema Único de Saúde. Disponível em: <www.datasus.com.br. Acesso em: 02 jan. 2009.

34 DAVIS, B.J; PRICE, H.C.; O'CONNOR, R.W.; FERNANDO, R.R.A.S.; MORGAN, D.L. Mercury vapor na female reproductive toxicity. Toxicol. Sci., v. 59, p. 251-296, 2001.

35 DRUMMOND, J.L.; CAILAS, M.D.; CROKE, K. Mercury generation potential from dental waste amalgam. J. Dent., v. 31, p. 493-501, 2003.

36 DUNCAN, A.; O'REILLY, D.StJ; MACDONALD, E.B.; WATKINS, T.R.; TAYLOR, M. Thirty-five year review of a mercury monitoring service for Scottish dental practices. Br. Dent. J., v. 210, n. 3, 2011. 
37 DUNNE, S. M.; GAINSFORD, I. D; WILSON, N. H. F. Current materials and techniques for direct restorations in posterior teeth. Part 1: silver amalgam. Int. Dent. J., v. 47, n. 3, p. 123-136, 1997.

38 DURAN, S.M.; LIMA, A.G.; GONÇALVES, S.E.P. Adhesive amalgam with glass ionomer cement: evaluation of the storage time on microleakage. Rev. Odontol. UNESP, v. 33, n. 1, p. 19-23, jan./mar. 2004.

39 ECHEVERRIA, D.; HEYER, N.J.; MARTIN, M.D.; NALEWAY, C.A; WOODS, J.S. Behavioral effects of low-level exposure to $\mathrm{Hg}^{\circ}$ among dentists.

Neurotox. Teratol., v. 17, n. 2, p. 161-8, 1995.

40 FARIA, M.A.M. Mercurialismo metálico crônico ocupacional. Rev. Saude Publica, v. 37, n. 1, p. 116-27, 2003.

41 FELIPE, L.A.; VIEIRA, L.C.C.; DANKER; A.L. Amálgama dental: fatos e controvérsias. Rev. APCD, v. 53, n.1, 41-5, 1999.

42 FERREIRA, R.C.H.; APPEL, L.E.; In: Ann. I Inter. Symp. on Environmental Studies on Tropical Rain Forests, Manaus, 1991.

43 FINNKBEINER, B.L. Selecting equipament for the ergonomic four-handed dental practice. J. Contemp. Dent. Pract.,v. 2, n. 4, p. 44-52, 2001.

44 FORTES, C.B.B.; SAMUEL, S.M.W. Avaliação de meios para armazenagem de resíduos de amálgama de prata. Rev. Fac. Odontol. Porto Alegre, v. 40, n. 1, p. 36-40, 1999.

45 FRIBERG, L.; NORDBERG, G. F.; VOUK, V.B. Handbook on the toxicology of metals. Amsterdam: Elsevier, 1979.

46 FUKS, A.B. The use of amalgam in pediatric dentistry. Pediatr. Dent., v. 24, p. 448-55, 2002.

47 GARBIN, A.J.I.; GARBIN, C.A.S.; ARCIERI, R.M.; CROSSATO, M.; FERREIRA, N.F. Biosecurity in public and private office. J. Appl. Oral Sci., v. 13, n. 2, p. 163-166, 2005.

48 GARCIA, L.P.; ZANETTI-RAMOS, B.G. Gerenciamento dos resíduos de serviços de saúde: uma questão de biossegurança. Cad. Saude Publica, v. 20, n. 3, p. 744-752, 2004.

49 GASPAR, J.G. Araguaína e sua região: saúde como reforço da polarização. 2002. Dissertação (Mestrado em Geografia) - Universidade Federal de Pernambuco, Recife, Pernambuco.

50 GIACHETTI, N. J. Resumos de Dentística. UNISA, São Paulo, p. 83-88, 1999.

51 GLINA, D.M.R.; SATUT, B.T.G.; ANDRADE, E.M.O.A.C. Occupational exposure to metallic mercury in the dentist's office of a public primary health care clinic in the city of São Paulo. Cad. Saude Publica, Rio de Janeiro, v. 13, n. 2, 1997. 
52 GOLDMAN, L.R.; SHANNON, M.W. Technical report: mercury in the environment: implications for pediatricians. American Academy of

Pediatrics: Committee on Environmental Health, v. 108, n. 1, p. 197-205, 2001.

53 GRANDJEAN, P.; GULDAGER, B.; LARSEN, I.B.; JORGENSEN, P.J.; HOLMSTRUP, P. Placebo response in environmental disease chelation therapy of with symptoms attributed to amalgam fillings. J. Occup. Environ. Med., v. 39, p .39, 707-14, 1997.

54 GRAZIANO, K.U; GRAZIANO, R.W. Limpeza, desinfecção e esterilização de artigos odontológicos e cuidados com o ambiente. In: Associação Paulista de Estudos e Controle de Infecção Hospitalar (APECIH). Controle de infecção na prática odontológica. São Paulo; 2000. p. 11-2412.

55 GRIGOLETTO, J. C.; OLIVEIRA, A.S.; MUÑOZ, S.I.S.; ALBERGUINI, L.B.A.; TAKAYANAGUI, A.M.M. Exposição ocupacional por uso de mercúrio em odontologia: uma revisão bibliográfica. Cienc. Saude Colet., v. 13, n. 2, p. 533-542, 2008.

56 GRONKA, P.A.; BOBKOSKIE, R.L.; TOMCHICK, S.J.; BACH, R.; RAKOW, A.B. Mercury vapor exposures in dental offices. J. Am. Dent. Assoc., v. 81, p. 923-925, 1970.

57 GUILHEN, S. N. Validação de metodologia analítica para determinação de mercúrio total em amostras de urina por espectrometria de absorção Atômica com geração de vapor frio (CV-AAS). 2009. Dissertação (Mestrado em Ciências na Área de Tecnologia Nuclear - Materiais) - Instituto de Pesquisas Energéticas e Nucleares da Universidade de São Paulo, São Paulo.

58 GUILHEN, S. N.; PIRES, M.A.F.; XAVIER, F.V.; DANTAS, E.S.K. Validação de metodologia analítica para determinação de mercúrio total em amostras de urina por espectrometria de absorção Atômica com geração de vapor frio (CVAAS): estudo de caso. Quim. Nova, v. 33, n. 6, p. 1285-1290, 2010.

59 GUIMARÃES, G. A. Efeitos tóxicos do mercúrio. Ambiente Brasil. Disponível em: <http://www.ambientebrasil.com.br/composer.php3?

base=residuos/index.php3\&conteudo=./residuos/artigos/toxicidade_mercurio.h tml. Acesso em: 08 nov. 2007.

60 GUIMARÃES-JÚNIOR, J.J. Biossegurança e controle de infecção cruzada em consultórios odontológicos. São Paulo: Santos, 2001. v. 1. 536 p.

61 GUZZI, G.; GRANDI, M.; CATTANEO, C.; CALZA, S.; MINOIA, C.; RONCHI, A.; et al. Dental amalgam and mercury levels in autopsy tissues: food for thought. Am. J. Forensic. Med. Pathol., v. 27, p. 42-45, 2006.

62 GUZZI, G.; MINOIA, C. Biological detoxification and mercury dental amalgam. Dent. Res., v. 87, n. 9, p. 800-801, 2008. 
63 HALBACH, S.; VOGT, S.; KOHLER, W.; FELGENHAUER,N.; WELZL, G.; KREMERS, L.; ZILKER, T.;MELCHART, D. Blood and urine mercury levels in adult amalgam patients of a randomized controlled trial: interaction of $\mathrm{Hg}$ species in erythrocytes. Environ. Res., 107, p.69-78, 2008.

64 HÖRSTED-BINDSLEV, P. Amalgam toxicity-environmental and occupational hazards. J. Dent., v. 32, p. 359-365, 2004.

65 HYLANDER, L.D.; LINDVALL, A.; GAHNBERG, L. High mercury emissions from dental clinics despite amalgam separators. Sci. Total Environ., v. 362, p. 74-84, 2006.

66 HYLANDER, L.D.; MEILI, M. 500 Years of mercury production: global annual inventory by region until 2000 and associated emissions. Sci. Total Environ., v. 304, p. 13-27, 2003.

67 IAVICOLI, I.; CARELLI, G.; LAJOLO, C.; RAFFAELLI, L.; MARINACCIO, A.; GIULIANI, M. Biomonitoring of titanium, Mercury, platinum, rhodium and palladium in dental heatlh care workers. Occup. Med., v. 54, n. 8, 564-566, 2004.

68 IBGE. Instituto Brasileiro de Geografia e Estatística. IBGE cidades. Disponível em: <www.ibge.gov.br>. Acesso em 12 fev. 2011.

69 ISACSSON, G.; BARREGÅRD, L.; SELDÉN, A.; BODIN, L. Impact of nocturnal bruxism on mercury uptake from dental amalgams. Eur. J. Oral. Sci., v. 105, p. 251-257, 1997.

70 JOKSTAD, A. Summary of: a thirty-five year of a mercury monitoring service for Scottish dental practices. Br. Dent. J., v. 210, n. 3, p. 122-123, 2011.

71 JOKSTAD, A.; FAN, P.L. Amalgam waste management. Int. Dent. J., v. 56, p. 147-153, 2006.

72 JONES, D.W. A Scandinavian tragedy. Br. Dent. J., v. 205, n. 5, p. 233-234, 2008.

73 JONES, L. M. Focus on fillings: a qualitative health study of people medically diagnosed with mercury poisoning, linked to dental amalgam. Acta

Neuropsychiatr., v. 16, p. 142-148, 2004.

74 JUNG, A. Avaliação do risco de exposição ao mercúrio elementar em uma unidade de terapia intensiva. 2004. 67p. Dissertação (Mestrado em Engenharia) Universidade Federal do Rio Grande do Sul, Porto Alegre.

75 KARAHALIL, B.; RAHRAVI, H; ERTAS, N. Examination of urinary mercury levels in dentists in Turkey. Hum. Exp. Toxicol., v.24, p.383-388, 2005.

76 KAZANTZIS, G. Mercury exposure and early effects: an overview. Med. Lav., v. 93, n. 3, p. 139-47, 2002. 
77 KINGMAN, A.; ALBERTINI, T.; BROWN, L.J. Mercury concentrations in urine and whole blood associated with amalgam exposure in a US Military Population. J. Dent. Res., v. 77, n. 3, p. 461-471, March, 1998.

78 LACERDA, R.A.S.V.; CÂMARA, V.M.; SETTA, D.X.B.; OLIVEIRA, C.F. Odontologia do trabalho: estudo de caso sobre exposição e efeitos do mercúrio sobre a saúde de profissionais da área. $\boldsymbol{R B O}$, v. 59, n. 4, 2002.

79 LANGWORTH, S.; SÄLLSTEN, G.; BARREGARD, L. et al. Exposure to mercury vapor and impact on health in the dental profession in sweden. $J$. Dent. Res., v. 76, n.7, p.1397-1404, 1997.

80 LEE, J.T; PAEK, D. Response to commentary on "Blood lead, cadminum, and mercury concentrations in the Korean population" by Minoia et al. Environ. Res., v. 110, p. 533-534, 2010.

81 LEVY, M.; SCHWARTZ, S.; DIJAK, M.; WEBER, .J.P.; TARDIF, R.; ROUAH, F. Childhood urine mercury excretion: dental amalgam and fish consumption as exposure factors. Environ. Res., v. 94, n. 3, p. 283-290, March, 2004.

82 LOBAS, C.F.S.; MONTEIRO, R.M.; DUARTE, S. THD e ACD: odontologia de qualidade. São Paulo: Santos, 2006.

83 LOPES, A. P. Araguaína-TO: a principal cidade econômica do estado e a periferia que esconde as vítimas do trabalho escravo por dívida. $4^{\circ}$ ENGRUP, p. 739-758, 2008.

84 LOPEZ-COLON, J.L.; LOZANO, R. Determination of mercury levels in blood and urine of occupationaly exposed workers using flow injection with cold vapor AAS. Atom. Spect., v. 27, n. 3, p.98-104, 2006.

85 LOWE, J.M. Mercury vapor exposure in the dental office. Dental Hyg., v. 54, n. 3, p. 118-120, 1980.

86 MARTIN, M.D.; NALEWAY, C.; CHOU, H.N. Factors contributing to mercury exposure in dentists. J. Am. Dent. Assoc., v.126, p. 1502-1511, 1995.

87 MASON, H.J.; HINDELL, P.; WILLIAMS, N. R. Biological monitoring and exposure to mercury. Occup. Med., v. 51, n. 1, p. 2-11, 2001.

88 MASTRANTONIO, S.D.S; COLDEBELLA, C.R; GONDIM, J.O; DINIZ, M.B.; SACONO, N.T.; CORDEIRO, R.C.L. Current view on the use of the bonded amalgam technique: an evaluation among dentists. Rev. Odontol. UNESP, v. 37, n. 4, p. 395-399, 2008.

89 MICARONI, R.C.C.M.; BUENO, M.I.M.S.; JARDIM, W.F. Compostos de mercúrio: revisão de métodos de determinação, tratamento de descarte. Quím Nova, v. 23, n. 4, 2000. Disponível em: < http://www.scielo. br/pdf/qn/v23n4/2648.pdf. >. Acesso em 12 de out. 2006. 
90 MINOIA, C.; RONCHI, A.; PIGATTO, P.D.; GUZZI, G.; SEVERI, G. Estimates of mercury in urine and dental amalgams [Abstract]. In: Proceedings of the 8th International Conference on Mercury Global Polluent. Madison, USA, R64, p.105-436, 2006.

91 MOEN, B.E.; HOLLUND, B.E.; RIISE, T. Neurological symptoms among dental assistants: a cross-sectional study. J. Occup. Med. Toxicol., v. 3, n.10, p.1-7, 2008.

92 MORALES FUENTES, I.; REYES GIL, R. Mercurio y salud en la odontología. Rev. Saude Publica, v. 37, n. 2, p. 266-272, 2003.

93 MOTA, L.A.L.; ARAÚJO, S.M.A; RAMOS, E. C.; ARAÚJO, K.D.; ROSA, P.R.O. Problemas ocasionados pelo elevado índice pluviométrico em Araguaína - TO. GEOAMBIENTE ONLINE, n. 9, p. 164-181, jul-dez/2007.

94 MOTA, S.M.; MAGALHÃES, C. S; PORDEUS. I.A; MOREIRA, A. N. Impactos dos resíduos de serviços de saúde sobre o homem e o meio ambiente. Arq. Odontol., Belo Horizonte, v. 40, n. 2, p. 111-206, abr./jun. 2004.

95 MUTTER, J.; NAUMANN, J.; GUETHLIN, C. Comments on the article "The toxicology of mercury and its chemical compounds" by Clarkson and Magos (2006). Crit. Rev. Toxicol., v. 37, p. 537-549. 2007.

96 NADORFY DE LOPEZ, E.; MENDEZ, M. An epidemiologic study over a population of dentistry workers exposed to environmental contamination to mercury vapors. Acta Odontol. Venez. v. 38, n. 3, p.10-14, Sept. 2000.

97 NALEWAY, C.; SAKAGUCHI, R.; MITCHELL, E.; MULLER, T.; AYER; W. A.; HEFFERREN, J. J. Urinary mercury levels in US dentists, 1975-1983: review of Health Assessment Program. J. Am. Dent. Assoc., v. 111, n. 1, p. 37-42, 1985.

98 NATIONAL INSTITUTE OF STANDARDS AND TECHNOLOGY. SRM 1641d - Mercury in water. NIST. Disponível em: <www.nist.gog.br/srm>, 2003. Acesso em agosto de 2009.

99 NATIONAL INSTITUTE OF STANDARDS AND TECHNOLOGY. SRM 2770a - Toxic elements in urine (freeze-dried). NIST. Disponível em: <www.nist.gog.br/srm>, 2003. Acesso em agosto de 2009.

100NAZAR, M.; PORDEUS, I.; WERNECK, M. Gerenciamento de resíduos sólidos de odontologia em postos de saúde da rede municipal de Belo Horizonte, Brasil. Rev. Panam. Salud Publica, v.17, n.4, p. 237-242, 2005.

101 NEGHAB, M.; CHOOBINEH, A.; HASSAN-ZADEH, J.; GHADERI, E. Symptoms of intoxication in dentists associated with exposure to low levels of mercury. Ind. Health, 2010.Dec., 2010.

102 NILSSON, B.; NILSSON, B. Mercury in dental practice. II. Urinary mercury excretion in dental personnel. Swed. Dent. J., v. 10, p. 221-232. 1986. 
103NOVEMBRINO, C.; BAMONTI, F.; MINOIA, C.; GUZZI, G.; PIGATTO, P.D. Homocysteine and mercury dental amalgam. In: Proceedings of the 8th International Conference on Mercury as a Global Pollutant, 6-11 August 2006, Madison, WI. Lancaster, PADESTech Publications, 434. 2006.

104 NUTTAL, K. L. Interpreting mercury in blood and urine of individual patients. Ann. Clin. Lab. Sc.i, v. 34, n. 6, p. 235-250. 2004.

105OIKAWA, T.; PINHEIRO, M.C.; VAZ, L. B. F.; TODA, K. S. Avaliação dos teores de mercúrio na urina dos graduandos de odontologia. Rev. Paraense Med., v. 21, n. 3, jul/set, 2007.

106 OSBORNE, J.W. Dental amalgam and mercury vapor release. Adv. Dent. Res., v. 6, p. 135-138, 1992.

107 PATEL, S.M.; PIKAL,M.J. Emerging freeze-drying process development and scale up issues. PharmSciTech., 2011.

108PIVETTA, F.; MACHADO, J. M. H.; ARAÚJO, U. C.; MOREIRA, M.F.R.; APOSTOLI, P. Monitoramento biológico: conceitos e aplicações em saúde pública. Cad. Saúde Pública. Rio de Janeiro, v. 17, n. 3, 2001.

109PUCCI, C.R.; GIACHETTI, N.J.; ARAÚJO, M.A.M. Estudo in vitro da microinfiltração em amálgama. Rev. Odontol. UNESP, São Paulo, v. 27, n. 2, p. 459-472, jul./dez. 1998.

110RICHARDS, D. Amalgam, risk, benefits and the precautionary principle.

Evidence-Based Dentistry, v. 9, n. 2, p. 2, 2008. Disponível em: $<$ www.nature.com/ebd $>$. Acesso em 03 de fevereiro de 2009. doi: 10.1038/sj.ebd.6400556.

111 RITCHIE, K.A.; BURKE, F.J.T.; GILMOUR, W.H.; MACDONALD, E.B.; DALE, I.M.; HAMILTON, R.M.; MCGOWAN, D.A.; BINNIE, V.; COLLINGTON, D.; HAMMERSLEY, R. A study of the Mercury levels in Scottish dentists. Br. Dent. J., v. 197, p. 625-632, 2004.

112ROJAS, M.; GUEVARA, H.; RINCÓN, R.; RODRÍGUEZ, M.; OLIVET, C. Exposicion ocupacional y efectos a la salud del mercurio metalico entre odontologos y asistentes dentales: un estudio preliminar. Valencia, Venezuela; 1998. Acta Cientif. Venezol., v. 51, p. 32-38, 2000.

113ROWLAND, A.S. The effect occupational exposure to mercury vapor on the fertility of female dental assistants. Occup. Environ. Med., v. 51, p. 28-34, 1994.

114SALGADO, P.E.T; LEPERRA, J.S.; OLIVEIRA, G.H; LARINI, L. Determinação de mercúrio, proteínas, sódio e potássio de amostras de urina de cirurgiõesdentistas expostos ocupacionalmente ao mercúrio. Rev. Bras. Saúde Ocup., v. 14, p. 7-11, 1986.

115SANDBORGH-ENGLUND, G.; ELINDER, C-G.; JOHANSON, G.; LIND, B.; SKARE, I.; EKSTRAND, J. The Absorption, blood levels, and excretion of 
mercury after a single dose of mercury vapor in humans. Toxicol. Appl.

Pharmacol., v. 150, p. 146-153, 1998.

116SANTOS, W.N.; COIMBRA, J.L. ACD: auxilia de consultório dentário. Rio de Janeiro: RUBIO. 216p.

117SAQUY, P.C. Identificação qualitativa de vapor de mercúrio captado de resíduo de amálgama de prata, em diferentes meios de armazenagem. Ribeirão Preto: 1996. Tese (Livre Docência) - Faculdade de Odontologia de Ribeirão Preto da Universidade de São Paulo.

118SAQUY, P.C.; SILVA, R.S.; NETO, M.D.S.; PÉCORA, J.D. Apresentação de um método, qualitativo, de identificação de vapor de mercúrio. Rev. Paul. Odontol., n. 2, março/abril, 1997.

119SATOH, H. Occupational and environmental toxicology of mercury an its compounds. Environmental Health Sciences, v. 38, p. 153-164, 2000.

120SCENIHR. Scientific Committee on Emerging and Newly Identified Health Risks. Scientific opinion on the safety of dental amalgam and alternative dental restoration materials for patients and users. 6 May 2008.

Disponível em: <http://ec.europa.eu/health/ph_risk/risk_en.htm>. Acesso em: 06 nov. 2008.

121 SIGEYUKI, A. Acute inorganic vapor inhalation poisoning. Pathol. Internat., v. 50, n. 3, p.169-174, 2000.

122SIMÕES, B.B.M.; CONSANI, S.; CORRER SOBRINHO, L.; SINHORETI, M.A.C. Infiltração marginal em restaurações de amálgama de prata associado a agentes seladores resinosos. Pós-Grad Rev Odontol, v. 5, n. 2, maio/ago. 2002.

123SKERFVING, S. Exposure to mercury in the population. In: Suzuki T, Imura $\mathrm{N}$, Clarkson T, editors. Advances in the mercury toxicology. New York: Plenum Press, p. 411-425, 1991.

124SUKEL, P. P. Signs \& symptoms of mercury vapor exposure from mercury amalgam dental fillings. 2000. Disponível em:

$<$ http://www.sukel.com/merc-exp.htm>. Acesso em: 10 fev. 2009.

125SUTOW, E.J; HALL, G.C.; MACLEAN, C.A. Effectiveness of wet and dry mercury vapour suppressant systems in a faculty of dentistry clinic. J. Oral Rehabil., v. 31, p. 822-826, 2004.

126SWEENEY, M.; CREANOR, S.L.; SMITH, R.A.; FOYE, R. H. The release of mercury from dental amalgam and potential neurotoxicological effects. $J$. Dent., v. 30, p. 243-250, 2002.

127TAVARES, S.S; FONSECA, S.J.T.; TIPPLE, A.F.V; SILVA E SOUZA, A.C.; PIMENTA, F.C; ANDERS, P. Efficacy of the pasteur oven as sterilization equipment in dental offices. Rev. Esc. Enferm. USP, v. 42, n. 1, p. 160-167, 2008. 
128TOCANTINS. Secretaria de Cultura do Estado do Tocantins - TO. Relatório de Gestão, ano de 2006. Palmas, 2006a.

129TOCANTINS. Secretaria Municipal de Saúde de Araguaína - TO. Estatística da SMS, ano de 2003. Araguaína, 2003.

130TOCANTINS. Secretaria Municipal de Saúde de Araguaína - TO. Estatística da SMS, ano de 2004. Araguaína, 2004.

131 TOCANTINS. Secretaria Municipal de Saúde de Araguaína - TO. Estatística da SMS, ano de 2005. Araguaína, 2005.

132TOCANTINS. Secretaria Municipal de Saúde de Araguaína - TO. Estatística da SMS, ano de 2006. Araguaína, 2006.

133TOCANTINS. Secretaria Municipal de Saúde de Araguaína - TO. Estatística da SMS, ano de 2007. Araguaína, 2007.

134TOCANTINS. Secretaria Municipal de Saúde de Araguaína - TO. Estatística da SMS, ano de 2008. Araguaína, 2008.

135TOCANTINS. Secretaria Municipal de Saúde de Araguaína - TO. Estatística da SMS, $1^{\circ}$ semestre de 2010. Araguaína, 2010.

136TREPKA, M.J.; HEINRICH, J.; KRAUSE, C.; WJST, M.; POPESCU, M.; WICHMANN, H.E. Factors affecting internal mercury burdens among eastern German children. Arch. Environ. Health, v. 52, p. 134-138, 1997.

137TRZCINKA-OCHOCKA, M.; GAZEWSKi, A. I.; BRODZKA, R. Exposure to mercury vapors in dental workers in Poland. IJOMEH, v. 20, n. 2, p. $147-$ 154, 2007.

138VAS, J.; MONESTIER M. Immunology of mercury. Ann. N.Y. Acad. Sci., v.1143, p. 240-267, 2008.

139 VILARINHO, R.H.; HETEM, S.; RAMALHO, L.T.O. Análise in vitro do efeito da toxicidade do amálgama sobre o fechamento do palato. Rev. Odontol. UNESP, v. 28, n. 1, p. 23-32, 1999.

140VIMY, M.J; TAKAHASH, Y.; LORSCHEIDER, F.L. Maternal fetal distribution of mercury (203 Hg) released from dental amalgam filling. Am. J. Physiol., n. 258, v. 4, p. 939-945, 1990.

141 WANNAG, A.; SKJAERASEN, J. Mercury accumulation in placenta and fetal membranes. A study of dental workers and their babies. Environ. Physiol. Biochem., v. 5, n. 5, p. 348-352, 1975.

142WARFVINGE, K. Mercury exposure of a female dentist before pregnancy. Br. Dental J., v. 178, n. 4, p. 149-52, 1995. 
143WHO-WORLD HEALTH ORGANIZATION. Concise international chemical assessment document 50. Elemental mercury and inorganic mercury compounds: human health aspects. Geneva: WHO, 2003

144WOODS, J. S.; MARTIN, M. D.; LEROUX, B. G.; DEROUEN, T. A.; LEITÃO, J. G.; BERNARDO, M. F.; LUIS, H. S; SIMMONDS, P. L.; KUSHLEIKA, J. V.; HUANG, Y. The contribution of dental amalgam to urinary mercury excretion in children. Environ. Health Perspect., v. 115, N. 10, p. 1527-1531, October 2007.

145WOODS, J.S.; MARTIN, M.D.; LEROUX, B.G.; DEROUEN, T.A.; LEITÃO, J.G.; BERNARDO, M.F.; LUIS, H.S; SIMMONDS, P.L.; KUSHLEIKA, J.V.; RUE, T.C.;KORPAK, A.M. Biomarkers of kidney integrity in children and adolescents with dental amalgam mercury exposure: findings from the Casa Pia children's amalgam trial. Environ. Research, v. 108, n. 3, p. 393-399, Nov., 2008.

146 YOSHIDA, M. Relation of mercury exposure to elemental mercury levels in the urine and blood. Scand. J. Work Environ. Health, v. II, p. 33-37,1985.

147 YÜZBASIOGLU, E.; SARAÇ, D.; CANBAZ, S.; SARAÇ, S.; CENGIZ, S. A survey of cross-infection control procedures: knowledge and attitudes of Turkish dentists. J. App. Oral Sci., v.17, n.6, p. 565-569, 2009.

148ZIFF, S. Silver dental fillings: the toxic bomb. São Paulo: Vega Luz, 1987.

149ZOLFAGHARI, G.; ESMAILI-SARI, A; GHASEMPOURI, S.M.;

FAGHIHZADEH, S. Evaluation of environmental and occupational exposure to mercury among Iranian dentists. Sci. Total Environ., v. 381, p. 59-67, 2007. 